University of Louisville ThinkIR: The University of Louisville's Institutional Repository

Electronic Theses and Dissertations

$5-2019$

\title{
The Division I men's basketball transfer redshirt requirement : hurting or helping black student- athletes?
}

Sarah B. Williams

University of Louisville

Follow this and additional works at: https://ir.library.louisville.edu/etd

Part of the Sports Studies Commons

\section{Recommended Citation}

Williams, Sarah B., "The Division I men's basketball transfer redshirt requirement : hurting or helping black student-athletes?" (2019). Electronic Theses and Dissertations. Paper 3212.

https://doi.org/10.18297/etd/3212

This Doctoral Dissertation is brought to you for free and open access by ThinkIR: The University of Louisville's Institutional Repository. It has been accepted for inclusion in Electronic Theses and Dissertations by an authorized administrator of ThinkIR: The University of Louisville's Institutional Repository. This title appears here courtesy of the author, who has retained all other copyrights. For more information, please contact thinkir@louisville.edu. 
THE DIVISION I MEN'S BASKETBALL TRANSFER REDSHIRT REQUIREMENT:

HURTING OR HELPING BLACK STUDENT-ATHLETES?

By

Sarah B. Williams

B.B.A., James Madison University, 2009

M.S., James Madison University, 2012

\begin{abstract}
A Dissertation
Submitted to the Faculty of the

College of Education and Human Development at the University of Louisville In Partial Fulfillment of the Requirements

For the Degree of
\end{abstract}

Doctor of Philosophy in Educational Leadership and Organizational Development

Health and Sport Science

University of Louisville

Louisville, Kentucky

May 2019 
Copyright 2019 by Sarah B. Williams

All rights reserved 

THE DIVISION I MEN'S BASKETBALL TRANSFER REDSHIRT REQUIREMENT:

HURTING OR HELPING BLACK STUDENT-ATHLETES?

By

Sarah B. Williams

B.B.A., James Madison University, 2009

M.S., James Madison University, 2012

A Dissertation Approved on

April 19, 2019

by the following Dissertation Committee:

Meg G. Hancock, Chair

Mary A. Hums

Meera Alagaraja

Evan L. Frederick

Ellen J. Staurowsky 


\section{DEDICATION}

To my best friends: Taylor, Mary Kate, and Brenna

To Alice Joseph 


\section{ACKNOWLEDGMENTS}

Dr. Hancock, thank you for being a wonderful mentor and hype woman throughout this process. I cannot express my appreciation for you taking me under your wing and guiding me through the past few years. You are, quite simply, a rockstar and I am honored to know you.

Dr. Hums, I cannot thank you enough for your guidance and support. You have been in my corner from our first conversation and I am so thankful for your direction and encouragement. Thank you for being my mentor and friend.

Dr. Alagaraja, thank you for being excited about this study and for guiding me along the way. Your knowledge and direction have been wonderful to have throughout the process and I am lucky to have you as a committee member.

Dr. Frederick, I greatly appreciate your mentorship, guidance, and support. Thank you for your help through the dissertation process.

Dr. Staurowsky, I cannot thank you enough for joining me on this journey. Your encouragement and expertise were invaluable. I greatly appreciate you and your mentorship.

Dr. Greenwell, thank you for teaching me how to be a researcher. I appreciate your professional guidance, but I most appreciate our life talks and trivia night dominations. You have been a wonderful mentor and I am lucky to have been your student. 
Tyler, thank you for being a wonderful colleague and even better friend. There is not a single person on the planet with whom I would have rather gone through the doctoral program. You have made me a better person and I can't wait for you to name your first-born after me.

To my family, thank you for not talking me out of leaving a full-time job to pursue my PhD. Mom, Taylor, Mary Kate, Brenna, Aunt Katheleen, and Lynn, having your trust and support throughout this journey has made me feel invincible. I am so excited to come home and make up for lost time. I love you all with my whole heart.

Gina, thank you for loving and managing me through busy days and sleepless nights. You have simultaneously been my rock and soft place to land throughout this journey. I would have flown to you every day if I could have, but a GA stipend is a GA stipend. I am so, so glad that's over. I love you.

Additionally, I would like to thank the people of the Kentuckiana Basketball Officials Association for embracing me and providing me the opportunity to stay involved in the game of basketball during my time in Louisville. I am thankful for the wonderful friendships I was able to build through the KBOA while cultivating my passion for a really cool hobby.

Finally, I would like to thank the wonderful former Division I men's basketball players I had the opportunity to interview for this study who took precious time away from their lives to speak with me. They picked up the phone all over the world, early in the morning and late at night, and trusted me with their stories. I am grateful for their insight and input into this study as it will hopefully provide a missing piece to the changing landscape of the NCAA transfer student-athlete experience. 
I could not have imagined, in my wildest, fearful, soon-to-be-ex-coach dreams, I would have been able to find an advocation that allowed me to connect my love for sport with my love for teaching. I grew significantly, both as an academic and as a person, over the three years I have spent in Louisville, and I owe it to the faculty, students, and people at $\mathrm{U}$ of $\mathrm{L}$. 


\begin{abstract}
THE DIVISION I MEN'S BASKETBALL TRANSFER REDSHIRT REQUIREMENT: HURTING OR HELPING BLACK STUDENT-ATHLETES?

Sarah B. Williams

April 19, 2019

The following study provided a voice to an otherwise unheard from population of former student-athletes as they explained their transition experiences with the Division I transfer and redshirt year. The purpose of the study was to explore the Black studentathlete's transition experience through the redshirt year in Division I men's basketball from a qualitative, phenomenological research perspective. The study used two theories as guiding frameworks: 1) Schlossberg's (1981) Transition Theory and 2) Critical Race Theory (Calmore, 1992; Tate, 1997).
\end{abstract}

Both Schlossberg's (1981) Transition Theory and Critical Race Theory were used to examine the transition experience of the Black male basketball student-athlete as he moved laterally from initial to receiving institution to better understand the issues surrounding the situation, self, supports, and strategies of the individual student-athlete (Schlossberg, 1995). Critical Race Theory provides structure to better examine complexities of racialized structures and how such structures shape the experiences of those marginalized by society (Solórzano \& Yosso, 2001). The researcher interviewed 15 former Division I men's basketball student-athletes who identified as men of color, had 
exhausted eligibility between 2013-14 and 2018-19, and transferred laterally to a Power Five institution during their career and were required to spend a redshirt year-in-residence at their receiving institution.

Findings indicate Schlossberg's (1995) Transition Theory provides an effective framework for analyzing the transition experiences of transfer student-athletes. Transition takes time (Lazarowicz, 2015), and the redshirt year provides time for the transfer student-athlete to acclimate academically, athletically, and socially. Academically, participants expressed the transfer transition resulted in earned credit loss or major change, often leading student-athletes to need a fifth year to complete an undergraduate degree. If student-athletes were able to stay on course academically and graduate in four years, the fifth year provided them an opportunity to begin graduate coursework either at their receiving institution or at another university without the redshirt penalty. Another key finding indicated student-athletes felt significantly isolated throughout the transition process. Black student-athletes native to their initial institutions report feelings of isolation on the predominately White institution campus (Brown et al., 2001), and the transfer transition seems to exacerbate such experiences.

Each of the 15 participants in the study expressed an abundance of advantages from their redshirt year experiences; however, 12 participants indicated they believed the redshirt policy should change. The cards are stacked against Black transfer studentathletes on PWI campuses, and yet, the current policy in place to assist the transition of the student-athlete was deemed unnecessary by 12 of the 15 participants who gleaned significant athletic, academic, and social benefits from their experience. This disconnect leads to a larger issue of how significantly student-athletes perceive their sport careers 
over all else. Overall, the study provides insight into how practitioners can better assist transfer student-athletes through their transition. 


\section{TABLE OF CONTENTS}

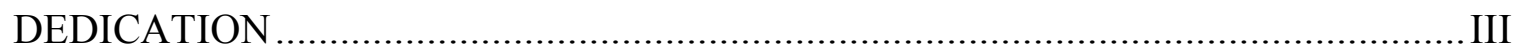

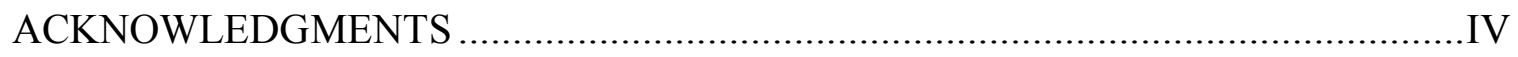

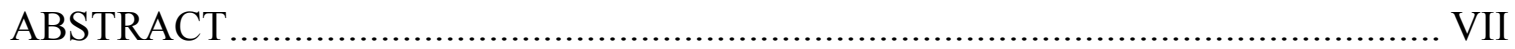

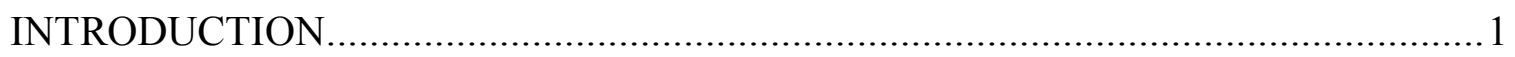

The NCAA Division I Men’s Basketball Transfer Climate...................................

Black Men's Basketball Transfers ....................................................

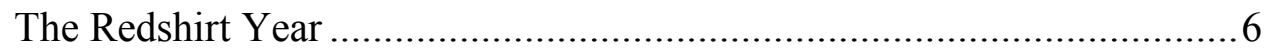

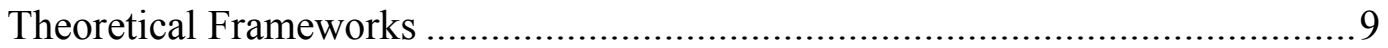

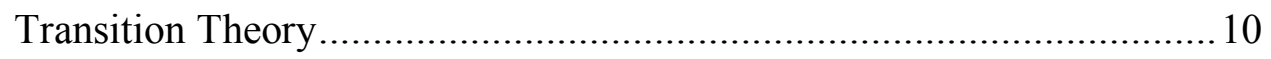

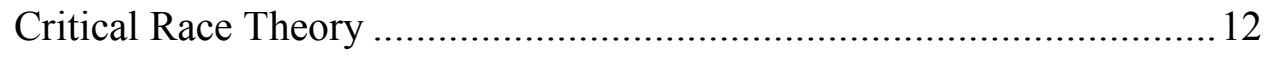

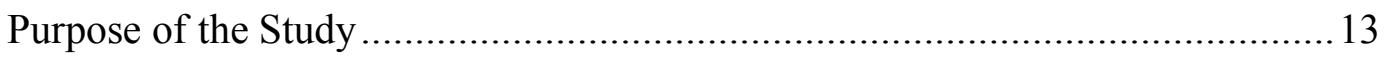

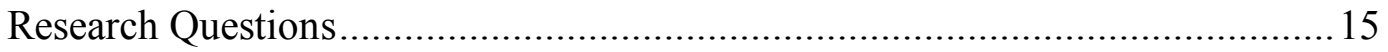

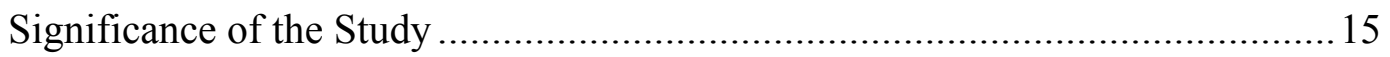

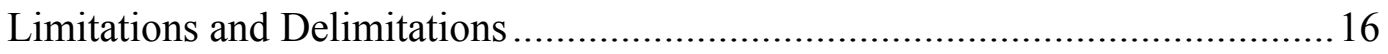

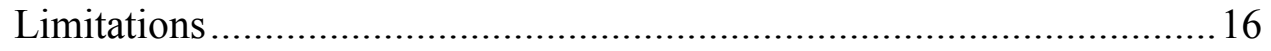

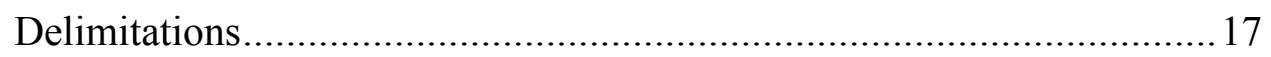

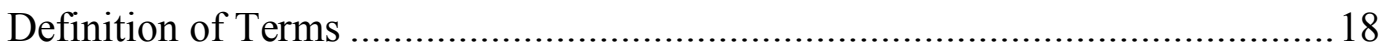

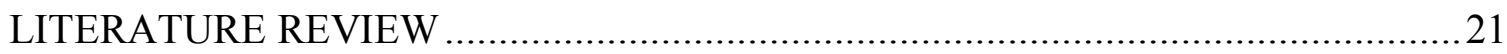

Black Students in Higher Education..............................................................22 
History of Black Students in Higher Education.................................22

The Black College Student Today .................................................... 31

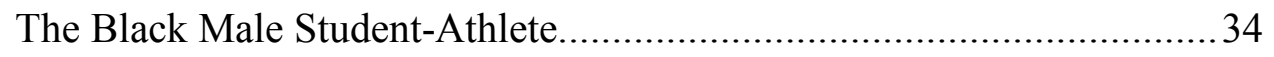

The Value of the Black Male Student-Athlete.......................................37

Transfer Students in Higher Education..................................................... 45

The Transfer Student................................................................... 45

The Transfer Student-Athlete .................................................5 52

The Black Division I Men's Basketball Transfer ...............................66

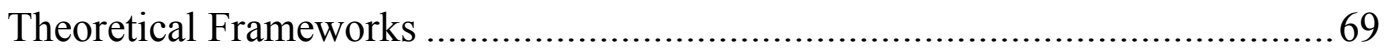

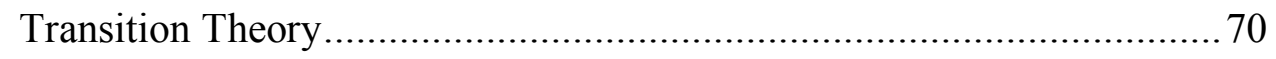

Critical Race Theory .......................................................... 85

Summary of Literature ...................................................................... 93

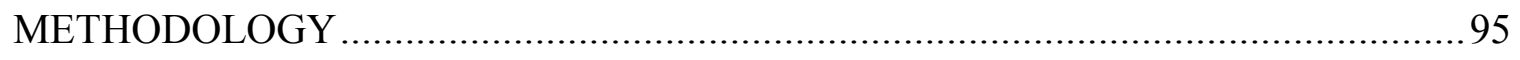

Research Questions ........................................................ 96

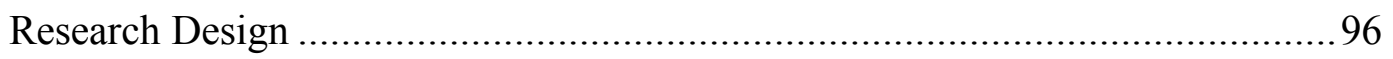

Data Collection Protocol .......................................................... 99

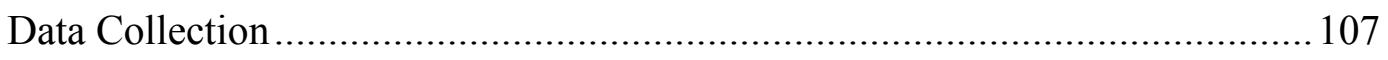

Data Organization .................................................................... 111

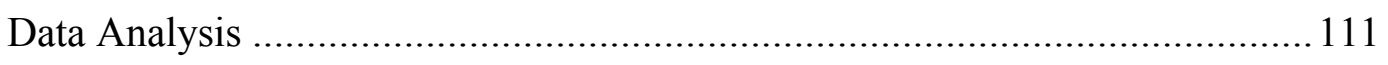

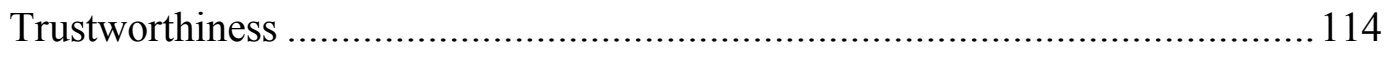

Researcher Positionality ...................................................... 115

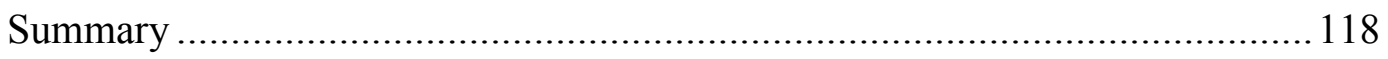

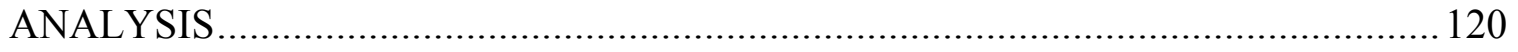


Demographics

RQ \#1: The Transition Experiences of Black Division I Men's Basketball

Transfer Student-Athletes........................................................... 124

RQ \#2: Perceived Benefits and Drawbacks................................... 162

Overall Impressions of the Redshirt Year................................................. 172

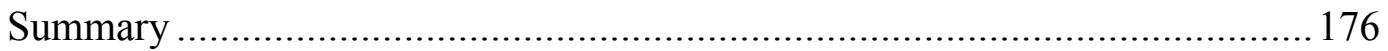

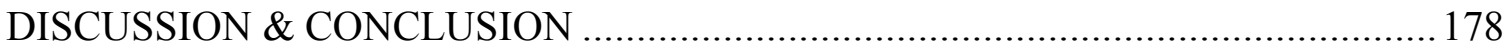

The Transfer Transition ........................................................................ 180

Perceived Benefits and Drawbacks of the Redshirt Year ................................ 190

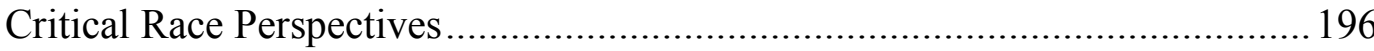

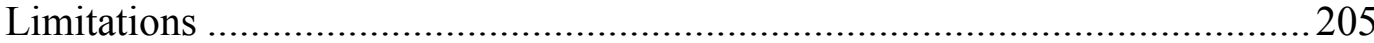

Potential Implications ...................................................................... 207

Implications for Research ...................................................... 208

Implications for Practitioners.................................................... 210

Future Research........................................................................ 214

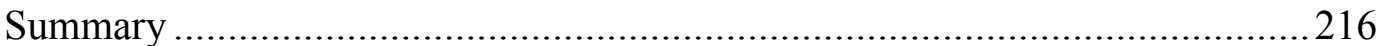

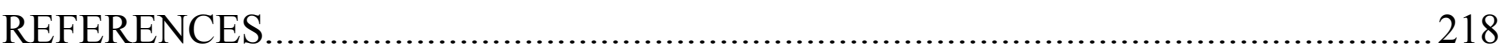

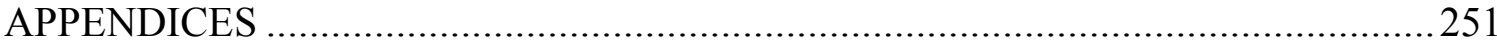

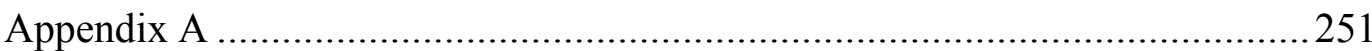

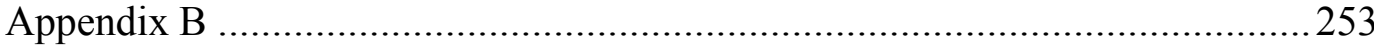

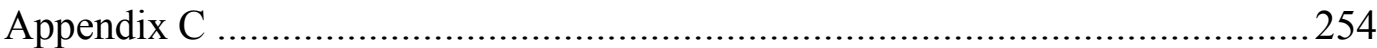

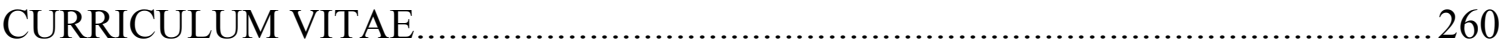




\section{CHAPTER I}

\section{INTRODUCTION}

\section{The NCAA Division I Men's Basketball Transfer Climate}

A Division I prospect sits at a table adorned with team-themed decorations and hats with university logos of prospective future teams. Proud family members are stationed close by in the auditorium filled with classmates and supporters, as the student athlete contractually promises his collegiate athletics careers to a university. This is National Signing Day. The image produced by such ceremonies promotes National Signing Day as a celebratory holiday complete with social media frenzy for member colleges and universities in the National Collegiate Athletic Association (NCAA) (Kercheval, 2018). When a National Letter of Intent (NLI) is signed during the final year of high school of the prospective student-athlete, he or she promises to enroll at the Division I institution to which he or she is now contractually bound to subsequently participate on an intercollegiate sports team.

In NCAA Division I men's basketball, in exchange for a student-athlete's written commitment in the form of the NLI, the higher education institution promises to provide financial aid consisting of room, board, and a cost of attendance gap stipend for a minimum of one academic year (National Collegiate Athletic Association [NCAA], n.d.c). The implied expectation of the written commitment and NLI signing and submission process cultivates a synergy among athlete, university, team, and coach with 
hopes that it will last the entire duration of an athlete's four- to five-year collegiate eligibility. However, given current NCAA rules, Division I men's basketball recruiting trends, and perceived potential to play professionally, a student-athlete's 4- to 5-year commitment to a single college or university is becoming less certain.

\section{Recruiting Trends}

Aggressive and accelerated prospective student-athlete recruitment trends in Division I NCAA men's basketball have resulted in the average verbal commitment occurring earlier each year (Hilbert, 2017). Some prospective men's basketball prospective student-athletes choose to verbally designate their collegiate destinations before competing in a single high school game (Winn, 2015b). The verbal commitment, the only commitment prospects can give an institution before National Signing Day during their senior year, is unofficial and does not contractually obligate the athletes to the said college or university; however, verbal commitments in men's basketball are typically honored through to the designated NLI signing date during the athlete's senior year of high school (Leccesi, 2017). The acceleration of the recruitment process is particularly troubling, however, as it likely contributes to the rate at which Division I men's basketball players transfer from the initial institution to which they commit and contractually bind themselves during their senior years in high school to enroll at another institution at some time during their collegiate careers. More specifically, over 40 percent of NCAA Division I Men's Basketball athletes elect to leave their initial Division I institution by the end of their sophomore season (Cleveland, 2017; NCAA, 2017a).

The 352 Division I men's basketball programs in the United States saw more than 700 players transfer during the 2016-17 season as each men's basketball team lost an 
average of two players, or 13\% of their rosters, to the transfer process (Cleveland, 2017). As a result, transfer attrition surpassed the previously noted most frequent DI men's basketball cause of player loss, injury, as $8.5 \%$ of players report season-ending injuries per year (Cleveland, 2017; Kerr, Marshall, Dompier, Corlette, Klossner, \& Gilchrist, 2015). The blame for the transfer epidemic, according to many Division I men's basketball head coaches, is attributed to the environment within which student-athletes are currently raised and groomed, suggesting student-athletes are presently being conditioned to simply switch teams if any conflict arises on their current team (Cleveland, 2017; Goodman, 2016). Southern Mississippi Head Coach Doc Sadler said, "If any sort of adversity hits, [players] automatically look for another place to play" (Cleveland, 2017, para. 8). University of Texas at El Paso Head Men's Basketball Coach Tim Floyd echoed a similar sentiment:

It's a culture we established, you've got players at the AAU who play for one team in the morning and then another in the afternoon, because they didn't get enough shots in the morning. It's me, me, me. They are selling the dream of you eventually can make more money in the NBA if you come play for me. Well, the number of basketball players who make the NBA is miniscule, and that's a fact (Cleveland, 2017, paras. 30-31).

Coach Floyd's statement is evidenced in that an estimated 3.6\% of draft-eligible Division I men's collegiate basketball players are chosen in the National Basketball Association draft each year (NCAA, 2017a). The odds of graduating from college are almost 22 times higher for Division I men's basketball players than the odds of being drafted to the NBA, as the NCAA boasts a $78 \%$ graduation success rate in Division I men's basketball 
(Lapchick, 2016). The focus of the student-athlete, if playing the odds, should be therefore be placed upon his academic pursuits. However, the ingrained culture of Division I men's basketball, particularly at the higher and more competitive levels, places pressures upon student-athletes to focus their time, energy, and decision-making reasons upon their sport careers.

\section{Black Men's Basketball Transfers}

The Black student-athlete population, in particular, is met with an increased number of barriers to success when competing in intercollegiate athletics for predominantly White institutions (PWIs) (Cooper \& Hawkins, 2014). The alienation of the Black student-athlete, particularly at predominantly White institutions (PWIs), often involves racial isolation and distortion of student-athlete visibility within either his home community or university community (Hawkins, 2010). There are two opposing perspectives of the opportunities provided to the Black student-athlete through college sport, which most often occurs at PWIs: a) intercollegiate athletics provide educational opportunities that would not be available otherwise, and b) intercollegiate athletics exploit Black student-athletes (Beamon, 2008).

Black student-athletes already face multiple barriers to academic success when they participate in intercollegiate athletics (Cooper \& Hawkins, 2014). The transfer epidemic, therefore, has the capability of most affecting the Black men's basketball student-athlete population, particularly with approximately $56 \%$ of Power Five Division I men's basketball roster spots are filled by Black student-athletes (Harper, 2018). Black Division I men's basketball players are twice as likely to expect professional sport careers than White athletes (Kennedy \& Dimmick, 1987). 
Due to overly optimistic professional sport career expectations and the negative impact such a focus may have on academic performance, the obsessive pursuit of a professional sport career has potential to be exponentially more tragic to Black studentathletes. The negative consequences are life changing if these athletes are unsuccessful in securing a professional sport contract and unfocused and unsuccessful in their academic pursuits (Beamon, 2008). If the decision to transfer is intrinsically motivated by the pursuit of a career as a professional athlete, a Black male student-athlete possesses a much higher risk of lower academic achievement and personal and social underdevelopment if he fails to do so than his White counterparts (Beamon, 2008; Harrison, 2000; Robbins, 2015). Such negative consequences for Black student-athletes are likely to multiply when a transfer transition is added into the academic, athletic, and social succession of the Black student-athlete on multiple PWI campuses.

Research supports the notion that the higher the expectation of a professional sport career the student-athlete possesses, the lower the individual's grade point average (GPA) and academic standing tends to be (Robbins, 2015). Simons and Van Rheenen (2000) found that the stronger the commitment a student-athlete makes to athletics, the lower the student-athlete's GPA. Robbins (2015) saw this relationship to have an even stronger negative correlation in Black student-athletes. The lack of academic commitment by student-athletes is likely a byproduct of NCAA Division I schools placing focus on athletics instead of nurturing the academic potential of the studentathlete, an issue even more limiting for the Black student-athlete (Sack \& Staurowsky, 1998). 
The unique challenges the Black student-athlete faces through the transfer process from initial institution to a new campus destination are concerning (Cooper \& Hawkins, 2014), particularly since transition can lead individuals to experience trauma and crisis (Schlossberg, 1981). Movement into, out of, and throughout colleges and universities is the new norm for the non-athlete and athlete contemporary college student population alike, but the complexity of the academic, social, and personal transfer student environment varies with each individual student (Bahr, 2009; Goldrick-Rab, 2006; Goldrick-Rab \& Pfeffer, 2009). Lateral transfer, or four-year to four-year college transfer, can decrease the chances of obtaining a credential or degree (Bahr, 2009). Additionally, Black transfer student-athletes are more likely to discontinue education than non-transfer student-athletes regardless of race (Cooper \& Hawkins, 2014). Therefore, Black student-athlete transfers put themselves at higher risk of academic failure than if they stay and finish their eligibility and careers at their native institutions.

\section{The Redshirt Year}

If an NCAA student-athlete in the sports of football, basketball, and hockey decides to leave the Division I institution to which he is contractually bound by an NLI or by attending classes at that particular institution, under basic NCAA transfer regulations the student-athlete is required to spend an academic year in residence. This time in residence is commonly referred to as a redshirt year at the institution to which he transfers (NCAA, n.d.c). During the redshirt year, the student-athlete cannot participate in any contests or scrimmages for an entire academic year but can participate in all other practices, training sessions, and team activities on campus (NCAA, n.d.c). This redshirt year-in-residence requirement must be fulfilled before the student-athlete can be declared 
eligible to participate in intercollegiate contests for the institution at which he is newly enrolled.

Division I student-athletes are typically allotted five calendar years within which to participate in four full seasons of competition (NCAA, n.d.c.). The five-year clock begins with enrollment as a full-time student and has room to include one redshirt year without a student-athlete losing any of the allotted four seasons of competition. A student-athlete can therefore, in theory, transfer one time within the duration of his career, requiring a year in residence and therefore permitting him to redshirt without penalty or loss of any allotted competition eligibility. Currently, Division I men's basketball transfer student-athletes decide to endure the redshirt waiting period in order to pursue perceived greener pastures at another institution for the remainder of their athletic careers (Ziller, 2016).

The NCAA redshirt requirements for Division I transfer student-athletes are argued to be constricting and even potentially unlawful. Current policies in place face challenges in the form of lawsuits against institutions and the NCAA and pleas for change from coaches, players, and fans (Ziller, 2016). Challenges to the requirement received so much attention that in 2018 the NCAA formed the Division I Transfer Working Group to seek feedback on the potential refinement of the redshirt requirement into a less stringent limitation process (Hosick, 2018a). The group seeks to obtain feedback on two specific, but mild, rules modifications: (a) to allow students who meet specific academic standards to play immediately, and (b) to allow student-athletes who have signed a National Letter of Intent, or binding contract to a specific institution, to transfer and play immediately if a head coach leaves that institution (Hosick, 2018a). 
In the summer of 2018, the Division I Council adopted alterations to the transfer process, eliminating the need for student-athletes to gain permission from institutions to contact certain schools of interest (Hosick, 2018b). The rules changes have not yet involved or altered the redshirt process; however, according to ESPN reporter Jeff Goodman (2016), NCAA Division I men's basketball coaches feel that a restructure of rules into an allowance of transfer without requirement to endure a redshirt penalty is imminent.

The redshirt year-in-residence affords countless benefits to transfer studentathletes, as it provides time to acclimate to a new campus from academic, social, financial, and athletic perspectives. The Black male basketball student-athlete benefits when he is exposed to the institutional environment of the college or university, further developing goals and sense of commitment (Cooper, 2016). A redshirt year likely advances such exposure.

NCAA 2018 Basketball Tournament Final Four participant Villanova had six players on its active roster who previously redshirted (Stubbs, 2017). Villanova forward Mikal Bridges explained his redshirt as "a real good thing. You get to work on your game a lot. You have more workouts. You get stronger" (Stubbs, 2017, para. 9). Bridges' teammate at Villanova, Phil Booth, said, "A year can change your life...It's not easy, but it's a very productive year" (Stubbs, 2017, para. 12). Gonzaga Men's Basketball Head Coach Mark Few, whose team reached the 2018 NCAA Tournament Sweet Sixteen, said, "I think (a redshirt season) gives those guys just a great opportunity to assimilate... as well as grow the basketball side of them" (Ogden, 2018, para. 7). 
While proponents of the redshirt year attest to its benefits, the transition is not guaranteed to be seamless. Often ignored, especially when student-athlete exploitation and amateurism challenges are present, is the time it takes a student-athlete to successfully transition to a new campus and team climate after transfer. Black Division I men's basketball players face specific abuses and discrimination at PWIs (Hawkins, 2010). Black male student-athletes must constantly fight the 'dumb jock' stereotype (Harper, 2009; Sailes, 1993), as well as racial stereotypes fueling perceptions of Black athletes being intellectually inferior to White athletes (Davis, 1990).

Adding the stress and crisis of transfer transition is likely to require additional support and assistance. If the redshirt year is altered, lessened, removed, or easily avoided, the already negative impact of NCAA rules and regulations disproportionately impacting Black student-athletes (Davis, 1996) will likely lead to advanced negative consequences in growth from an academic and social perspective. The removal of transfer redshirt requirements could result in Black student-athletes being pushed through an already broken NCAA academic system even faster (Cooper \& Hawkins, 2014). College sports persistently present cultural biases, placing Black student-athletes at a disadvantage both economically and academically (Davis, 1996) and loosening or eliminating the transition-enhancing requirement of the redshirt year will likely perpetuate the cyclically reproduced racial inequities of NCAA Division I athletics (Harper, 2018).

\section{Theoretical Frameworks}

It is necessary to explore the transition process of the Division I Black male basketball student-athlete through transfer to better understand the redshirt process and 
weigh the benefits of the transition period for the Black male student-athlete. Two theoretical frameworks, Transition Theory and Critical Race Theory (CRT), shape this study. Transition theory allows the researcher to examine an individual's capacity to cope with change (Schlossberg, 1995) while Critical Race Theory provides the lens of the experiences of "raced" people with the goal of eliminating racial oppression in the United States (Matsuda, Lawrence, Delgado, \& Crenshaw, 1993). The chosen theoretical frameworks provide their own respective lenses through which the study is shaped (Reeves, Albert, Kuper, \& Hodges, 2008).

\section{Transition Theory}

Transition theory, initially developed by Schlossberg (1981), seeks to clarify an individual's transition experiences by analyzing surrounding factors, which include anticipation, preparation, alteration capability, individual experience, and available support (Schlossberg, 2011). Transition includes everything from large, life-altering change leading to and requiring major adaptation to small-scale change requiring little to no adaptation. The more a transition alters routine patterns of behavior, the more significant it becomes in the life of the individual experiencing the transition (Schlossberg, 1981).

Often more important than the transition itself is the individual's perception of the transition (Schlossberg, 1981), as it exists only if the individual defines the experience as transition (Schlossberg, Waters, \& Goodman, 1995). Transitions are often considered significant when roles, relationships, beliefs, or customary actions of achievement are altered (Schlossberg, 1984). Environment plays a significant role in a person's perception of transition, indicating no two individuals will experience the a given transition the same 
way (Schlossberg, 1981). Demographics and prior experience can significantly influence the experience of an individual's transition (Schlossberg, 1981; Swain, 1991).

Schlossberg et al. (1995) presented the 4 S's system as a useful model for understanding development through transition. The 4 S's include the following four major categories or variables: (a) the situation, (b) the self, (c) the supports, and (d) the strategies. The established framework of Schlossberg's (1995) 4 S's provides a pathway of gathering information that increases the likelihood of successful transition (Schlossberg, 2011).

Schlossberg's (1995) 4 S's are frequently used in education settings (Browne, Webb, \& Bullock, 2018; Goodman \& Pappas, 2000; Griffin \& Gilbert, 2015; Heggins \& Jackson, 2003; McCoy, 2014; Pelegrino \& Hoggan, 2015; Pendleton, 2007; Rall, 2016; Schaefer, 2010). Additionally, the 4 S's have been successfully applied to understanding the transition processes of athletes (Flowers, Luzynski, \& Zamani-Gallaher, 2014; Lavallee, 2005). Specifically, Flowers et al. (2014) examined male transfer studentathletes in a variety of sports who transferred from a variety of levels. The study found Transition Theory to be a relevant framework to examine the transition experiences of the student-athletes and suggested transfer student-athletes present feelings and actions of self-reliance, a finding of particular interest when applied to the already underserved population of Black students at PWIs. Lavallee (2005) used the 4 S's to evaluate the effectiveness of intervention on former professional athletes' coping through transition into retirement and found the athletes to benefit significantly from assistance through the career termination adjustment processes. Lavallee's (2005) study supports the need of the present study to better understand whether it is helpful or not for Division I Black men's 
basketball transfer student-athletes to experience the redshirt year to assist in their transition.

\section{Critical Race Theory}

Critical race theory (CRT) focuses on issues and experiences of "raced" people (Tate, 1997) and challenges the authoritative standard set by the American White experience (Calmore, 1992). Critical race methodology provides structure to better understand the complexities of racialized, gendered, and classed structures shaping experiences of those who have been marginalized by society (Solórzano \& Yosso, 2001). There is no single, overarching definition of CRT (Tate, 1997) and the methodology draws upon literature from multiple disciplines, epistemologies, and approaches to the what, why, and how of human behavior as it pertains to race and racism (Matsuda et al., 1993; Scheurich \& Young, 1997; Solórzano \& Yosso, 2001).

CRT was originally developed by legal scholars with strong roots in the social change era of the 1960s (Tate, 1997). CRT was proposed by Ladson-Billings and Tate (1995) as an appropriate means to examine race and racism in education. CRT as a whole contains both academic and social goals for improvement (Tate, 1997). The application of CRT in education is solidified with the premise that race and racism are native, permanent, and central factors in defining individual experiences of students of color (Solórzano \& Yosso, 2001), as race is salient in United States society (LadsonBillings \& Tate, 1995).

CRT has been used in education and social sciences research as it has the benefit of utilizing hindsight to focus on race and racism to challenge dominant ideologies, work for social justice, and validate experiences of people of color (Solórzano \& Yosso, 2001). 
Valdes, Culp, and Harris (2002) present three main beliefs of mainstream society that must be continuously challenged, including: (a) colorblindness will eliminate racism, (b) racism is individual, not systemic, and (c) racism can be fought without the context of sexism, homophobia, and other forms of oppression. Harper et al. (2009) also recognize CRT as a useful methodology to examine the experiences of Black students in higher education as it offers a critique of policies impacting the Black student experience.

Critical race theory frequently provides the theoretical framework in sport management research (Baker \& Hawkins, 2016; Cooper \& Hawkins, 2014; Hawkins, 2010; Hylton, 2005; Long et al., 2000). Cooper and Hawkins (2014), in particular, used CRT as a theoretical framework to examine the impact of race and racism on the experiences of student-athletes who transferred from PWIs to HBCUs. Participants in their study revealed experiences with both covert and overt forms of racism at their respective PWIs which resulted in negative experiences leading them to transfer to HBCUs, an alarming finding when considering the present study of athletes transferring both to and from PWIs. While Cooper and Hawkins (2014) captured the lived experience of the Black transfer student-athlete, they did not explore the redshirt process or delve into the transition experience of the student-athlete.

\section{Purpose of the Study}

The purpose of this study was to explore the Black men's basketball studentathlete's transfer experience through the redshirt year in Division I men's basketball from a qualitative, phenomenological research perspective. By applying Schlossberg's (1981) transition theory, the study aimed to provide a better understanding of the advantages and disadvantages experienced during the redshirt year. The transition experience through 
transfer from one NCAA Division I institution to another, as evaluated by Schlossberg's (1995) 4 S's (i.e., situation, self, supports, strategies), varies based on an individual's experiences during and through transition (Goodman, Schlossberg, \& Anderson, 2006; Schlossberg, 2011; Schlossberg et al., 1995). Furthermore, given the socio-political climate of institutions of higher education, collegiate athletics, and the impact of such climates on the Black athlete experience, this study also employed Critical Race Theory (CRT). CRT frames the what, why, and how of human behavior as it pertains to race and racism and focuses on socially constructed qualities of racism in society (Glesne, 2016; Matsuda et al., 1993; Scheurich \& Young, 1997; Solórzano \& Yosso, 2001).

The structure provided by critical race methodology supports the examination of the experiences of marginalized individuals to better comprehend the complexities of racialized societal structures (Solórzano \& Yosso, 2001). CRT is applicable to this study, as such racialized societal structures exist on the PWI campus. For example, research has shown Black student athletes experience additional pressure on predominantly White campuses to develop their athletic identity rather than apply attention to academics (Bimper, Harrison, \& Clark, 2013). Therefore, the value of the Black student-athlete on the predominantly White campus is often solely measured by his athletic performance (Hawkins, 2010), leading to alienation and isolation based on his athlete status (Sato, Hodge, \& Eckert, 2017). Such alienation, from a transfer student-athlete perspective, puts student-athletes in isolated conditions both at their initial and receiving institutions.

The transition experience through transfer likely varies on an individual basis (Goodman, Schlossberg, \& Anderson, 2006; Schlossberg, 2011; Schlossberg et al., 1995). The transition experience of the Black student-athlete is likely impacted by 
socially constructed perceptions of race and racism (Glesne, 2016; Matsuda et al., 1993; Scheurich \& Young, 1997; Solórzano \& Yosso, 2001). To examine the transition and redshirt experience of the Division I Black men's basketball student-athlete, the study used two research questions, as explained in the following section.

\section{Research Questions}

To uncover racial complexities, this study encouraged storytelling and counterstorytelling through interviews, which are methods of telling stories by marginalized individuals, as such experiences are not often shared (Solórzano \& Yosso, 2001). Thus, critical race methodology and counter-storytelling were utilized to specifically examine the experiences of Black Division I men's basketball student-athletes. Through such stories, this research aimed to capture experiences of the Division I Black men's basketball transfer redshirt student-athlete with methods anchored in both Schlossberg and colleagues' (1995) 4 S's and critical race theory (Creswell, 2013; McCoy, 2014; Solórzano \& Yosso, 2001). The following research questions guided the study:

RQ1. What are the transition experiences of Black Division I men's basketball transfer student-athletes with the redshirt year?

RQ2. What are the perceived benefits or drawbacks of the redshirt year requirement experienced by Black Division I men's basketball players?

\section{Significance of the Study}

This study was significant for many reasons. This study will serve as the first known exploration into the unique and underrepresented perspective of Black Division I men's basketball players as they experience the complexities of the transfer and redshirt process. Results from this study will influence future practice and enhance the 
development of rules and guidelines for the NCAA transfer and redshirt student-athlete process. Further, by understanding the experiences of the Black male student athlete, student support personnel in athletic departments (e.g., student athlete development and welfare, academic and career advisors) will have information to assist in better development of personalized and inclusive programming and support for this group of student athletes.

\section{Limitations and Delimitations}

This study, like all studies, is not without limitations and delimitations (Simon \& Goes, 2013). Limitations are occurrences in a study that are out of the control of the researcher, while delimitations arise from the limitations of the study due to decisions made in development of the study (Simon \& Goes, 2013). The following sections outline both the limitations and delimitations of the study.

\section{Limitations}

Limitations in qualitative studies are related to validity and reliability of the study (Simon \& Goes, 2013). Additionally, the selection of phenomenology for the design of the study presents certain limitations. From a validity perspective, phenomenological studies are valid if the essential description of the phenomenon captures the essence intuited, as every reader of a phenomenological research study is a critical evaluator of the essence of the study.

The present study has a few limitations. As the study was conducted qualitatively, results are not generalizable to all transfer student-athletes. Additionally, the sample population was limited to only former Division I transfer men's basketball studentathletes with social media accounts. Lastly, the researcher, a former NCAA Division I 
basketball player who is a White woman who laterally transferred during her college basketball career and experienced the redshirt year process, consciously bracketed beliefs and assumptions to seek to understand a truly fresh and unbiased perspective of the phenomenon (Creswell, 2013). However, the previous experience of the researcher could affect or influence the results of the study.

\section{Delimitations}

This study cannot address every aspect associated with the Division I men's basketball transfer redshirt process, and specific delimitations were chosen for the proposed study to maintain boundaries (Glesne, 2016). The proposed study was specific to lateral transfer student-athletes in Division I men's basketball (4-year school to 4-year school). The study did not incorporate any transfer experiences of community or junior college or fifth-year graduate transfer student-athletes. Redshirt policies covering these two groups differ from the policies of the lateral transfer, although findings from such participants' experiences through their respective transitions have potential to be transferrable to other transfer status situations.

The decision to focus solely on the experiences of Black student-athletes through the transfer and subsequent redshirt processes was made because this population is underserved and underrepresented in sport management research despite making up over half, or 56\%, of the general NCAA Division I men's basketball player pool (Harper, 2018). Additionally, the researcher chose to interview participants who had exhausted eligibility, thus reflecting upon their transition experiences in the past. Although studentathletes presently experiencing the transition may have provided a different perspective, Henderson (2013) found student-athletes during moments of transition lacked an accurate 
reflection on their experience. The research questions focused on the redshirt experiences of Black Division I men's basketball players through their analysis of benefits, detriment, and overall impact of the redshirt year experience with guidance from Schlossberg's (1995) 4 S's framework.

\section{Definition of Terms}

- Historically Black College or University - Colleges and universities established prior to 1964 with the principal mission of the education of Black Americans and accredited or in the process of being accredited for quality of education (Gasman, Baez, Drezner, \& Sedgwick, 2007).

- Lateral transfer - Transfer students leaving one four-year higher education institution to enroll into another four-year higher education institution (GoldrickRab \& Pfeffer, 2009). This term also encompasses two-year to two-year transfer, however, for the purposes of this study, the term will refer only to the four- to four- year transfer.

- Mid-year transfer - Transfer student-athletes leaving their initial Division I institution between the fall and spring semesters. This method of transfer, if occuring laterally from Division I to Division I institutions in men's and women's basketball, men's ice hockey, and FBS football, requires a student-athlete complete a full, calendar year-in-residence.

- National Letter of Intent - A binding agreement between the prospective studentathlete and the institution to which the athlete agrees to attend for one academic year in exchange for financial aid (NCAA, n.d.c.). 
- Native institution - The first college or university in which the student-athlete enrolls and attends

- Power Five - The five Division I conferences consisting of 65 Division I member schools granted autonomy by the NCAA Board of Directors in 2014 (Mandel, 2014).

- Predominantly White institution - Institutions of higher learning with White students accounting for $50 \%$ or more of the student body (Brown \& Dancy, 2010).

- Receiving institution - The college or university to which the transfer studentathlete goes and subsequently attends after being released from their native institution

- Redshirt year - The academic year in residence required by the NCAA when student-athletes in the sports of football, basketball, and hocker decide to leave their currently attended Division I college or university for another, during which they are barred from participation in contests or scrimmages but can participate in all other practices, training sessions, and team activities on campus (NCAA, n.d.c.).

- Verbal commitment - A non-binding, verbal promise made by a prospective student-athlete to a specified NCAA-member institution with which to sign at National Letter of Intent (Yen, 2011).

- Year in residence - The calendar year commonly referred to as the 'redshirt year' during which the student-athlete cannot participate in any contests or scrimmages 
for an entire academic year but can participate in practice, training, and team activities on campus (NCAA, n.d.c.) 


\section{CHAPTER II}

\section{LITERATURE REVIEW}

It is imperative to frame this study around the unique and underrepresented perspective of Black Division I men's basketball players as they experience the complexities of the transfer transition and redshirt process. Moreover, this student population is underrepresented in research despite comprising more than half $(56 \%)$ of the NCAA Division I men's basketball player pool (Harper, 2018). The following literature review contains sections on the experiences of Black students and transfer students in higher education as well as the theoretical frameworks for the proposed study. The review also includes what is currently known about the Black student-athlete experience. To date, limited research exists on the combination of Black student and transfer student experiences. As such, research is even more limited when the lens is further focused upon Black Division I men's basketball student-athletes.

Contextualizing the experiences of the Black men's basketball transfer studentathlete within higher education from both a historical and contemporary perspective is necessary to better understand the context of the systems present in today's educational and societal climates that may impact - positively or negatively - the Black studentathlete experience. Thus, understanding the complexities of these systems may allow college coaches and other athletic department personnel to better serve this significant portion of student-athletes. Therefore, the purpose of this study is to explore the Black 
student-athlete's transition experience through the redshirt year in Division I men's basketball from a qualitative, phenomenological research perspective.

The literature review is divided into three segments. The first segment explores the experiences of Black students in higher education from a historical and contemporary perspective; it also illustrates the experiences of the Black student-athlete in the United States. The second segment explores the transfer student experience in higher education. The third segment provides discussion on the theoretical frameworks of this study: transition theory and critical race theory. A comprehensive summary of each segment concludes the literature review.

\section{Black Students in Higher Education}

Throughout history, the role of schooling has been to bestow knowledge to the learner in order to be a better functioning member of society (Epps, 1995). Schooling too, therefore, supports and facilitates socialization and normative societal outcomes (Epps, 1995). Higher Education in the United States, modeled by Western European patterns and traditions with American modifications, has developed a unique system (Brubacher \& Rudy, 1997). Schooling in the United States functions as a socializing agent, indoctrining students into a system within which they are socially defined by their demographic characteristics (Epps, 1995). Interestingly, the history of education and schooling aligns with social history in the United States (Nasaw, 1981).

\section{History of Black Students in Higher Education}

Since its inception, the United States education system has been filled with an abundance of racism and racial oppression (Johnson-Ahorlu, 2017). The inferiority paradigm, or the system of belief that people of color are genetically inferior to Whites, 
relies upon racial assumptions and stereotypes legitimizing the ideology (Clay, 1993). Although policies (e.g. School Desegregation) have been enacted to give Black students access to education, enrollment rates have fluctuated over time (Allen, 2002). As such, the gaps in opportunity and perpetuation of the struggle for racial equity still exists (Harper, Patton, \& Wooden, 2009). Although Black Americans view education as a pathway to social equity and mobility, Black Americans still lack social equality and opportunities for mobility (Epps, 1995).

Racial composition on the higher education campus has influenced and impacted Black students throughout history (Allen, 1992). For example, Cokley (2002) found Black students to possess higher self-concepts on campuses that reflect and represent their race when compared to a campus that is predominantly White. As such, Black student populations on predominantly White college campuses across the United States differ from White student populations in many ways (Allen, 1992). White students, for instance, on PWI campuses, are more satisfied with their social environments than Black students, and the racially-charged stresses minority students face on PWI campuses negatively impact their educational experience (Karkouti, 2016).

Students of Color in the United States have historically been given access to and attended the most underfunded higher education institutions in America which subsequently produce the lowest graduation rates (Johnson-Ahorlu, 2017). As research shows, Black students attribute racial characteristics to schools and racially categorize academic achievement as White (Ispa-Landa \& Conwell, 2015). To better discern the issues unique to the Black student in the United States, it is vital to explore the history of Black students in higher education in the United States. 
Credible history of Black higher education in the United States is murky and has relied primarily on word of mouth. Black slaves were forbidden to learn and denied access to formal systems of education for centuries in the United States (Allen \& Jewell, 2002). Blacks were instrumentally, and by law, discriminated against during slavery, as they were excluded from economic, political, and educational opportunities open to White citizens (Ogbu, 2004). Thus, the educational systems in America - grounded in politics, science, and religion - have allowed racial stereotypes to perpetuate throughout time (Tate, 1997).

The first institution of higher learning in the United States, Harvard College, was established in 1636 by the Massachusetts Bay Colony (Peirce, 1833); a person of Color would not be admitted to an American college or university for over a century thereafter. Although there is no clear proof, John Chavis is said to be the first Black person to have attended an American college or university, as he studied at Princeton sometime between 1768 and 1794. It is rumored his attendance was the result of a wager in which the bettor doubted a Black man might be able to be educated (Knight, 1930).

Alexander Lucius Twilight was the first known African American to be awarded a higher education degree, as he did from Middlebury College in Vermont in 1823 (Bennett, 1988). Oberlin College in Ohio was the first predominantly White higher education institution in the United States to openly admit Black students, as it began admitting Black men in 1835 and Black women in 1837 (Rudolph, 1990). The increase in access to education for Black Americans was accompanied by dramatic life changes and newly opened doors. Education afforded some Black Americans higher statuses in 
society and opened the opportunity to seek occupations not previously available to them (Harper et al., 2009).

Instead of the threats of physical harm or death derailing Black Americans from pursuing education, the pursuit of learning and knowledge instead became a mythical one, often leading to opportunities forbidden from them in the recent past (Allen \& Jewell, 2002). However, participation in higher education was still limited. For instance, by the end the Civil War in 1865 only 28 of over 4 million freed slaves had earned bachelor's degrees (Bowles \& DeCosta, 1971). All the degrees earned by that time were granted from colleges and universities in the northern United States, as racial antipathy continued to persist in the south (Tate, 1992). Following the Civil War, the passing of the Civil Rights Act of 1866 conferred civil rights to all natural-born Americans, including former slaves and free Black Americans (Kaczorowski, 1987). This meant all people born in the United States, regardless of skin color, were afforded freedom and equality. While opportunities in education for Black Americans were still limited, newly afforded civil rights for Black Americans opened the door for greater access to formal education.

The Reconstruction Era (1865-1877) was a period of unabated access to education for Black Americans as it demonstrated a reprieve from educational discrimination and, ultimately, a reconstruction of social order (Tyack \& Lowe, 1986). During this time, Black Americans pursued educational opportunities with determination in an attempt to seize educational and social revolutions (Allen \& Jewell, 2002; Tyack \& Lowe, 1986). Efforts to expand educational opportunities for Black Americans increased significantly, as religious denominations and organizations in the post-Civil War movement perceived their act of providing education to the freed Black slave to be their God-assigned task 
(Allen \& Jewell, 2002). Southern Black Americans seeking to gain access to education relied heavily upon their allies in Congress to begin a collective movement with the help of the Freedmen's Bureau, Northern philanthropy, and other White groups (Tyack \& Lowe, 1986).

The period for growth of secondary and post-secondary schools for Black Americans was short-lived, particularly in the South, as expansion and support slowed dramatically in the decades following Reconstruction (Butchart, 2010). Literacy was required for suffrage, and after educational opportunities were stifled following the Reconstruction era, the short-lived attainability of equal rights for Black American citizenship, including the right to vote, severely diminished (Tyack \& Lowe, 1986). State educational institutions sought to exclude Blacks from learning environments in higher education based on unfounded and discriminatory assumptions of lack of capacity to learn and capability to succeed in the classroom (Tyack \& Lowe, 1986). In particular, northern White Americans often doubted the educational capability of the Black student (Tyack \& Lowe, 1986). More harshly, southern White Americans were hostile to even the idea of giving Blacks the opportunity of obtaining an education in general (Tyack \& Lowe, 1986). Radical racists considered any and all education available to Black Americans a threat to the White-dominant social system in the United States (LeMelle, 2002).

The American higher education system continued to develop elaborate institutional barriers throughout history to deny Black Americans access to education; nevertheless, Black Americans continued to pursue knowledge and formal education (Allen \& Jewell, 2002). Commonly accepted as the first historically Black institution, 
Cheyney State Teachers College, was established just outside Philadelphia in 1837 to provide educational opportunities for the pursuant Black population (Allen \& Jewell, 2002; Harper, 2007). Some challenge, however, that Ashmum Institute, now known as Lincoln University, was the first all-Black institution (Harper, Patton, \& Woodsen, 2009). These two institutions, along with Wilberforce University in Ohio, were created explicitly for freed slaves and their children and began what is now considered establishment of the Historically Black College/University (HBCU) (Harper et al., 2009).

HBCUs officially only include institutions that were founded prior to 1964 for the purpose of providing education to Black Americans (Brown \& Davis, 2001). Throughout history of higher education in the United States, HBCUs have embodied and represented the Black quest not just for education, but for societal equality (Allen \& Jewell, 2002). Throughout history, HBCUs have been committed to the uplifting and empowering the Black community (Albritton, 2012).

In addition to northern HBCUs, Black colleges and universities were established in the southern United States to meet the needs of newly freed Black American citizens. However, these institutions could only operate as long as White leaders provided support and maintained positions on boards and state legislature, as maintaining control the Land Grant colleges and institutions' finances and curricula was of utmost importance (LeMelle, 2002). Black graduates were expected to contribute to the well-being of the South, but only to certain extents so as to not pose a threat to the dominance of White society (LeMelle, 2002). The education available to Black students in the south, therefore, was limiting and controlled, not allowing Black students to earn similar educations as White students. Additionally, Black Americans were limited in their power 
to control their own educational pursuits by their White allies, as Black students were at the will of the philanthropy and financial support that was simultaneously provided by such White leadership (Allen \& Jewell, 2002).

In 1896, the landmark Supreme Court case of Plessy v. Ferguson declared segregation as constitutional (Kauper, 1954). "Separate, but equal" became the standard by which educational opportunities were afforded to Black Americans, indicating the facilities and quality of education available to Black Americans was expected to be equal to those of Whites (Kauper, 1954). Although this concept of equality was law, it was not reality for HBCU students (Brown, Donahoo, \& Bertrand, 2001). HBCUs, therefore, reinforced the Jim Crow legislation that stemmed from Plessy v. Ferguson, providing higher education for Black Americans throughout the South and in parts of the North as well, but not with the same resources of predominantly White institutions (LeMelle, 2002).

Following Plessy v. Ferguson, controversy arose over what would be taught in curriculum of the HBCUs, as many scholars and supporters, most notably Booker T. Washington, supported a more industrial and practical approach to education, whereas others supported a more classical curriculum to better prepare Black graduates to break the perpetual racial divide in the order of Southern American society (LeMelle, 2002). Despite the industrial versus classical debate on course curriculum, all HBCUs in the United States had the same common goals of educating Black youth, training teachers and scholars, and maintaining a continuous tradition and priority of Black education (Allen \& Jewell, 2002). 
At the turn of the century, there were approximately 100 colleges and universities solely dedicated to educating Black Americans (Allen \& Jewell, 2002). Early HBCUs were not only educational institutions but also served as places of social resistance, uplift, and empowerment for the Black community, as education also equated to liberation (Albritton, 2012). Still, funding for HBCUs was lacking, as most schools were still governed by White philanthropic agencies and therefore, the "curriculum often reflected the biases of the culturally dominant majority" (Allen \& Jewell, 2002, p. 244). Even in the HBCU educational environment of leadership training and learning, Black cultural inferiority persisted (Allen \& Jewell, 2002).

Industrial education was the concentration at many HBCUs at the time, as manual labor training was stressed by White governance (Allen \& Jewell, 2002). Booker T. Washington founded Tuskegee Normal School to support Black industrial education in the South, with the central theme of academics correlating with the social and industrial environment from which students came and into which students would likely enter after graduation (Gardner, 1975). W. E. B Dubois, on the other hand, promoted the liberal arts education at HBCUs in order to uplift the race to the level of White intellectual elites (Albritton, 2012).

Many Black student groups revolted against the conservative leadership that existed within the HBCU educational model during the 1920s (Franklin, 2016). HBCUs at this time were often criticized for perpetuating segregation by limiting curricula (Brown et al., 2001). It was not until the Black Panther movement of the 1960s that the relevance of HBCUs in the United States regained support and reverence with Black students. It was during this time HBCUs reached a pinnacle, as young Black Americans 
began to turn back to HBCUs to prepare them for the rapidly changing world (LeMelle, 2002). However, the Brown v. Board of Education decision of 1954 resulted in predominantly White institutions granting and increasing admissions to Black students (Albritton, 2012).

As they still do so today, educational credentials (i.e., college degrees) were a requirement for employment in many industry sectors, particularly those paying living wages to its respective work force (Ogbu, 2004). White employers often used this standard in educational discrepancies of Black employees, both potential and already hired, as a means of denying access to work, promotions, and advancement (Ogbu, 2004). The existence of the job ceiling, in turn, perpetuated the systemic oppression of Black advancement in the workplace and subsequent increases in wages, trickling down to limitations in Black education. The generation of Black families in the 1950s and early 1960s therefore could not provide better educational opportunities for their children due to such an instrumental status problem, often requiring the following generation to enter the work force early, decreasing their educational advancement opportunties (Ogbu, 2004).

The Civil Rights Act was signed in 1964 and in the decades thereafter, the increase of Black political power strengthened the HBCU model while supporting its continuous existence within higher education (LeMelle, 2002). Simultaneously, the Civil Rights Act led to an increase in Black access to predominantly White higher education institutions throughout the United States, thus resulting in dramatic increases in the number of African-American student attendance at predominantly White colleges and universities in the United States (Allen, 1992). The percentage of Black students in 
higher education dropped from $90 \%$ attending HBCUs prior to Brown v. Board of Education to approximately $70 \%$ by the early 1960 s (Albritton, 2012). By the 1980 s, the percentage dropped to approximately $20 \%$ (Freeman \& McDonald, 2004) and has continued to drop year by year. However, research by Karkouti (2016) shows the enrollment of Black students at four-year PWIs to be constantly declining due to the fact that Black students face hostile, alienating, and culturally insensitive environments when enrolled in PWIs.

\section{The Black College Student Today}

In today's society, educational equality and opportunity are more commonly available for Black Americans; however, there exist deficiencies in higher education commitments to minorities (Allen, 1992). United States higher education, as a whole, has opened its doors to students of color, but it has not come without subsequent issues. Research suggests that although Black students now have increased opportunities to attend PWIs, these institutions may not provide the level of education and social growth available at HBCUs (Brown et al., 2001). Allen, Epps, and Haniff (1991) found Black college students at PWIs to experience lower academic achievement, lower persistence, poorer psychological development, less likelihood of pursuing advanced degrees, and lower post-graduation earnings than Black college students at HBCUs. Many Black students at PWIs have difficulty developing personal identity and express feelings of isolation and discrimination (Brown et al., 2001).

Schools in the United States have historically favored a European perspective in social studies curricula, leading students to view race as a genetic or biological characteristic rather than a social construct (Brown, 2011). Textbook standards and 
content often do not include representations of racial violence or resistance to racial violence in the United States, particularly in the contexts of slavery (Brown, 2011). The sociocultural knowledge gap occurring in the United States primary and secondary education curriculum thus leads students to rationalize racial violence throughout history, therefore perpetuating the racial structures of opportunity in U.S. schools (Brown, 2011). The problem has remained, as "students of color remain severely underrepresented in historically White colleges and universities" (Yosso et al., 2004, p. 1).

The United States is becoming more racially and ethnically diverse, and because of this, colleges and universities are responsible for preparing students to live in a multicultural society (Jones, Liu, \& Bell, 2017). Many institutions across the United States have prioritized enrollment of a heterogeneous student body to encourage interactions and inclusion (Jones et al., 2017). However, the cumulative effects and impacts of the experiences of Black students at PWIs including racial microaggressions, stereotypes, and threats can be devastating to academic success (Solórzano, Ceja, \& Yosso, 2000).

Racial microaggressions often occur in the academic setting, presenting students with very tense racial climates within which to learn (Solórzano et al., 2000). Black students report lowered expectations and nonverbal assumptions about their capabilities in the classroom from both faculty and fellow students, often resulting in being ignored, segregated, or omitted from in-class engagement opportunities (Solórzano et al., 2000). Such interactions in the academic space contribute to the negative racial climate and discouragement of Black students on campus (Solórzano et al., 2000). Furthermore, racial microaggressions on campus affect the academic performance of the Black student in 
overt ways and can push students to drop classes, change majors, or even leaving their universities (Solórzano et al., 2000).

Black male college students. While Black college students in the United States represent just $13.7 \%$ of students attending American colleges and universities (National Center for Education Statistics, 2018), Black men are outnumbered approximately 2 to 1 by Black female college students on campus (National Center for Education Statistics, 2014). Additionally, approximately two thirds of Black men who enroll in higher education do not finish with a degree, accounting for the highest rate of attrition in all races and sexes (Strayhorn, 2014). Environmental issues such as racial marginalization on campus lead Black male students, in particular, to depart college without a degree (Strayhorn, 2014).

Specifically focusing attention on Black male college students attending a PWI, Strayhorn (2014) examined the importance of the existence of grit, a noncognitive trait, on academic success, finding grit to positively correlate with Black male college student grades. Grit, or "the tendency to pursue long-term challenging goals with perseverance and passion", is a noncognitive trait that positively impacts the Black college male's academic success at a PWI (Strayhorn, 2014). Therefore, Black male college students may need different encouragements to persevere with passion through difficulty, setbacks, and adversity than White students.

A group even further marginalized on the predominantly White campus is the Black male student-athlete. The issues Black male student-athletes face are systemic, as exploitations by colleges and universities of athletic abilities is prioritized before developing academic growth (Murty \& Roebuck, 2015). The following section further 
examines the experiences and climate of the Black male student-athlete on the college campus.

\section{The Black Male Student-Athlete}

Black male college student-athletes, in particular, struggle to duplicate their athletic prowess and success on the field into academic success in the classroom (Bimper, Harrison, \& Clark, 2013). They also feel more pressure than their White counterparts to develop an identity based upon their athletic prowess, often ignoring their academic endeavors (Bimper et al., 2013). Bimper et al. (2013) found that Black student-athletes realize later in their careers as student-athletes the importance of education, often too late to make significant changes.

Historically, Black student-athletes followed the same trends as Black students in terms of access to participation in college athletics. Particularly in the South, during the Jim Crow era, Black athletes were excluded from playing sports for White schools (Davis, 2008). Black athletes seeking college sport participation were limited to HBCUs and a select few colleges and universities in the North (Davis, 2008). HBCUs offered academic programs with relevant curricula and faculty and staff support systems likely not available to the Black student-athlete at a PWI (Cooper \& Hall, 2016), and therefore, the HBCU environment had its benefits to the Black student-athlete. HBCUs provided athletes environments within which to develop their athletic talents, thus producing legendarily dominant teams, such as the Tuskegee football teams of the 1920s and the Morgan State basketball teams of the 1930s (Cooper et al., 2014). Specifically, prior to the Civil Rights era, the majority of Black athletes in the United States attended HBCUs (Cooper et al., 2014). 
Beginning in the 1930s, there was a significant shift in increased opportunities for Black athletes to participate in sport at predominantly White institutions. As predominantly White colleges and universities transitioned from informal sport participation to more formal, organized sport teams, so too did HBCUs (Cooper, Cavil, \& Cheeks, 2014). This was primarily due to the increased competitiveness of intercollegiate athletics and the desire of athletic departments, particularly in the North, to have the best athletes available, regardless of race, competing for their institution (Davis, 2008). However, opportunities for Black student-athletes at PWIs were still scarce during the era of segregation.

The absence of Black student-athletes at predominantly White institutions, particularly in the South, was not contended (Davis, 2008). Southern intercollegiate athletics departments went so far as to even refuse to compete against schools outside the South that boasted rosters with Black athletes (Martin, 1999). Racism and discrimination met Black athletes when they were afforded the rare opportunity to participate in intercollegiate athletics (Davis, 2008). For instance, the University of North Carolina men's basketball team won the NCAA title in 1957 with an all-White roster, joining every major intercollegiate athletics program in each of the eleven ex-Confederate states, with the exception of Texas Western, to have all-White rosters in both football and basketball (Martin, 1999). It was not until the Civil Rights era that increased commercialization of college sports led to integration when the number of Black athletes competing for intercollegiate athletics teams in the South did not begin to shift substantially until the 1960s (Davis, 2008). 
PWIs sought the athletic ability of athletes by enticing them with resources, but had little interest in the betterment of the Black student-athlete from a holistic perspective (Cooper et al., 2014). The opportunities afforded to Black student-athletes during and after the Civil Rights movement at predominantly White institutions provided progress, however, negatively impacted HBCU athletics programs significantly (Cooper et al., 2104). Economic and governmental actions have led to financial challenges at HBCUs, and as a result of Black student-athletes' assimilation into PWI intercollegiate athletics, the once dominant culture of HBCU sports has disappeared (Cooper et al., 2014). Facilities, budgets, and opportunities for Black student-athletes at HBCUs, which significantly impacted the success of the HBCU athletics teams, could no longer compare to the opportunities afforded to student-athletes at PWIs (Cooper et al., 2014). PWIs, according to Black student-athletes in attendance, possessed economic advantages that allow them to place their focus more highly upon athletic commitments (Sato et al., 2017), therefore making them more competitive, thus perpetuating the separation from an athletics standpoint between PWIs and HBCUs.

The environment within which the Black student-athlete develops is one in which there are positive student-faculty relationships, academic options, and social networks that cater specifically to the Black student-athlete; thus, empowering the athlete academically, socially, and athletically (Cooper \& Hall, 2016). Cooper, Cavil, and Cheeks (2014) found HBCUs to have been unjustly impoverished due to the prevalence of racism in the United States, thus leading to the categorization of HBCUs as limited resource institutions (LRIs). Additionally, from an athletics perspective, HBCU athletics programs continue to suffer from the pillage of Black student-athletes by major Division 
I PWIs (Cooper, Cavil, \& Cheeks, 2014), leading to deficiencies in talent and on-court success, ultimately causing a perpetual deficiency in financial support from donors and fans.

\section{The Value of the Black Male Student-Athlete}

The value of the Black student-athlete is often placed solely upon his athletic performance, and therefore perpetuates the problem of Black student-athletes being singularly purposed as athletes, and not students, on predominantly White college campuses (Hawkins, 2010). Black student-athletes at PWIs cite their academic underpreparedness as the causation for their experiences with academic challenges and social engagements on campus (Sato et al., 2017). Additionally, Black student-athletes lack social support and mentorship at PWIs, adding to their alienation and isolation based on race and status as athletes (Sato et al., 2017). With that in mind, social networks, most often comprised of parents and extended family, can provide appraisal, emotional, and instrumental support for Black student-athletes at PWIs (Carter-Francique, Hart, \& Cheeks, 2015). The campus community appears to appreciate and value athletes when they perform on the field more than when they participate in the classroom (Frazier, 2012). In academia, the faculty, staff, and support members of the campus community embrace black student-athletes and fight for their rights with a simultaneous recognition of potential for personal gain (Harper, 2009).

Black male student-athletes constantly curb and dodge the 'dumb jock' stereotype, a stereotype often racially fueled (Harper, 2009; Sailes, 1993). The popular stereotype in U.S. sport supporting Black superiority in sport simultaneously contributes to the idea that Black athletes are intellectually inferior to White athletes (Davis, 1990). 
Strong racial stereotypes associated with the Black male student-athlete allude to racist implications of their sole purpose on campus is for athletics (Harper, 2009). The marketability of the African American male athlete as a "success story" is often counterproductive, perpetuating the stereotype that the African American male athlete is expected to underachieve academically (Singer, 2016). Academic clustering, or the systematic encouragement of athletes representing specific demographic groups to enroll in specific majors, can be detrimental to the lives of student-athletes of color long after their athletic careers have culminated (Comeaux, 2010).

Black Division I men's basketball student-athletes contend with two separate cultures of the work site and the home site between which they must live. They often are forced to tolerate their marginality in order to navigate predominantly White institutions (Hawkins, 2010). Student-athletes in revenue-generating sports such as basketball are often perceived as economic capital within Division I athletic departments (Hawkins, 2010). Student-athlete exploitation has handcuffed the development of Black studentathletes from an academic perspective while simultaneously demanding the pursuit of athletic excellence (Beamon, 2008).

Jones et al. (2017) examined the current perceptions of inclusive team climates in NCAA athletics. Research indicated there is currently a high level of agreement that coaches and teammates foster inclusive environments for all student-athletes, which is necessary for positive group socialization (Jones et al., 2017). However, White studentathletes believed team environments were more inclusive than Black student-athletes, which can be attributed to Black student-athletes feeling pressure to conform to racial stereotypes, encountering racial hostility, or navigating unequal treatment from 
administration, faculty, and staff (Jones et al., 2017). Additionally, the larger the size of the student body at the institution, the less likely cross-racial interactions and inclusive environments existed (Jones et al., 2017).

Separation of the Black student-athlete, depending on the situations present within each individual athletic department, further alienates the student-athlete from their home site community and involves racial isolation and distortion of visibility (Hawkins, 2010). Black student-athletes have reported their relationships with faculty often revolve around the fan identity of the faculty member and can accompany lenient academic standards for that student-athlete (Bell, 2009). The clouded mentorship such faculty provide is acutely detrimental to the already limiting academic expectations involved in the revenueproducing student-athlete experience.

Black student-athletes also have a history of academic challenges not experienced by White student-athletes (Carter-Francique et al., 2013). Sato, Hodge, and Eckert (2017) found Black student-athletes at PWIs to experience stereotypical or offensive backlash from faculty, feeling as though professors were concerned about their dedication to academics with constant reminders of refusal to prioritize student-athletes. Additionally, Black student-athletes experience negative social experiences, lack of peer support both from other students and teammates, and racial discrimination on PWI campuses (Sato et al., 2017). Carter-Francique et al. (2013) examined the way Black student-athletes define academic success as well as the social supports provided by their social networks to achieve such success, and found social support to significantly impact the definition of academic success of Black student-athletes. 
Racism is not something that can be ignored on a college campus, particularly when it applies to college athletics and black student-athletes. In terms of racial discrimination, Black student-athletes cited feeling detached, excluded, or separated from other students and teammates on campus (Sato et al., 2017). While it is imperative to view race, racism, and the racial climate that exists on the college campus through the eyes of students of color to truly understand their needs (Solórzano et al., 2000), the systems often put in place to assist Black student-athletes in their pursuit of a college education and potentially a professional sports career are often handcuffing, limiting the Black student-athlete to specific academic pathways to support their sport career (Hawkins, 2010). Additionally, the systems are whitewashing, as education at predominantly White institutions is White-centric, shaping the dissemination of knowledge around White perspectives (King, 2005). Perceptions of differential treatment and mistrust leave Black student-athletes without support systems necessary to acclimate to PWI campus culture (Cooper \& Hawkins, 2014). Black student-athletes have chosen to leave PWIs due to experiences with cultural dissonance from faculty, other students, and campus communities (Cooper \& Hawkins, 2014).

The stereotypes and negative labels placed upon Black Division I male studentathletes are significantly detrimental to their academic experience (Beamon, 2014; Beamon \& Bell, 2006; Bimper et al., 2013; Martin, Harrison, Stone, \& Lawrence, 2010; Sailes, 1993). Beamon (2014) reported Black student-athletes feeling mistreated and stereotyped in the racially hostile classroom. Beamon and Bell (2006) found Black student-athletes to have higher incidences of academic probation, suspension, and ineligibility than White student-athletes. Bimper et al. (2012) examined academically 
successful Black student-athletes who still reported negative racial beliefs of others impacting their abilities and expectations. Martin et al. (2010) found Black studentathletes felt the need to prove their worth to faculty and fellow students which caused them to question their abilities in the classroom. Sailes (1993) examined the beliefs of college students in regards to stereotypes surrounding college student-athletes and data revealed White students and male students to hold stronger negative stereotypical beliefs about Black student-athletes, including beliefs that Black student-athletes are not academically prepared for college, received lower grades, and are not as intelligent as White athletes.

Cooper, Davis, and Dougherty (2017) examined male student-athletes' experiences at different racial, sport, and NCAA divisions to better understand the differences between social attitudes and behaviors across groups. Black student-athletes in this study reported less positive perceptions of the campus climate, stronger perceptions of feeling as though they were viewed and treated differently as athletes on the campus rather than students (Cooper et al., 2017). Black student-athletes at the Division I level, therefore, reported higher athletic identity than their non-Black counterparts. Additionally, Black male student-athletes reported a stronger likelihood of feeling as though their athletics participation had a positive impact in their relationships with others on campus not in their racial or ethnic group (Cooper et al., 2017), indicating a stronger need and requirement for athletic identity to socialize on a predominantly White campus. This strong athletic identity is cause of concern, as Beamon (2012) found exclusive, high-level athletic identities to negatively affect an athlete transitioning out of sport and finding a redefined identity. 
Minority student-athletes are more often academically clustered into specific majors not necessarily aligned with their future goals to maintain eligibility (Beamon, 2008; Fountain \& Finley, 2009). Beamon (2008) found Black student-athletes to express athletics responsibilities as the primary constraint upon major choice due to set practice times and majors being "athlete-friendly", or easy to pass. Bimper (2015), for example, found that not a single participant in his study of Black student-athlete experiences at PWIs identified their major of study as their chosen major, but rather, a process directed by athletics policies, advisors, and academic counselors. The student-athletes, then, end up pursuing a major that is not their intended choice, but rather, one that allows them to participate in sport (Beamon, 2008).

Research by Stokowski, Rode, and Hardin (2016) indicates that academic counselors and advisors in athletics departments possess negative views of both the student-athletes with which they work as well as the athletics department by which they are employed. The more negatively the academic counselor or advisor views the NCAA Division I athletics department for which they work, the more likely he or she is to negatively stereotype the student-athletes he or she supervises (Stokowski et al., 2016). This is particularly troubling to academically clustered Black student-athletes who have been herded into athlete-friendly classes or eligibility-preserving academic plans by academic counselors and advisors, often without the authorization of the student-athletes themselves, which has shown to possess and perpetuate negative student-athlete stereotypes.

PWIs have a social responsibility to the Black student-athlete (Carter-Francique, 2015). Successful academic experiences for Black student-athletes in the PWI 
environment have been found to rely upon interactions with faculty (Carter-Francique et al., 2015). Additionally, faculty members have been found to have a more positive opinion of student-athletes taking on less rigorous academic majors than those pursuing more challenging majors (Carter-Francique et al., 2015). The academic environment present at most PWIs socially isolates and therefore limits the social support of the Black student-athlete (Carter-Francique et al., 2015). This results in a failure to meet and understand the cultural needs of the Black student-athlete, which often results in lack of academic success (Carter-Francique et al., 2015).

Baker et al. (2017) examined correlations between national rankings and academic progress scores of Division I basketball teams and found no program in the Power Five conferences to be efficient in both calculations. This study suggests Division I high-profile basketball programs choose to be either athletically or academically successful but cannot do both. This can be attributed to the lack of Black role models available after athletic eligibility of the student-athlete is complete (Carter-Francique et al., 2015).

The influence of NCAA policy. The NCAA promotes intercollegiate athletics, at all Divisions, as vital and necessary components of the college or university's structure (Davis, 1996). The NCAA lists the collegiate model of athletics where student-athletes balance academic, social, and athletics experiences as its primary core value (NCAA, n.d.c.). Critics often question the legitimacy and effectiveness of the NCAA core values placed upon the holistic experience of the student-athlete, particularly when many institutions fail to provide student-athletes with adequate opportunities to benefit from the values promoted by the NCAA (Davis, 1996). 
Rules and regulations that support the educational benefits associated with NCAA athletics participation have a direct racial impact on the student-athlete, as many of such rules were created for the PWI setting which dominates the NCAA member school makeup (Davis, 1996). Such policies harm disadvantaged and at-risk student-athletes, disproportionately represented by, and therefore most affecting, Black student-athletes (Davis, 1996). NCAA rules reflecting racial and cultural bias include: a) the cultural bias of NCAA academic initial eligibility standards, b) rules restricting student-athlete employment and earnings, and c) legislation limiting coaches access of prospective student-athletes (Davis, 1996).

The NCAA promotes ideals supporting the beliefs that athletics participation at any one of the Division I-, II-, or III-member schools leads to positive development of the student-athlete in academics, social engagement, leadership, and athletics, ultimately culminating with obtaining a college degree (NCAA, n.d.a.). However, many NCAA member schools fail to do so for Black male student-athletes. Black male student-athletes consistently underperform academically when compared to their White teammates as indicated in APR rates and graduation rates (Baker \& Hawkins, 2016; Bolen, Rezek, \& Pitts, 2017).

Many Division I PWIs, a designation pertaining to all NCAA Power Five institutions, are unfit to meet the needs of Black male students (Cooper \& Hawkins, 2014). The term "Power Five" designates the five Division I conferences consisting of 65 Division I member schools granted autonomy by the NCAA Board of Directors in 2014 (Mandel, 2014). Black male student-athletes are overrepresented in student-athlete population on campuses, particularly on high-profile sport rosters, but are 
underrepresented by the general student body population (Baker \& Hawkins, 2016; Cooper \& Hawkins, 2014). Black student-athletes play the predominant role in college athletics as it grows and prospers as they simultaneously experience the system exploiting their athletic abilities at the expense of receiving disproportionate educational opportunities (Baker \& Hawkins, 2016; Singer, 2016).

Black male student-athletes face their own set of unique experiences participating in sport at PWIs that have a direct impact upon their academic success and social support (Carter-Francique, Hart, \& Steward, 2013). Microaggressions, social isolation, negative stereotypes, and lack of institutional support for academic and social needs of studentathletes of color often result in poor academic performance by Black student-athletes (Cooper \& Hawkins, 2014). To unpack the issues Black male student-athletes face throughout the transition process of transfer requires further explanation of critical race theory and methodology as well as an analysis of the academic, social, and financial experiences of Black students in postsecondary education.

\section{Transfer Students in Higher Education}

\section{The Transfer Student}

The American college student makes three important decisions throughout the college journey: (a) whether or not to go to college, (b) where to go to college, and (c) where to graduate from college (Goldrick-Rab \& Pfeffer, 2009). As college application rates increase at all levels of postsecondary education across the United States, so too does the rate of college student transfer (Bahr, 2009). Opportunity, tuition cost, choice and availability of major, and on- and off-campus social experience draw students away from initially attended institutions and toward institutions possessing potential for a better 
college experience (Bahr, 2009). However, the transfer experience can have lasting negative effects upon the academic and social well-being of the student (Tobolowsky \& Cox, 2012), although the complexity of the transfer student's academic, social, and personal environments do show to fluctuate on a case-by-case basis (Bahr, 2009; Goldrick-Rab \& Pfeffer, 2009).

Two main avenues of transfer exist in the United States: (a) the community college transfer, or the two-year to four- year institution transfer, and (b) the lateral transfer, or the two-year to two- year or four-year to four- year institution transfer (Bahr, 2009). Most research pertaining to student transition through transfer focuses upon the two-year to four- year community college transfer (Jain, Bernal, Lucero, Herrera, \& Solórzano, 2016; Volkwein, King, \& Terenzini, 1986; Wang, Wickersham, \& Sun, 2017). There is a significant gap in available literature on student transition experiences with lateral transfer, particularly when focusing upon the four- to four- year lateral transfer.

For the remainder of the study, the term "lateral transfer" will refer only to the four- to four- year transfer. Bahr (2009) found lateral transfer to decrease the chances of obtaining a credential or degree. However, Goldrick-Rab and Pfeffer (2009) found that the lateral transfer has not been found to reduce the transferring student's ability to earn a degree when compared to students who began their academic careers at the institution with similar academic performance standards.

Community college student movement or transfer to four- year institutions represents a natural academic progression for the Bachelor degree-seeking student, whereas lateral transfer is perceived to occur when a 4-year student recognizes a need for 
repair or alteration in his/her college experience (Goldrick-Rab \& Pfeffer, 2009). Lateral transfer occurs most often because students are dissatisfied with their initially chosen institution (Ishitani, 2006). McCormick (1997) found 63\% of transfer students to attribute dissatisfaction with their individual intellectual growth at their initial institution as the reason for transfer. Other indicators of dissatisfaction included teacher ability, institutional prestige, and social life (McCormick, 1997). Motivation to transfer differs between community college and lateral transfer students; however, the student experience at the receiving institution is relatable to both populations as they arrive on new campuses.

Stigmas surround the transfer student upon arrival in new campus climates. Reputations of transfer students, such as designation of “outsider" status, negatively impacts confidence, expectations, and acceptance capabilities within the new campus culture and community (Goldrick-Rab \& Pfeffer, 2009). In reality, the transfer student transition is complex, intricate, and personal, and often requires procedures and systems present and available at receiving institutions to better assist transfer students in being more successful (Wawrzynski \& Sedlacek, 2003).

The larger the consistent contingent of transfer students at an institution, the more successful transfer students will be overall (Nutting, 2008). Four-year colleges and universities with large transfer student populations and a steady stream of transfer student applicants have the highest reason to hire a designated transfer admissions employee or staff to streamline the transfer student process (Cotomicalos, 2014; Nutting, 2008). However, there is a general lack of care, guidance, and assistance provided by the receiving institutions to transfer students across the country (Cotomicalos, 2014). 
Transfer student populations are not often viewed as institutional priorities at 4-year institutions mostly due to the lack of experience the faculty and staff possess with transfers at colleges and universities across the country, regardless of their numerical abundance (Tobolowsky \& Cox, 2012).

Lateral transfer students often lack assistance acclimating to their new college campus because they are perceived having experience on a 4-year college campus; thus, there is often a lack of recognition that a transfer student may be at risk of social isolation and academic unpreparedness. Lateral transfer students often arrive on new campuses disengaged and disconnected, often lacking direction, mentorship, or social support (Lipka, 2008; Nuñez \& Yoshimi, 2016). Receiving 4-year institutions are often surprised at the lack of preparation and capability of lateral transfer students, as campus officials believe the adjustment should be smoother for this student population than a 2- to 4- year transfer (Nutting, 2008).

The cultivation of the lateral transfer student body population is not often a priority for receiving institutions (Werther, 2012); however, transfer students can prove to be beneficial for colleges and universities in several ways. Transfer student enrollment has the quantifiable capability of easing inefficiencies colleges and universities face from outgoing native students transferring to other schools or dropping out (Cheslock, 2004). Accepting transfer student enrollment has the financial capability of decreasing inefficiencies colleges and universities face from student body attrition over time (Cheslock, 2004). Transfer students can provide balance in class sizes and replenish tuition dollars lost through student attrition. 
Academic, social, and financial processes and systems in place to facilitate academic success are hot buttons for a student to transition successfully to the receiving institution, and should be prioritized by institutions seeking the financial benefits of transfer students (Cheslock, 2004; Li, 2010). Werther (2012) found lateral transfer students to report increases in difficulties with social adjustment and institutional attachment. A stronger understanding and support system of the transfer student process, therefore, from an academic, social, and processing standpoint can provide educational, social, and most notably, financial benefits to the receiving institution while simultaneously meeting the needs of the incoming transfer student population (Volkwein et al, 1986).

Five particular elements are found to give transfer students legitimacy and solidify their membership in a new campus community and include: (a) prioritization of nontraditional students, (b) providing outreach and resources fulfilling needs unique to the transfer student, (c) providing financial and academic support, (d) acknowledging and supporting intersectionalities of the transfer student, and (e) creating appropriate assessment practices supporting transfer student academic success (Jain et al., 2016). Such support leads to higher transfer student success rates (Heddy, Sinatra, Seli, Taasoobshirazi, \& Mukhopadhyay, 2016).

Priority of established connections with transfer students and their new campus communities in the first stages of transfer, from recruitment to application to campus visits to move-in, is paramount to the transfer student transition success (Heddy et al., 2016). Establishing and maintaining a campus culture of transfer student acceptance is necessary to success as a student and individual (Wang et al., 2017). This can be 
accomplished through outreach, recruitment, guaranteed transfer acceptance and credit transfer programs, availability of curriculum assistance, and availability of transfer student financial assistance (Wang et al., 2017).

Transfer students experience few advantages over the native freshman population at 4-year institutions. One advantage transfer students find and embrace in particular, is the perceived and required academic standards for acceptance when entering a 4-year institution as a transfer student. The availability of more selective choices in terms of quality and reputation of education in the search process for transfer students is greater than native student populations at the same institution with comparable credentials (Cheslock, 2004).

From a longitudinal perspective, current research lacks the consistency in followup and re-evaluation to understand not only how transfer students experience the initial transfer process overall, but how their academic careers evolve and how their eventual job searches and work preparedness is affected by their transfer experience (Nuñez \& Yoshimi, 2016). Again, literature on the experiences of lateral transfer students is lacking overall. Available literature on the academic and social transition of lateral transfer students provides a framework from which to expand to more fully grasp the transition experiences of lateral transfers on campuses in the United States.

Academic transition. Transfer students face difficulty when presented with the task of establishing and maintaining relationships with faculty and staff on new campuses (Nuñez \& Yoshimi, 2016; Townsend, 2012). Transfer students often feel marginalized, shocked with new campus culture and academic expectations, and are in dire need of guidance through the acclimation process (Townsend, 2012). Transfer students often 
experience a transfer dip, equating to a drop in academic performance due to the accumulation of crisis experiences and shock (Cuseo, 1998). However, the dip often attributed to "transfer shock" may not be attributed to the transfer itself, but rather, with the coursework often accompanying the student once s/he transfers, as later-stage students often take more challenging major classes later in 4-year curricula (Tobolowsky \& Cox, 2012).

Transfer students need a streamlined application process, increased transparency with credit transfer, and qualifications necessary through transfer matriculation (Wang et al., 2017). Academic performance of the student, heavily influenced by student-faculty relationships on campus, has a direct impact upon the holistic transition experience of the transfer student (Volkwein et al., 1986). The informal contact a student can have with a faculty member has been shown to be integral to student retention, as student intellectual growth is enhanced when faculty are devoted and show interest into student advancement (Volkwein et al., 1986).

Social transition. The campus climate, as perceived by the transfer student, is important and is influenced by institutional priority on faculty, teaching, and establishing a multicultural environment (Oseguera \& Rhee, 2009). Emphasis placed upon engagement in campus social activities for transfer students is a necessary piece to transfer student assimilation, but lacks availability (Nuñez \& Yoshimi, 2016; Wang et al., 2017). The capability of transfer students to connect socially with fellow students can prove to be a major challenge during the transfer transition (Townsend, 2012). Student persistence in naturally-occurring, dyadic relationships with peers is key to successful transition (Oseguera \& Rhee, 2009). 
Peer relationships are a viable means of student socialization but such interactions cannot be forced upon students by universities and must occur organically (Oseguera \& Rhee, 2009). The majority of the responsibility of maintaining student success is placed on the reception capabilities of the receiving institution, but responsibility must be shared by the transfer student to be prepared, have realistic expectations, and to work to acclimate into the campus environment of the receiving institution. The more a transfer student asserts him or herself, the more improved his or her social experience, academic experience, and quality of life will be through the transition experience (Swigart \& Murrell, 2010).

\section{The Transfer Student-Athlete}

Athletes constantly experience transitions, including but not limited to: team change, roster change, role change, and ability change (Pearson \& Petitpas, 1990). As sports seasons come and go, new and fresh seasons bring about new teams and teammates, new levels of qualification and competition, new and enhanced equipment, and new individual and team skill sets, among other physical, psychological, and social changes (Pearson \& Petitpas, 1990). Some athletes successfully transition into new roles or environments, whereas others struggle to realize their potential to be successful in a new situation (Hollings, Mallett, \& Hume, 2014).

Elite athletes rquire an intense commitment to sport and are driven by personal goals (Hollings et al., 2014). Student-athletes experience both psychological and psychosocial transitions in abundance throughout the five-year clock of eligibility (Cummins \& O’Boyle, 2015). Student-athlete demographic characteristics such as chronological age, gender, race, and socioeconomic status can affect the individual 
athlete's perceived capability of transition success throughout the pursuit of an individual athletic career (Pearson \& Petitpas, 1990).

The available literature on transition experiences of student-athletes is very limited and focuses primarily upon the individual athlete's transition out of a sport career and adaptation into a new venture or career rather than transition to another institution for continued participation in sport (Baillie, 1993; Lavallee, 2005; Pearson \& Petitpas, 1990; Ungerleider, 1997). Although focused upon retiring athletes, Baillie (1993) indicated athletes experiencing transition often feel left behind. Similarly, Pearson and Petitpas (1990) focused research on athletes retiring from sport, but identified factors contributing to an athlete being particularly vulnerable to transitional stress, including developmental factors of early focus and priority of sport over all other life commitments, the establishment of personal identity reliant upon sport, and the lack of exploratory behavior outside sport.

Pearson and Petitpas (1990), through an extrapolation from Schlossberg's (1981) Transition Theory model, predict transition to be most difficult for athletes who most strongly identify as athletes and base their happiness upon athletic success, athletes with the greatest discrepancy between athletic aspiration and actual ability, athletes inexperienced with transition, athletes with emotional or behavioral deficits, athletes lacking the capability to form relationships, and athletes transitioning within a situation without helpful resources. Ungerleider (1997) focused his research primarily upon sport retirement as well, but indicated athletes experiencing success in sport do so at the expense of all else, especially socialization, and therefore, do not build relationships necessary to aid in transition when a transition event is presented. Athletes often do not 
cultivate or possess the emotional and/or educational resources outside of the realm of sport to support themselves through a transition and therefore must look elsewhere (Ungerleider, 1997).

Lavallee (2005) examined the transition adjustment of retired professional athletes by comparing athletes that had received a life development intervention package preparing them for retirement to those that did not receive any formal development training. Through this comparison, Lavallee (2005) saw the life development intervention package to have a significantly positive impact on the group, whereas the control group that did not receive the package experienced an increase in transition difficulty. This study, although focused upon athlete retirement and life transition, adds to the notion that even the smallest support structure present and available for athletes experiencing transition can help ease them through the experience.

Other literature on transition in the sport context focuses on the transition of athletes as they finish their sport careers due to injury or being eliminated from a roster (Kleiber \& Brock, 1992; Saxe, Hardin, Taylor, \& Pate, 2017; Stoltenburg, Cindra, \& Bremer, 2011). Kleiber and Brock (1992) examined athletes with career-ending injuries, but asserted through their findings that excellence in athletic performance can only be cultivated from a committed focus of serious attention to athletics, therefore identifying with sport over all else. Coaches and institutions too require this level of focus and commitment forcing young student-athletes to commit an irrational level of focus to athletics (Kleiber \& Brock, 1992).

Saxe et al. (2017), while examining the transition of female student-athletes throughout their NCAA Division I Football Bowl Subdivision (FBS) eligibility, found 
information supporting the necessity of athletics support staff to diversify their resources to assist the transitioning college student-athlete, as going through such transition experiences often leads to anxiety. Stoltenburg et al. (2011) evaluated the transition of athletes with career-ending injuries out of sport, citing the largest regret as the general student-athlete lack of focus and dedication toward education while pursuing sport. Additionally, those student-athletes receiving positive social support had more positive experiences throughout their transition than student-athletes citing a lack of social support. Student-athletes lacking social support cited isolation, alienation, and loneliness contributing to the negativity of their overall experience through transition out of sport (Stoltenburg et al., 2011).

Cooper and Hawkins (2014) examined the experiences of Black male football and basketball student-athletes as they transferred from PWIs to HBCUs. Similarly to the present study, Cooper and Hawkins (2014) chose to focus their work on student-athletes participating in sports producing historically low graduation success rates, academic success rates, and academic progress rates when compared to other NCAA sponsored sports. The results supported the salience of the four Critical Race Theory tenets with two themes emerging: 1) "We were the outcasts" and 2) "They want to see you succeed" (Cooper \& Hawkins, 2014, p. 89). However, the demographic of student-athletes used for the study attended both JUCO and Division I PWIs before transferring to a single Division II HBCU. This transition, therefore, eases the experience of the Black studentathlete, as Cooper and Hawkins (2014) reported student-athletes receiving more readily available faculty assistance in a more accepting, more representative campus climate. Additionally, transferring from a Division I to a Division II institution, by NCAA rule, 
lessens the commitment time required or allowed for athletics participation (NCAA, n.d.b.).

Flowers et al. (2014) examined twelve male Division I student-athletes at one midwestern Division I institution. While the study found Schlossberg's Transition Theory to be a relevant framework to examine the transition experiences of the student-athletes, this study, like Cooper and Hawkins' (2014), did not focus on one sport and incorporated JUCO transfers. Additionally, Flowers et al.'s (2014) study did not examine race.

Flowers et al. (2014) suggests that transfer student-athletes are self-reliant in their new campus climate and depended primarily upon themselves to navigate the process, a finding that is alarming when applied to the already underserved population of Black students at PWIs.

In addition to the limited scope of the literature, many transition models used in present research have lacked operational details specific to sport transition (Gordon \& Lavallee, 2012). Gordon and Lavallee (2012) found career intervention programs to assist in the facilitation of career transition for athletes to be beneficial, particularly when supplied at the organizational level. Programs that focus upon athlete enrichment when coping with transitions can provide athletes with career awareness and planning strategies (Gordon \& Lavallee, 2012).

Student-athletes, as a group, have separate and distinct characteristics of experiences throughout their collegiate career eligibility not generalizable to the general undergraduate student population. For instance, student-athletes have time requirements in athletics that distract from academic and social experiences (Levine, Etchison, \& Oppenheimer, 2014). In turn, student-athletes are referred to in sport management 
literature as a unique group of the student population with associated unique needs (Ferrante, Etzel, \& Lantz, 1996). What is often clouded by the perceptions of the student-athlete, however, is the fact that they, too, experience the same, ordinary problems and issues as other undergraduate students in addition to their own unique set of characterized experiences (Watson, 2003).

Student-athletes are likely aware of the unique social, academic, and physical benefits derived from participation in intercollegiate athletics (Singer, 2016). Studentathletes may either cherish or despise their own unique experiences, depending on their own personal understanding of the importance and overall necessity of lifestyle separated from the general student population (Singer, 2016). The general student body population does not have to deal with retirement issues or contract negotiation, external and internal social pressures, or individual characteristics and preparedness for life after sport (Pearson \& Petitpas, 1990).

The process of development through transition occurs during both voluntary and involuntary transition (Goodman, Schlossberg, \& Anderson, 2006). Predictability of transition significantly impacts the transition experience. The less prepared the individual student-athlete is for a sudden or unexpected transition, the more support the studentathlete needs to adjust and adapt to the associated changes (Pearson \& Petitpas, 1990). Although prior research particular to the transfer student-athlete transition is limited, exploration of the academic and athletic transitions of student-athletes provides perspective on the unique experiences possessing potential to confront a transfer studentathlete. 
Academic transition. Student-athletes are often considered to be extremely athletically motivated and focused, but conversely, academic performance and selfmotivation in the classroom have been shown to contradict such considerations and motivations (Simons, Van Rheenen, \& Covington, 1999). Student-athletes begin their athletic careers with strong athletic abilities, identity, and commitments to improvement and the student-athlete focus on academic ability and commitment varies depending on individual ability, history of success, and parental, sibling, teacher, and peer influence (Simons et al., 1999).

The stress associated with participation in Division I athletics has a significant effect on a student-athlete's academic performance (Stansbury, 2003). Due to such stressors, the NCAA designed the redshirt year requirement (NCAA, 2017b). The redshirt year requires student-athletes to sit out of competition for a year after transfer to encourage decisions to be made and motivated by both academics and athletics, as most student-athletes benefit from a year to adjust to their new environment and focus on classes without the pressures and distractions associated with competition (NCAA, 2017b).

Ferrante et al. (1996) proposed the perception of the lazy, pampered, out of control, over-privileged, student-athlete is motivated solely by athletics participation. Student-athletes face strong pressures that deter their focus from academic commitment and potential for success (Simons et al., 1999). Research has shown that student-athletes in the high-profile sports of football and men's basketball do not perform as well academically as the general student body population (Eitzen, 2016). Academic clustering, or the enrollment of $25 \%$ or more of a team into a single select major, is not limited to but 
occurs most frequently in Division I men's basketball and football (Fountain \& Finley, 2011). Additionally, Fountain and Finley (2009) found academic clustering for both White and Minority football student-athletes, but occurs more frequently for Minority student-athletes.

Academic clustering occurs in intercollegiate athletics to allow schedule flexibility but can also occur to aid in the eligibility of student-athletes (Fountain \& Finley, 2009). Academic clustering, therefore, has potential to pose more of a threat to Black men's basketball transfer student-athletes facing credit transfer issues and NCAA eligibility standards. As Black student-athletes are more often clustered, they may be forced into a major at their initial institution, then when going through the transfer process, cannot find a school with that major, therefore having capability to impact their degree progress requirements, thus putting them at risk for eligibility issues and added stress toward degree completion.

The focus placed upon pursuit of academic goals for a transfer student-athlete can be lost due to stress associated with the transition. From an academic perspective, revenue-generating student-athletes receive more support and extrinsic rewards than other student-athletes but are challenged with additional time and energy requirements associated with sport participation (Levine et al., 2014; Simons et al., 1999). Revenuegenerating student-athletes are also more likely to fail academically as the culture of revenue-generating sports both formally informally leads to the conclusion that athletics are more important than academics (Simons et al., 1999). The transferring studentathlete's eligibility may be in jeopardy if the number of his/her transferrable credits is too low (NCAA, n.d.c.). Concern over credit transfer could also contribute to the choice of 
the institution to which a student-athlete transfers, as some Division I institutions have lower academic standards than others.

Flowers et al. (2014) found transfer credit issues to require transferred studentathletes to take on heavier course loads, or take more courses throughout the summer, to maintain eligibility and curb credit loss. The NCAA requirements placed upon athletics eligibility standards, therefore, can impact transfer student-athletes stronger than nontransfer student-athletes, thus putting them at a disadvantage. This added time commitment required when taking on additional credit hours can negatively impact a student-athlete's ability to acclimate to campus and engage with the university community, thus limiting the student-athlete's support system and sense of belonging (Flowers et al., 2014).

Transfer student-athletes motivated to transfer in order to pursue a professional sports career are placing themselves in jeopardy of academic failure (Robbins, 2015). Aspirations of professional sport careers will likely continue as a main goal of studentathletes in revenue-generating sports, however, a focus placed upon educational pursuits likely and more dependably serve the student-athlete from a lifelong perspective (Bimper et al., 2012). From an academic perspective, it is of utmost importance to assist the transfer student-athlete through transition to the new university's academic structures and expectations.

Transfer often carries strong potential for loss of transferrable credit hours and therefore could hamper the student-athlete's academic progress, as NCAA standards of progress-toward-degree are specific benchmarks affecting eligibility (NCAA, n.d.c.; Townsend, 2012). Additionally, Black male student-athletes frequently come to the 
realization towards the end of their academic careers rather than the beginning that their best interest as student-athletes does not align with the athletic department's interests (Bimper et al., 2012). The capability of the redshirt year to provide an academic cushion for the student-athlete from the progress-toward-degree perspective and alleviate issues with transferrable credits could serve to be a vital attribute of the transition process (NCAA, n.d.c.).

Athletic transition. Compatibility is a necessary element to team success. New team members are responsible for connecting to support networks within the team structure regardless of the ability or interest by others in embracing a newcomer (Surujlal \& Zyl, 2014). Openness to alternatives, positive social support, and pre-transition planning are beneficial to a smooth transition for a student-athlete (Cummins \& O’Boyle, 2015).

Athletes in transition often find themselves in a neutral zone of unproductivity before embracing a compatible role with new responsibilities (Coakley, 2006). A studentathlete who takes a long time to acclimate to new surroundings and does not embrace the existing culture is less likely to have success either inside the locker room or out on the playing field (Louis, 1980). The more quickly a student-athlete executes the transition and acclimates to his or her new environment, the easier and more positive his or her transition experience (Coakley, 2006; Louis, 1980).

Social pressures are present when a player transitions onto a roster, as studentathletes face issues and problems they often not equipped to understand or navigate appropriately (Saxe et al., 2017). As sport is often associated with team, the perception of the team or others involved within the transition is important to the dynamic of the 
transition (Pearson \& Petitpas, 1990). While the head coach or coaching staff of a team often determines the potential presence of a player on his or her roster, existing team members are found to have the final say (Saxe et al., 2017). New teammates, when attempting to acclimate to a new team nucleus, are often required to execute a process of required adaptation and transition into the existing team culture. Depending on the dynamics of the existing team leadership structures, the task of forming new relationships with other teammates more established within the existing team structure can sometimes derail an athlete from a successful career either on or off the playing surface (Saxe et al., 2017).

Coaches impact the environment of the team as well, and have power to foster a positive, respectful, and inclusive environment for a new team member to be embraced by (Jones et al., 2017). The consistently evolving team and coaching staff as well as various levels of player experiences and abilities presents a significant challenge during the acclimation process of the transfer student-athlete (Saxe et al., 2017). Additionally, team climate can alter a team member's experience within the team setting, as inclusive team climates on the basis of race or ethnicity can allow student-athletes to feel better about experiences with teammates of other races or ethnicities, fostering growth and acceptance (Jones et al., 2017).

Athletes often experience the "transition blues" when navigating the acclimation process, as the emotional experience of transition may not occur as expected, may prove to be more difficult than anticipated, or may be more difficult than what the individual is prepared for (Saxe et al., 2017). Transfer student-athletes have reported feeling isolated from their former team support network (McKnight, Bernes, Gunn, Chorney, Orr, \& 
Bardick, 2009). Separation from teammates leads to a loss of an established and vital camaraderie, loss of family, and loss of the sense of belonging to a group, and is often one of the hardest adjustments necessary to have experienced by an athlete as he or she navigates through the transition (Coakley, 2006). The mutual benefits to the athlete and the school to which s/he is transferring are great, however, understanding how to facilitate the athlete's transition is of utmost importance for that result to come to fruition (Harper, 2009).

The redshirt year. NCAA Division I student-athletes are allotted five full calendar years within which to participate in four seasons of competition with rare exceptions for extension (NCAA, n.d.c.). The five-year clock begins when a studentathlete enrolls as a full-time student at the institution with which he or she signed a National Letter of Intent. This five-year clock has room to include one redshirt year as well as four competition years, therefore a student-athlete will not lose any of the allotted four seasons of competition. If a student-athlete elects to endure an academic year in residence for one of many reasons approved by the NCAA, the academic year-inresidence requirement must be fulfilled in full so as the student-athlete does not lose eligibility of his or her four full years of competition. Approved reasons for enacting the academic year in residence include injury, hardship, academics, or transfer to another institution (NCAA, n.d.d.).

During the academic year in residence, more commonly referred to as the redshirt year, the student-athlete is not eligible to participate in any outside contests or scrimmages for the entirety of the year in residence, however, is eligible to participate in all other practices, training sessions, and team activities occurring on campus (NCAA, 
n.d.c.). The term "redshirt" began its association with the year in residence when Warren Alfson was a football student-athlete at the University of Nebraska in 1937 (McGee, 2012). Alfson fell down the depth chart due to his undersized frame, and therefore, was asked by a coach to practice but not play in order to preserve future eligibility (McGee, 2012). Alfson then received a red practice jersey without a number to wear throughout the season, thus coining the term "redshirt" (McGee, 2012). Alfson continued on to become a three-year starter at Nebraska while twice earning All-America honors (McGee, 2012).

Division I NCAA transfer student-athletes in the sports of football, men's and women's basketball, and men's ice hockey are required by NCAA policy to spend an academic year in residence, which spans from August to June, at the receiving institution to which he or she transfers if he or she decides to leave the institution to which he or she was initially contractually bound by the National Letter of Intent (NCAA, n.d.c.). If a student-athlete transfers after the fall semester, he or she must participate in an academic year in residence consisting of two full semesters (NCAA, n.d.c.). Student-athletes participating in all other Division I NCAA-sponsored sports too face the same academic year in residence requirements, however, athletes participating in such sports are granted a one-time transfer waiver of the academic year in residence by the NCAA (NCAA, n.d.c.).

The NCAA redshirt requirements for Division I transfer student-athletes are argued to be constricting and even unlawful, as policies currently face challenges from lawsuits and arguments for change from coaches and players (Ziller, 2016). Challenges to the requirement received so much attention that in 2018, the NCAA formed the Division 
I Transfer Working Group to seek feedback across the country on the potential refinement of the redshirt requirement into a less stringent limitation process (Hosick, 2018a). The group seeks to obtain feedback on two specific, but mild, rules modifications: (a) To allow students who meet specific academic standards to play immediately, and (b) To allow student-athletes who have signed a National Letter of Intent, or binding contract to a specific institution, to transfer and play immediately if a head coach leaves that school (Hosick, 2018a).

In the summer of 2018, the Division I Council adopted alterations to the transfer process eliminating the need for student-athletes to gain permission from institutions to contact certain schools of interest (Hosick, 2018b). The rules changes have not yet involved or altered the redshirt process, however, according to the ESPN reporter Jeff Goodman (2016), NCAA Division I men's basketball coaches feel that a restructure of rules into an allowance of transfer without requirement to endure a redshirt penalty is imminent. Currently, Division I men's basketball transfer student-athletes must elect to participate in the redshirt waiting period to pursue presumably greener pastures for the remainder of their NCAA-allotted eligibility (Ziller, 2016).

The redshirt year-in-residence affords countless benefits to transfer studentathletes, as it provides time to acclimate to campus from academic, social, financial, and athletic perspectives. However, Konsky (2003) argues the NCAA transfer rules are not consistent with the purported and promoted interest in the academic success and welfare of student-athletes, as the redshirt year harms student-athletes who depend on their college career eligibility to lead to professional sport careers or student-athletes who elect 
to transfer for loss of scholarship fears, coaching changes, or changes in academic pursuits.

\section{The Black Division I Men's Basketball Transfer}

Although Black male students represent just $2.5 \%$ of the undergraduate student population at the 65 Division I Power Five institutions, Black student-athletes are heavily concentrated in the revenue-producing sport of Division I men's basketball, representing approximately $61 \%$ of rosters (Harper, 2016). Black male student-athletes at Power Five schools graduate within six years at a lower rate $(53.6 \%)$ than Black undergraduate men who graduate at a rate of $58.4 \%$. The aforementioned numbers contrast with the general student-athlete population that graduates at a rate of $68.5 \%$, and the general student population that graduates at a rate of $75.4 \%$ (Harper, 2016). Black male student-athletes in basketball, therefore, graduate at a rate substantially lower than the $78 \%$ men's basketball student-athlete graduation rate reported by the NCAA (2016). Considering such a low average graduation rate, the addition of a transfer transition process during the academic progress of the Black male student-athlete in a revenue-producing sport like basketball likely only adds pressure, confusion, and hardship to the already arduous process of obtaining an undergraduate degree.

Many reasons for Division I men's basketball transfer are cited each year and are heavily reported when top prospects seek better opportunities to continue careers and eligibility elsewhere (Associated Press, 2017; Daniels, 2017; Greer, 2017; Groeschen, 2016; Katz, 2009; Miller, 2017). The most cited reasons for Division I men's basketball transfer are to (a) move closer to home, (b) pursue potential to earn more playing time, (c) play at a higher or more glamorous level, (d) pursue potential to earn a role with 
increased scoring options, and (e) pursue a team with more potential to win (Alexander, 2011).

The Black male transfer student-athlete's experience is evermore unique and therefore requires exploration to better serve the population. Critical race theory can be applied, as racism is a permanent aspect of general society and applies to both the college campus and the nucleus of the athletic department and Division I basketball team (Cooper \& Hawkins, 2014). Hawkins' (2010) comparison of the Black student-athlete to oscillating migrant laborers lends itself to the transfer transition, as the student-athlete follows the same patterns as oscillating laborers pursuing the most viable option for work. The Black transfer student-athlete encounters similar situations as an oscillating migrant laborer as they too must navigate an internal colonial relationship that exists, in this case, within a PWI (Hawkins, 2010).

While often detrimental to the academic performance of the student-athlete, the obsessive pursuit of a professional basketball career after college can be tragic to Black men unsuccessful in achieving that goal (Beamon, 2008). The transfer decision intrinsically motivated by athletic pursuit, as mentioned above (Alexander, 2011) and very likely in a Division I men's basketball transfer decision, places the Black studentathlete at higher risk of failure (Beamon, 2008). If a Black Division I men's basketball transfer does not value his academic experience and fails in securing a professional sport contract, he falls prey to the exploitation of big-time, commercialized NCAA athletics (Beamon, 2008). Exploring the experiences of the Division I Black men's basketball athlete is necessary to better understand how to improve academic persistence and focus (Cooper \& Hawkins, 2014). 
To place the cited reasons for transfer in context with the aforementioned literature, a few high-profile Black Division I men's basketball transfer cases that have occurred within the past five years are listed below:

- Sam Cunliffe transferred to the University of Kansas after playing one semester at Arizona State, citing that Kansas was going to give him an opportunity to play more minutes once eligible (Daniels, 2017).

- Marcus Keene transferred from Youngstown State, where he averaged 15.6 points per game, to Central Michigan University, where he averaged over 30.0 points per game during his first season of eligibility (Miller, 2016).

- Cane Broome transferred from Sacred Heart University after one season to join the University of Cincinnati men's basketball team in 2016, drawn by the winning tradition and opportunity to win championships (Groeschen, 2016).

- Chase Jeter decided to depart Duke University after two seasons with plans of attending a school closer to his home in Las Vegas, Nevada (Associated Press, 2017).

- Jordan Barnett, a St. Louis, Missouri native, transferred to the University of Missouri after playing three semesters at the University of Texas, as he explained that there was no better place to play than home, surrounded by family, friends, and support (Palmer, 2016).

None of the aforementioned cases of Black Division I men's basketball transfer, or any cases identified in the research, designates academic reasons as deciding factors for transfer, a cause for concern in the current climate of challenges to the transfer redshirt requirements. 
From a student-athlete transition perspective, with similarity to a career transition, the transfer from one Division I to another Division I institution can cause studentathletes to experience trauma and crisis (Schlossberg, 1981). What is necessary is to more extensively explore the transition process of the Black men's basketball student-athlete through the transfer to better understand the redshirt year processes and whether a transition period is beneficial for the Black male student-athlete. In order to do so, two theoretical frameworks shape the study with abstract principles to predict the facts and organize obtained information (Schlossberg, 1995): Transition Theory and Critical Race Theory.

\section{Theoretical Frameworks}

Theoretical frameworks are used in research to assist in the design of research questions, guide the research process, help interpret collected data, and offer constructive explanations or causes of the eventual findings (Reeves et al., 2008). Employing theoretical frameworks appropriate to address and answer the questions at hand while simultaneously understanding the importance of the participant perspective is integral to the successful execution of a study (Bekker \& Cheater, 2011). For the present study, two theoretical fameworks, Transition Theory and Critical Race Theory, were chosen. Transition Theory examines an individual's capacity to cope with change, while Critical Race Theory focuses on the experiences of "raced" people. The combination of transfer, student-athlete, racial, and gender identity of the participants statuses has the potential to have a profound impact academically, socially, and personally on the Black male studentathlete. 


\section{Transition Theory}

Adapting to an array of changes is part of the everyday human experience. Change can require a new or changed network of relationships or an altered selfpresentation in a new or changed situation (Schlossberg, 1966; 1981). Schlossberg's (1981) Model of Human Adaptation to Transition was created to examine the capacity of human beings to cope with change. According to Schlossberg (1981), "A transition can be said to occur if an event or nonevent results in a change in assumptions about oneself and the world and thus requires a corresponding change in one's behavior and relationships" (p. 5).

Transition includes large-scale, life-altering change leading to major adaptation down to small-scale change requiring little to no adaptation. Schlossberg's (1981) transition theory seeks to clarify individual experiences by analyzing factors surrounding transition. Transition factors include anticipation, preparation, alteration capability, individual experience, and available support (Schlossberg, 2011). Transition does not necessarily incite crisis or negative reaction, but can also include positive or pleasant feelings and expressions. The more a transition uproots and alters routine patterns of behavior, the more significant it becomes and the more it is perceived as crisis (Schlossberg, 1981).

More important than the transition itself is the perception of the individual experiencing the transition (Schlossberg, 1981), as the transition exists only if the individual defines the experience as transitional (Schlossberg, Waters, \& Goodman, 1995). Transitions are significant when challenges are posed to roles, relationships, beliefs, or customary actions of achievement (Schlossberg, 1984). While Swain (1991) 
posits that people have similar experiences through relatable transitions, Schlossberg (1981) suggests that environment has a significant effect on a person's perception of transition. Demographics and prior experiences most significantly influence the individual transition experience (Swain, 1991).

The key to successful transition is understanding transition factors to achieve quick and smooth adaptation (Gordon \& Lavallee, 2012). Adaptation is influenced by three sets of characteristics possessing their own salience levels and includes (a) specific characteristics of the transition itself, (b) characteristics of the support structure surrounding the transition, and (c) characteristics of the actual individual experiencing the transition (Schlossberg, 1981). Different factors and identifiers have different effects on the individual experiencing transition and often depends on transition specifics (Schlossberg, 1981).

Four major theoretical perspectives influence transition theory and include (a) the contextual perspectives of adulthood, (b) the perspective of human development, (c) the perspective of life-span, and (d) the perspective of the transition (Schlossberg et al., 1995). Contextual perspectives of adulthood relates to the context within which the adult exists (Schlossberg, 1995), for instance, in order to understand the transitioning studentathlete, it is also necessary to understand the context of the environment within which the student-athlete exists. The development perspective relates to the sequential nature of development based on age, situation, or domain (Schlossberg, 1995), for instance, the early adult student-athlete at 20 years of age deciding to transfer and how his age places him within the situation. The life-span perspective relates to individual issues of continuity (Schlossberg, 1995), for instance, the continuity an individual transfer student- 
athlete faces when he enters into another college or university's environment. The perspective of the transition relates to the life events that entail the change (Schlossberg, 1995), for instance, the life event of transferring to another college or university and how he copes through it.

The physical, psychological, and social experiences through which a person participates and executes a transition directly impact the person's experiences through transition (Morrison, 2002; Pearson \& Petitpas, 1990). The nature of a transition can be further broken down into type, pattern, and property of transition (Meleis, Sawyer, Im, Messias, \& Schumacher, 2000). Transition conditions, either presented as facilitators or inhibitors, include personal, community, and societal influences (Meleis et al., 2000). A personal condition influencing the transition in the student-athlete context could include the mindset of the individual to push through physical or mental roadblocks. A community condition influencing the transition of a student-athlete could include the student-athlete's family structure. A societal condition influencing the transition of a student-athlete could include the toleration necessary of a Black student-athlete to navigate a predominantly White institution (Hawkins, 2010).

Patterns of response can involve either process indicators, outcome indicators, or consequences, each of which focuses on different stages of the transition process (Meleis et al., 2000). Process indicators are characteristics that can be manipulated, for example, the extent to which a student-athlete seeks counseling through the transition process (Berger \& Malaney, 2001; Scheerens, 1991). Outcome indicators are characteristics that cannot manipulated by the individual, for example, the eligibility requirements set by the NCAA (Berger \& Malaney, 2001). Consequences are caused by the response, for 
example, being ineligible due to such NCAA eligibility requirements. All three, evaluated on the stage of transfer, can indicate transfer readiness of the individual student (Berger \& Malaney, 2001). A more thorough understanding of such properties and conditions involved in and inherent in a transition experience can, consequently, lead to better suited and tailored responses to transition (Meleis et al., 2000).

Projected and actual vulnerabilities an individual faces present a unique set of complexities in evaluating adaptation through transition (Meleis et al., 2000). Projected vulnerabilities, such as a student-athlete's estimated academic capabilities at a new institution, can very from actual vulnerabilities, such as the distance from home or support system the student-athlete undertakes after transition. Therefore, the complex intricacies of the transition matter significantly in the transition process, particularly from the perspective of successful or unsuccessful adaptation to change.

Schlossberg's (1981, 1987, 1989, 2011) contribution to the understanding of transition theory encompasses decades of research and introduces formulas and models to generate knowledge of transition experiences. Through application of transition theory with such models, particularly in education and business research, individuals can be better supported through various transitions. Next, we examine the model most frequently used in transition research, Schlossberg et al.'s (1995) 4 S's system for coping with transitions.

Other psychosocial theories exist and are employed within higher education research to better explore and understand the development of the student through the progression of his or her educational evolution. Chickering's (1969) theory of Identity Development explores the pattern of college student development, however, maintains a 
typical pattern for typical college students (Kodama, McEwen, Liang, \& Lee, 2002).

Phinney, Lochner, and Murphy’s (1990) Model of Ethnic Identity Development focuses upon psychological adjustments in minority students, however, focuses more upon cultivating ethnic identity in the educational setting and ignores the transition of a transfer student. Schlossberg's Transition theory applies most closely to this research because it focuses upon the four major factors influencing a student's ability to cope in transition (Schlossberg, 1995).

4 S's. Schlossberg (1987) first introduced four major categories to better predict and appraise how a person will use his or her available resources to cope with either an anticipated or unanticipated change. Schlossberg, Lynch, and Chickering (1989) applied the four categories, which were for the first time referred to as the $4 \mathrm{~S}$ 's, to improve higher education environments for adults going through transition. While this specific work by Schlossberg et al. (1989) focuses primarily upon nontraditionally aged students in higher education, it can also be translated to transfer students as well as studentathletes, as both groups are nontraditional and have specific difficulties in the transition process than traditional students (Laanan, 1996; Simons, Bosworth, Fujita, \& Jensen, 2007).

Schlossberg et al. (1995) presented the 4 S's system for coping with transition as a useful model for understanding adult development through exploration of personal and social dimensions and interpretations of transition. The 4 S's includes four major categories, or variables: (1) the situation, (2) the self, (3) the supports, and (4) the strategies. Guidelines provided by the 4 S's framework strengthen both individual and practitioner abilities to understand the process an individual experiences through 
transition (Goodman, Schlossberg, \& Anderson, 2006; Schlossberg, 2011; Schlossberg et al., 1989; Schlossberg et al., 1995).

The first S, situation, refers to the overall circumstances of the individual throughout the transition. The more stimulation and attention the transition requires, the more likely the individual will experience added stress as a consequence (Schlossberg, 2011). The type of transition and whether it is deemed positive or negative, expected or unexpected, and desired or dreaded, directly impacts the situation of the individual (Sargent \& Schlossberg, 1988). Timing, choice, and place within the process also have the capabilities to impact the individual (Sargent \& Schlossberg, 1988).

The second S, self, describes the individual experiencing the transition. The selfdescription of the individual includes demographics (e.g. gender, race, age, etc.) and psychological characteristics (e.g. level of optimism or self-efficacy) (Workman, 2015). The perception of self incorporates strengths, weaknesses, previous experiences within context, available options, and capability to cope with ambiguity through transition (Sargent \& Schlossberg, 1988). Self-esteem characteristics of higher levels of confidence, commitment, and control, are found to result in decreased stress during transition (Sargent \& Schlossberg, 1988).

The third S, support, refers to people, organizations, systems, or institutions to which an individual can turn for support through transition (Workman, 2015). Perceived supporters can either hinder or help the transition (Sargent \& Schlossberg, 1988). An individual should be leery of any perceived supporters as not all are equipped to effectively support the transition. Better understanding how a person's social networks provide social support to an individual is often beneficial (Carter-Francique et al., 2015). 
The fourth and final S, strategies, includes the ways an individual copes with transition. The plan of action to cope with events and factors of the transition includes strategy choice, creative capabilities, assertion, and reactions to stress (Sargent \& Schlossberg, 1988). The ability of an individual to become aware when a strategy is no longer effective and the ability to enact a back-up plan are major contributing factors to smooth transition (Sargent \& Schlossberg, 1988).

The established framework of 4 S's provides a designated pathway to gather information that increases the positive capabilities of a transition experience through evolution of individual processes and perceptions (Schlossberg, 2011). The 4 S's are frequently used in business and education settings (Goodman \& Pappas, 2000; Griffin \& Gilbert, 2015; Heggins \& Jackson, 2003; McCoy, 2014; Pelegrino \& Hoggan, 2015; Pendleton, 2007; Rall, 2016).

Factors indicated by selected undergraduate Asian international students experiencing transition into college and campus life fell in line with Schlossberg's (2011) Four S's and included participation, traditional values, external pressures, and development of leadership skills (Heggins \& Jackson, 2003). The framework provided by Schlossberg (2011) helps identify effective practices and actions that can be executed to support and assist individuals facing transition (Heggins \& Jackson, 2003). While specific and significant factors are attributed to groups and individuals alike who may approach the transition from differing perspectives, having a generalizable model to better understand transition as an overall concept allows potential practitioners, in an array of settings including business, education, or other, to better prepare and execute a 
set of processes and understanding through transition that result in the best outcomes possible for the transitioning person.

Goodman and Pappas (2000) used the Four S's model to evaluate the transition of college faculty into retirement. The survey utilized in this study was developed to assess the application of each of the dimensions included in Schlossberg's (1989) Four S's Transition model, as it applies to adult life transition (Goodman \& Pappas, 2000). Results indicated that Schlossberg's (2011) Four S's provided a viable means of conceptualizing retirement transition in order to correlate the experience with satisfaction (Goodman \& Pappas, 2000). This study's survey structure provides a guide into how to apply a qualitative design to Schlossberg's (2011) Four S's Transition model (Goodman \& Pappas, 2000).

Pendleton (2007) used Schlossberg's (1989) Four S's in a qualitative case study examining the coping strategies enacted by welfare recipients while they were enrolled in courses in postsecondary institutions. The study supported the Four S's (Schlossberg, 1989) framework's ability to determine how the individual copes with stress through transition. By better understanding this particular population's needs through this specific transition, practitioners at postsecondary education institutions can better assist the applicable population through transition into academic life and experiences (Pendleton, 2007).

Schaefer (2010) examined older baby boomer students' transition back into college in order to evaluate the specific challenges and experiences they faced as they assimilated back into college life. Two of the S's in particular, situation and support, were most relevant for these participants. It is most beneficial to understand the situations 
surrounding student enrollment experiences and types of support required to assist in successful navigation of the processes of higher education (Schaefer, 2010). Understanding the needs of this specific population adds to the current and available literature on the transition of the specific population of students transitioning into a new higher education environment.

Griffin and Gilbert (2015) used the Four S's Transition model (Schlossberg, 2011) to frame narratives from veteran administrators and student affairs professionals to examine the influence of veteran status on the transition to higher education. Focus groups were asked questions surrounding the Four S's (Schlossberg, 2011). The responses were categorized into each dimension, indicating that while the structure is not often used in higher education research, the applicability of transition research can expand and translate to the area (Griffin \& Gilbert, 2015). In addition, Griffin and Gilbert (2015) explained that while there is no distinctive correct protocol for facilitating the transition of veterans into higher education, by gaining a better understanding of the group's contextual needs within each dimension of the Four S's (Schlossberg, 2011), general guidance can be improved.

Pellegrino and Hoggan (2015) also examined veterans' transition into higher education in the community college setting. By focusing on this specific student population, the researchers identified the complex and nuanced financial, family, and obligation strains veteran students face during their transitions into education (Pellegrino \& Hoggan, 2015). Case studies were utilized to capture and understand the transition as holistically as possible. Research questions focused on the situation, self, supports, and strategies of participants as they coped with their first years as community college 
students (Pellegrino \& Hoggan, 2015). Implications from this study indicated that by understanding the transition of this specific population of students, retention efforts can be improved and systems to help veteran students better balance their roles outside of being students can be better executed (Pellegrino \& Hoggan, 2015).

Rall (2016) applied Schlossberg's Four S's (2011) to the transition experiences of college-intending high school graduates into their successful college matriculation processes. The researchers focused on the challenges faced by low-income racial and ethnic minority students. A transitioning student's environment is comprised of relationships, both interpersonal and institutional, as well as the physical setting in which he or she is present. By applying the framework of Schlossberg's Four S's (2011) to the transitioning individual's environment, Rall (2016) aimed to better understand which variables most significantly impact the students' transition.

Knowing this will stregnthen interventions during the transition period, with the goal of increasing the number of successfully matriculated students. Rall's (2016) study supported Schlossberg's (1989) indication that interpersonal and institutional support is necessary for a successful adaptation. The addition of the student-centered perspective, as well as interventions targeting the community surrounding the student, can be impactful in the transition into college for low-income, racial and/or ethnic minority high school graduates (Rall, 2016).

Browne, Webb, and Bullock (2018) applied Schlossberg's Four S's (2011) framework to explore perceptions of medical educators' transitions into the profession. More specifically than mere transition theory, the researchers focused on psychosocial transition theory. Psychosocial transition theory was originally explored by Parkes 
(1971), as a tool to evaluate specifics surrounding transitions involving sudden, major, and lasting changes in a person's life. The more sudden, major, and lasting the change, the more support the individual needs to negotiate the change (Browne et al., 2018). The Four S's (2011) model was, however, considered an appropriate framework for analysis to develop support services through transition in this particular education setting (Browne et al., 2018). The authors found that focus group discussions applying the Four S's (2011) framework may lead to better and more focused support and mentoring to cope with change in medical education (Browne et al., 2018).

Additionally, the 4 S's have been successfully applied to understanding the transfer student-athlete process through transition (Flowers, Luzynski, \& ZamaniGallaher, 2014). Lavallee (2005) used the 4 S's to examine the effectiveness of life development intervention on elite athletes' transition out of professional careers and into life and found the intervention to have a significant effect on the Situation, Self, Support, and Coping Strategies of the transitioning athletes. Interestingly in this study, the life development intervention did not add to the support of the athlete, however, by better understanding how to utilize their previously existing support networks through the intervention, the athletes felt more supported (Lavallee, 2005). Lavallee (2006) examined the transition needs of recently retired sport coaches and found support to be the most significant of the 4 S's, signifying the importance of interpersonal relationships when going through a transition in sport.

While limited literature on the phenomena is available, what is understood through literature is that student-athletes experience particularly unique psychological issues throughout their careers (Kissinger \& Watson, 2009). While such psychological 
issues and experiences have been recognized and addressed at many colleges and universities through the employment of counseling and psychology staff members specifically designated to intercollegiate athletics, such processes and systems are in need of further exploration and adjustments to continuously improve in providing better services and best practice objectives for the student-athletes they intend to serve (Kissinger \& Watson, 2009). Student-athletes are aware of the potentially and most likely very unique social, academic, and physical benefits they can, and likely will, incur from their participation in intercollegiate athletics (Singer, 2008). Athletes may both cherish or despise their unique experiences, depending on their own personal understanding of the importance and overall necessity of lifestyle so separated from the general student population.

Athletes, in particular, often possess and exhibit different and unique styles of learning than their non-athlete counterparts. Athletes learn and grow through a persistence in performance under pressure, acquiring and developing skills from worldclass coaching staffs, exhausting themselves both physically and mentally, and collectively working together toward a common goal (Weight, Navarro, Smith-Ryan, \& Huffman, 2017). Athletes' experiences in the intercollegiate athletics setting are unlike the experiences of non-athlete students and are therefore difficult to generalize. In addition, many differences arise depending on the revenue generation of the chosen sport in which athletes participate as well as other demographic factors attributed to their designated university, community, and region of the United States, demographic factors attributed to the student-athlete themselves, as well as the amount and quality of support services and resources available to the student-athlete. 
Barriers to transition exist in sport just as they exist outside of sport. However, the barriers particular to sport are not necessarily applicable or translatable to the world outside of sport. Predictability of transition, in particular, has a direct impact on the experience of the athlete unlike it would on the experience of the non-athlete.

Experiencing the events and factors associated with the transition the less prepared the individual athlete is for a sudden or unexpected transition, the more support is needed for the athlete to adjust and adapt to the changes associated within the transition (Pearson \& Petitpas, 1990).

The positive or negative perceptions of others of a specific athlete's transition strongly impacts the experience of the individual athlete. As sport is often a social experience, others' perceptions of the transition, including fans, peers, or coaches, can also impact the experience and perceptions of the athlete through transition (Pearson \& Petitpas, 1990). When focusing specifically upon the collegiate student-athlete, a perceived lack of tangible support deters the success of the transition process, indicating that a lack of guidance hinders the student-athlete during and after transition (Cummins \& O'Brien, 2015). This can be of particular concern, especially when the unique aspects of the student-athlete's environment are analyzed and taken into account. For example, the experiences of Division I student-athletes at Power Five conference schools differ from small, low-major Division I schools due to inequitable financial resources available at larger, more fiscally endowed colleges and universities, and therefore, cannot likely be generalized or widely applied.

Workman (2015) explained, through analysis of the individual's parental influence on college choice, that Schlossberg's (1981) transition theory is applicable to 
better understand student adjustment to college life, as well as the environmental influences of the learning community into which the individual enters through transition. Like other applications of transition theory to practice, the generalizability of the application of Workman's (2015) study is low. The necessity for a support system within the context of entry into college is evident, however, as indicated by Workman (2015).

The more control an athlete has over the decisions being made surrounding the transition, the more positive the transition experience (Coakley, 2006). The studentathlete experiencing transition, therefore, is in dire need of control and normalcy throughout the experience. Student-athletes need to feel simultaneous strength and acceptance without abundant added stressors. It is also beneficial for the student-athlete to understand former perspectives and biases when entering into a transition, with an understanding of the experience of the entry with its own experiences and surprises (Lewis, 1980). The more adept the team surrounding the student-athlete is to the socialization necessary for a newcomer, the more successful the newcomer's acclimation to the team (Lewis, 1980).

Schlossberg (1981) found sex and sex-role identification to be the most salient factors in adapting to transition, indicating men and women differ greatly while experiencing transition. Men are psychologically more likely to be averse to the feelings of powerlessness that often accompany a transition and, therefore, may have a harder time through involuntary transition (Schlossberg, 1981). The more typical and less stressful the transition process for the individual, and the perceptions of the individual making the transition, the smoother the individual's adaptation to the new situation (Birnie-Lefcovitch, 2000). 
Transition adaptation. The key to successfully experiencing transition is for the individual to adapt to the transition as quickly and smoothly as possible. Better understanding of the factors and qualities of the transition, therefore, assists the individual in adapting to his or her new surroundings. Factors that affect transition adaptation include the characteristics of both the pre-transition and post-transition environments, the characteristics of the individual experiencing the transition, and the perceptions of the particular transition itself (Schlossberg, 1981).

Different factors and identifiers have different effects and influences on the individual experiencing transition, and can often depend on the specifics of factors affecting the transition itself (Schlossberg, 1981). Swain (1991) found Schlossberg's transition model provided a helpful framework for better and more consistently assessing athletes experiencing withdrawal from sport or endings of sport careers, thus better understanding the process and experience of a transition. Adjustment to transition is vital to the human experience and draws upon similarities with adaptation. A smooth adjustment experience allows for a more successful transition (Gordon \& Lavallee, 2012).

Facilitating the adaptation phase of transition is paramount to the success of the individual experiencing the transition. The support and situation surrounding the transition directly affect the transition itself. The model of adaptation to transition as presented by Schlossberg (1981) indicates that attributes such as age, sex, health status, race/ethnicity, competence, socioeconomic status, and previous experience with similar transitions all have a direct and significant impact on how an individual adapts to transition (Gordon \& Lavallee, 2012). Adaptation through transition is also influenced by 
available interpersonal or physical resources which potentially support an individual's ability to cope with and better handle making the adjustments necessary for a successful transition (Gordon \& Lavallee, 2012).

\section{Critical Race Theory}

Race is, and always has been, salient in United States society (Ladson-Billings \& Tate, 1995). Although gender- and class-based analyses are often the topic of inquiry in sociology research, and often share frames in philosophical considerations, the same cannot be asserted in race research (Ladson-Billings \& Tate, 1995). Critical race theory (CRT) moves beyond the boundaries of race and class to focus upon issues and experiences "raced" people (Tate, 1997). CRT challenges the authoritative standard set by White experience in the United States that "normatively measures, directs, controls, and regulates the terms of proper thought, expression, presentation, and behavior" (Calmore, 1992, p. 2161).

While there is no single definition that exists for CRT (Tate, 1997), the methodology draws upon literature from multiple disciplines, epistemologies, and approaches to frame the what, why, and how of human behavior as it pertains to race and racism (Matsuda et al., 1993; Scheurich \& Young, 1997; Solórzano \& Yosso, 2001). CRT focuses primarily upon the socially constructed and embedded qualities of racism in society (Glesne, 2016). CRT challenges and expresses skepticism toward the dominant opinions and efforts of neutrality, claims of objectivity and colorblindness, and promotion of meritocracy in society (Matsuda et al., 1993). The analysis of any human behavior in US society, through CRT methodology, requires recognition of the 
experiential knowledge of people and communities of color (Dixson \& Russeau, 2005; Matsuda et al., 1993).

Critical race methodology provides structure to explore experiences of those who have been marginalized to gain understanding of the complexities of the racialized, gendered, and classed structures of society (Solórzano \& Yosso, 2001). The conceptual framework of CRT, as used by critical race theorists, relies upon the social realities of people of color in society (Tate, 1997). The exchange, or telling, of individual stories is critical to the exposure of the experience of minorities in the United States, as "Distinguishing the consciousness of racial minorities requires acknowledgement of the feelings and intangible modes of perception unique to those who have historically been socially, structurally, and intellectually marginalized in the United States (Barnes, 1990, p. 1864). Tate (1997) stresses that in order to fully understand critical race theory, it is crucial to understand the voice of the individual contributing to the critical race conversation.

Originally developed by legal scholars and rooted in the social change era of the 1960s (Tate, 1997), CRT was proposed by Ladson-Billings and Tate (1995) as applicable to examine race and racism in educational systems as it contains goals both academically and socially inclined (Tate, 1997). The application of CRT in educational research is solidified with the premise that race and racism are native, permanent, and central factors in defining individual experiences of students of color (Solórzano \& Yosso, 2001). Racism, in the majority of circumstances, is often difficult to specifically pinpoint (Bimper et al., 2012). 
In education and social sciences, CRT provides a framework to evaluating the benefits of utilizing the lens of hindsight in its purpose to focus on race and racism. CRT framework provides the lens to challenge the dominant ideologies, to work towards social justice, and to validate experiences of people of color (Solórzano \& Yosso, 2001). Valdes, Culp, and Harris (2002) present three central beliefs of mainstream society that must be continuously challenged, including: 1) colorblindness will eliminate racism, 2) racism is individual, not systemic, and 3) racism can be fought without the context of sexism, homophobia, and other forms of oppression.

Tate (1997), through analysis of CRT literature, delineated five defining elements of CRT. These include: 1) Racism is deeply ingrained in U.S. society from a legal, cultural, and psychological perspective, 2) CRT borrows from liberalism, law and society, feminism, Marxism, and more epistemological traditions to provide a better analysis of "raced" people in society, 3) CRT must reinterpret civil rights law due to limitations undermining laws remedying racial inequality before they are even implemented, 4) CRT explores the legal and societal claims of neutrality, objectivity, colorblindness, and meritocracy, which serve the self-interests of the dominant members of society, and 5) CRT insists upon the challenge of history to examine the history of the law to recognize the experiences of those affected by it most closely and drastically (Tate, 1997).

Harper, Patton, and Wooden (2009) outlined seven elements of CRT centrally relevant to education research. The seven elements include: 1) Racism is a normal part of life in America and difficult to eliminate or address, as microaggressions demonstrate racism in most settings, 2) CRT rejects the presence of "colorblindness", 3) CRT gives a 
voice to the perspectives and lived experiences of people of color, 4) CRT includes interest convergence, or the process of tolerance and encouragement of the racial advancement of Black people to serve the self-interests of White people, 5) CRT includes revisionist history, or the reinterpretation and reexamination of history previously told from a White perspective and interpretation, but now recognizing and more accurately portraying the experiences from a minority perspective, 6) CRT relies upon racial realists, or people who recognize race as a social construct as well as a system of the society that allocates privilege and status, and 7) CRT critiques claims of the meritocracy sustaining White supremacy in society (Harper et al., 2009). Harper et al. (2009) also recognizes CRT as a particularly useful methodology to examine experiences of Black students in higher education as it offers a critique of the regressive policies impacting Black student opportunities and participation.

Critical race theory and its ideologies of race and racism in society have frequently provided adept analysis in sport management research (Baker \& Hawkins, 2016; Cooper \& Hawkins, 2014; Hawkins, 2010; Hylton, 2005; Long et al., 2000). Racism is native to life in the United States (Matsuda et al., 1993), and because of this, race and racism are core factors of sport sociology research (Hylton, 2005). In the context of sport, race and racism are often trivialized and considered inherent and impossible to eliminate (Long, Hylton, Dart, \& Welch, 2000). The critical race theoretical perspective provides a lens to examine post-racial narratives in sport that impact the Black studentathlete experience (Bimper, 2015). Racism in sport is not merely present in isolated incidents, but rather, is perpetually endemic in all parts of society and American culture (Bimper, 2015). 
Comeaux (2010) explored faculty perceptions of academic and postundergraduate accomplishments of both Black and White student-athletes. Comeaux (2010) used CRT to understand the underlying issues from a critical race lens. The results of the study showed that faculty viewed black student-athletes' accomplishments less favorable than white student-athletes' accomplishments. The study is of major concern to the future of the black student-athlete as it has potential to perpetuate long into the future, as the makeup of an athletic department, society, and the systems in place that are extremely lucrative are not likely to change (Comeaux, 2010).

Bimper et al. (2012) used CRT to investigate the self-perceptions and behaviors of Black male student-athletes' academic and athletic role management. Complex identities, communities, and liberation emerged as themes through the interviews and aligned with key tenets of CRT. Complex identities referred to race impacting their identity development as people, students, and athletes.

Communities referred to the desire to engage in interactions with supportive social networks and communities on campus to foster development. Liberation referred to the realization of self-empowerment through education. Bimper (2017) suggests Black student-atheltes are challenged and encouraged by mentors through discussion considering the presence and impact of Whiteness, how race manifests in their experiences, and how social capital must be developed to become better advocates for themselves.

McCoy (2014) used critical race methodology to examine the transitional experiences of first-generation college students of Color into an extreme PWI environment and invited participants to share stories and/or counterstories about their 
transitions. Stories and counterstories, in CRT methodology, broaden the perspective and challenge the master narrative (McCoy, 2014; Solórzano \& Yosso, 2009). The transition into the extreme PWI setting presented the students of Color with both expected and unexpected challenges often leaving the students unprepared and without guidance (McCoy, 2014). The stories supported the need to be received at a racially diverse campus, as the lack of diversity presented experiences of racial isolation, overt racism, and racial microaggressions (McCoy, 2014).

Beamon (2014) encouraged Black former student-athletes to engage in storytelling to express their perceptions of their race and racism on their campuses. Findings indicated Black student-athletes face and cope with racism as obstacles to academic success. Participants in this study also indicated they are often discouraged from telling their stories and experiences with racism, causing them to feel isolated due to their race.

Black male student-athletes in the United States possess cultural connection to sport and the identity that it supplies (Anderson \& McCormack, 2010). However, this cultural connection can often serve as simultaneously detrimental to the development of the Black male athlete as well. The sport culture often encourages and socializes Black athletes into more strongly identifying with sport than other, more pertinent parts of their being (Bimper et al., 2012).

According to Ladson-Billings and Tate (1995), three central propositions of social inequity in the United States exist: 1) Race is a significant factor in determining inequity, 2) Society is based upon property rights, and 3) The intersection of race and property creates an analytical tool to better understand social inequity. According to Johnson- 
Ahorlu (2017), five main tenets shape CRT and provide a roadmap for researchers to engage in robust work recognizing race and racism in education: 1) The intersectionality of race and racism with other forms of oppression, 2) The utilization of other interdisciplinary approaches, 3) The challenge of dominant ideology, 4) The centrality of experiential knowledge, and 5) The commitment to social justice. Therefore, race and racism pervade society, and therefore, the educational system as well, in the United States (Johnson-Ahorlu, 2017). Features of CRT, according to Ladson-Billings and Tate (1995), include: 1) Racism is deeply ingrained in life in the United States, 2) The need for Civil Rights laws to be re-interpreted to address ineffectuality, 3) A challenge to neutrality, color-blindness, and meritocracy, 4) The need for subjectivity and reformation of legal doctrine to reflect those who experience racism firsthand, and 5) The use of first-person stories and accounts.

Using the tenets of CRT, Bimper et al. (2012) examined the experiences of Black student-athletes managing roles of both student and athlete at a Division I FBS university, citing the experiences of the student-athletes had a significant impact upon the development of their identity, Blackness, role within the university community as an athlete, experiences within their beliefs about the educational system, and how to better construct learning environments for Black student-athletes in similar circumstances. As these participants valued their educations as a tool for liberation from the systemic oppression that has held them down in the past, they too recognized the need to adopt a "culturally sensitive environment and holistic education" to better serve the needs of Black students (Bimper et al., 2012, p. 18). Bimper et al. (2012) posited that counselors, coaches, educators, and other support staff should better understand the role race plays in 
the development of the Black male student-athlete identity to better foster supportive and inclusive environments within which they can grow.

Bimper (2015) examined the impact of post-racial narratives, or, according to Donner and Brown (2011), the misguided narratives of race after the first Black President, Barack Obama, was elected in 2008. These post-racial narratives indicating that race is no longer a barrier in America, have a direct impact on Black student-athletes. The research indicated a significant impact of post-racial narratives and discourses on experiences and participation of Black student-athletes in relation to issues of race and racism (Bimper, 2015). Bimper's (2015) research, through a CRT perspective, categorized Black student-athletes' perceptions of race and racism and indicated the colorblind frames of abstract liberalism, naturalization, cultural racism, and minimization of racism are used to rationalize issues of race in sport. Additionally, Bimper's (2015) results advance post-racial discourse through the rationalization of the status of persons of Color in society, linking racial inequity to lowered expectations and foreclosed identities.

Cooper et al. (2014) analyzed the NCAA using CRT methodology to better comprehend the inequitable relationship it has with PWIs over HBCUs. However, through CRT, what cannot be ignored is the presence of racism and dominance of Whiteness in government, which regulates NCAA policy and practice. Throughout history, this has shaped the NCAA through permanence of racism and Whiteness as the norm (Cooper et al., 2014). Macro-, meso-, and micro-level challenges, according to CRT, therefore, face Black athletes (Cooper et al., 2014). 
The goal of CRT is to eliminate racial oppression (Matsuda et al., 1993). The elements of CRT, from a theoretical perspective, can serve as a tool for improving racial subordination (Tate, 1997). If used effectively, CRT can generate a theoretical vocabulary to better understand the formation of raced ideologies (Hylton, 2005). CRT shifts colorblind paradigms into a race-conscious space to provide an environment within which perspectives can be challenged and shifted (Hylton, 2005). CRT will provide this lens for the present study to better understand raced ideologies and perspectives of Black Division I men's basketball transfer student-athletes through their transition from one PWI to another.

\section{Summary of Literature}

Transfer student-athletes find themselves in a predicament of needing to be relatively self-reliant through the transfer transition process despite the fact that the process puts athletes in isolated and disengaged positions without potential of participation in the holistic college experience (Flowers et al., 2014). The necessity transfer student-athletes have for a provided margin of error through the transfer process exists, especially in the case of Black Division I men's basketball players. This is particularly evident when taking into account the stressors related to transition from an academic, social, financial, and athletic perspective. Ultimately, the preceding literature builds a strong case for the necessity of examining the gaps in research, as scholars have not yet focused on the transition experiences of Black Division I men's basketball players through the transfer redshirt experience. Therefore, the purpose of this study is to explore the Black student-athlete's transfer experience and examine the experiences through the 
redshirt year in Division I men's basketball from a qualitative, phenomenological research perspective. 


\section{CHAPTER III}

\section{METHODOLOGY}

The purpose of this study was to explore the transition experience of the Black male student-athlete through the lateral transfer process and current redshirt year-inresidence requirement policy in Division I men's basketball. This specific population was chosen due to the academic, social, and cultural stereotypes presently and specifically challenging Black basketball student-athletes at PWIs. The intention of the present study was to examine how such stereotypes impact the transition experience of Black men's basketball student-athletes through the transfer and redshirt process by applying Schlossberg's (1981) transition theory.

The aforementioned literature, including the history of Black students in higher education (i.e. Allen \& Jewell, 2002; Johnson-Ahorlu, 2017; Rudolph, 1990), the current climate of Black student-athletes' experience at Division I PWIs (i.e. Bimper et al., 2012; Cooper et al., 2014), and the experiences of transfer student-athletes (Cooper \& Hawkins, 2014; Flowers et al., 2014), were used to inform the research questions of the study. The theoretical frameworks of Transition Theory (Schlossberg, 1966; 1981) and Critical Race Theory (Calmore, 1992; Ladson-Billings \& Tate, 1995; Tate, 1997) established the interpretive lens of the research (Creswell, 2013).

To date, few studies have examined the transition experiences of the 4-year to 4year, lateral transfer student-athlete (Cooper \& Hawkins, 2014; Flowers et al., 2014) with 
no known studies explicitly examining the Division I to Division I transfer student-athlete or the men's basketball transfer student-athlete. Given the current climate of the Division I men's basketball transfer processes and the potential for NCAA policy changes, there is a growing need to better understand this specific population of student-athletes, their experiences through the redshirt year and its impact on their lives thereafter. As the phenomenon of the lateral transfer and subsequent redshirt process of the Black Division I men's basketball player has not been examined in literature located prior to this study, using a qualitative method design provided a rich base of information and contributed substantially to sport management research. Such a study lends itself best to qualitative research to examine the phenomena of the student-athlete's interactions, settings, cultures, and experiences in a real-world setting without manipulation (Patton, 2001; Tweksbury, 2009).

\section{Research Questions}

The following research questions addressed the purpose and guided the study:

RQ1. What are the transition experiences of Black Division I men's basketball transfer student-athletes with the redshirt year?

RQ2. What are the perceived benefits or drawbacks of the redshirt year requirement experienced by Black Division I men's basketball players?

\section{Research Design}

Qualitative research is defined by Creswell (2013) as "the study of research problems addressing the meaning individuals or groups ascribe to a social or human problem" (p. 44). Qualitative research seeks to understand phenomena in real-world settings without any manipulation by the researcher to organically examine the meanings 
and characteristics of people's interactions, settings, cultures, and experiences (Patton, 2001; Tweksbury, 2009). This study used a qualitative research methodology to explore the lived experiences of Division I Black men's basketball players who have experienced the transfer and subsequent NCAA redshirt requirement. In order to acquire as much information as possible about the experiences of Black Division I men's basketball players' going through the transfer and redshirt process, a qualitative research paradigm produces descriptive data to develop a deeper understanding of the phenomenon (Bogdan \& Taylor, 1975; Creswell, 2013; Glesne, 2016).

A wide variety of qualitative research methodologies exist in sport management literature (Edwards \& Skinner, 2009). As it is essential to ensure the selected qualitative methodology matches the research questions being asked, popular qualitative research designs were considered in the design of the present study (Wimpenny \& Gass, 2000). Many research designs exist within qualitative research, but five main approaches are most commonly used: narrative, grounded theory, ethnography, case study, and phenomenology (Creswell, 2013). Each of these five main qualitative approaches possess capabilities of application to various research problems, as aspects of qualitative projects vary from study to study (Creswell, 2013).

Phenomenology, or the use of interpretive approaches examines how a phenomenon is experienced through understanding of human behavior from the perspective of the actor (Bogdan \& Taylor, 1975). Phenomenology is the exploration of "lived experiences and the ways we understand those experiences to develop a worldview" (Marshall \& Rossman, 2011, p. 112). Phenomenological research is centered on eliciting the experiences of several individuals through a lived experience to reveal a 
phenomenon (Creswell, 2013; Wimpenny \& Gass, 2000). To explore the lived experience of Black Division I men's basketball players through the transition experiences of transfer and the NCAA redshirt year requirement, phenomenology serves as a relevant and applicable methodology to understand the essence of the phenomenon.

Phenomenological research design. Phenomenology was developed in the early $20^{\text {th }}$ century by Husserl (1931) to supplement the objective approaches to studying the existence of human subjects. Phenomenological research provides a highly analytical stance on embodiment with possibilities of interrogating racialized conceptions of socially located individuals (Hockey \& Collinson, 2007). Additionally, phenomenological research relies upon the notion that there is a shared structure to similar lived experiences that can be narrated by those who have lived through them (Marshall \& Rossman, 2011). Phenomenological research attempts to describe and understand phenomena as experienced by the individuals who have lived through them (Draucker, 1999; Geanellos, 1998).

Phenomenology seeks to describe the "what" and "how" persons have experienced a particular phenomenon connected to a specific population and focuses on deep, lived meanings (Marshall \& Rossman, 2011; Moustakas, 1994). Seidman (1998) developed three in-depth interview styles to capture phenomenological inquiry, including: (a) a focus upon past experience with the phenomenon, (b) a focus upon the present experience of the phenomenon, and (c) a conjuncture of the two narratives into an individual's essential experience with the phenomenon of interest.

Phenomenological research is considered central to the interpretive paradigm (Clark, 1998; Koch, 1995). Interpretation of phenomenological data focuses upon 
reducing individual experiences with the phenomenon to a description of the essence of the phenomenon (Creswell, 2013). Although objective reality cannot be captured through interviews, a better understanding of the phenomenon through its representations can be achieved (Denzin \& Lincoln, 2003). A primary advantage to phenomenological inquiry is that it allows the researcher to explicitly focus upon his or her personal experience combined with the experiences of the interviewees (Marshall \& Rossman, 2011).

Phenomenology is a popular methodological framework utilized in sociology and education studies (Creswell, 2013). Education research, as a whole, has embraced phenomenology as a method of qualitative research based on the realization that it allows the researcher to retain what is most important about a particular phenomenon (Randles, 2012). From a sport management perspective, phenomenological research has provided valuable tools for reflection (Kerry \& Armour, 2000). More specifically, phenomenology has recently been used to study issues of race in the sport context in higher education (Armstrong \& Jennings, 2018).

\section{Data Collection Protocol}

The primary data collection method was audio-recorded, in-depth interviews conducted over the phone lasting approximately twenty minutes. Telephone interviews were conducted as access to the population of participants was very limited (Tausig \& Freeman, 1988), with participants in locations all over the world. Recent comparisons of face-to-face and telephone interviews show no significant differences or advantages to either method (Sturges \& Hanrahan, 2004; Vogl, 2013; Zhang, Kuchinke, Woud, Velten, \& Margraf, 2017), therefore the use of telephone interviews did not jeopardize the quality of the data. 
Phenomenological interviews must remain as non-directive as possible, allowing subjects to describe their lived experience of a phenomenon without directing or suggesting their description in any way (Waters, 2017). Any follow-up questions should ask for further description without suggestion (Waters, 2017). This interview process allowed the researcher to explicitly focus on the deep, lived meaning the event of transfer had on the individual (Marshall \& Rossman, 2011). In addition to the interviews, the researcher also collected demographic data, including the participants' gender, race or ethnicity, institutions attended, status of transfer (i.e. what year the transfer[s] took place), degree progress (Bachelor's or Master's degree status), and current occupational status (Flowers et al., 2014).

Participants. Prospective participants were identified to ensure specific criteria for inclusion for the study are met (Marshall \& Rossman, 2011). Criteria for selection of eligible participants in this study were:

- Self-identified as a man of color

- Played Division I basketball and ended his career during any season between 2013-2014 and 2018-2019

- Transferred laterally during his undergraduate years (4-year to 4-year, Division I to Division I)

- Was required to participate in and completed an academic year-inresidence, or redshirt year, at the receiving institution to which he transferred

Purposive criterion sampling was used in this study (Beamon, 2008). NCAA Division I men's basketball rosters during the 2013-14 to 2018-19 seasons from each of 
the 65 Power Five schools were analyzed to identify initially qualified subjects. Limiting the scope to the 65 Power Five institution rosters provided the researcher with participants who had likely gone through similar experiences due to participating on teams historically exhibiting the highest level of play in the country. The decision allowed for participants who experienced similar pressures and constraints, thus strengthening potential results from the phenomenological examination.

Student-athletes at this stage have exhausted their NCAA-permitted eligibility and have therefore experienced their full athletic careers in the very recent past. Having exhausted all eligibility, this demographic can likely reflect upon their experiences much more readily and completely than other student-athletes who have done so much further in the past or have not completely exhausted all eligibility and therefore, perhaps, possess a different mindset and outlook. The ability of the participants to recall their experiences from the most recent perspective possible was integral to the validity of the results of the study.

A list of all potential participants was generated through searching for recent men's basketball rosters on the 65 respective Power Five Division I intercollegiate athletics websites, one by one, from the 2013-14 season to the 2018-19 season. Potential participants were flagged when their roster biographies listed information regarding a redshirt year. A list of 102 names was generated from the roster analysis and ordered alphabetically by conference, then within each conference. Once this list was generated, the researcher pulled names from the list at random so as to vary conference and institutional affiliation of the participants. Once a name was pulled, it was checked off the list and the researcher attempted to contact the potential participants through two social 
media outlets - the mobile Twitter and Instagram applications - to solicit involvement in the study. Data collection occurred from November 2018 through January 2019. The list of 102 names was exhausted by the end of the study.

Social media sites can be facilitators in finding and soliciting potential respondents who are typically much less accessible off-line (Sikkens, van San, Sieckelinck, Boeije, \& de Winter, 2017). Additionally, recruiting non-volunteer samples in internet-mediated research can be done successfully through channels enabling direct contact, such as social media sites (Hewson, Vogeland, \& Laurent, 2016). However, social media recruitment possesses its own challenges. While social media recruitment is often faster and less expensive, the data quality can be poor (Guillory et al., 2018). While Facebook is often the most successful tool to recruit difficult-to-reach participants (Martinez et al., 2014; Patino, Pitta, \& Quinones, 2012) and Twitter has been utilized successfully as a modern variation of snowball sampling of a specific population as it provides accessibility to participants and opportunity for real-time responses (O'Connor, Jackson, Goldsmith, \& Skirton, 2013), the researcher found the social media application Instagram garnered the most participants.

The researcher initially sought to contact the first three groups of participants through the social media platform Twitter. Through the search tool, the researcher searched the former student-athletes' names and identified available accounts attributed to the likeness of the former student-athletes. If the direct messaging function was enabled, the researcher sent the potential participant a message describing the study and an inquiry about connecting to perform the interview from the researcher's personal Twitter account with information supporting the legitimacy of the researcher. In addition, 
the researcher followed the account. If the potential participant did not have the direct messaging function enabled, the researcher followed the account in hopes of the direct messaging function being available after an acceptance or a reciprocal follow.

Out of the first three groups of ten, equalling thirty potential participant name searches, 20 identifiable Twitter accounts were discovered and attributed to the qualified former student-athlete names. Of the 20 initial student-athlete Twitter accounts discovered and contacted, seven were followed and sent a direct message and 13 were just followed. The researcher received a total of zero responses from the intitial contact and solicitations. After waiting ten to 14 days for responses to the initial follow or message, the researcher re-sent the initial direct message to the seven participants. After the second solicitation, one participant answered the direct message and set up an interview.

The researcher then solicited the next three groups of ten potential participants. Of the next thirty names, 16 identifiable Twitter accounts were discovered and attributed. Six accounts were followed and sent a direct message and ten were just followed. After a few hours, one participant responded to schedule an over-the-phone interview. Thereafter, the researcher waited approximately one week without hearing from the other potential participants. The initial message was re-sent to the five other accounts without garnering a response. Overall, through the solicitations through Twitter, the researcher contacted 36 participants and interviewed two, garnering a 5.6\% success rate. As the pool of potential participants qualifying for the study was $n=102$, if the researcher contacted each potential participant through Twitter and averaged the same response rate, the 
participant pool would result in $n=6$ participants, lower than the $10-15$ participants recommended by Steeves (2000).

Due to the low response rate and difficulty faced in soliciting participants through Twitter during the first six rounds of contacts, the researcher decided to alter the purposive criterion sampling platform and attempt the same tactics through the use of Instagram. Instagram is the fastest-growing social media site around the world (Sheldon \& Bryant, 2015). While Instagram is predominantly used and marketed as a mobile-only application, it is the second-most popular social networking application in the United States behind Facebook (Sheldon \& Bryant, 2015). Approximately 71 percent of people in the US aged 18 to 24 use Instagram, while 45 percent use Twitter (Smith \& Anderson, 2018). The aforementioned statistic likely attributed to the low response rate the researcher received from Twitter messages. Additionally, of Instagram users aged 18 to 24,81 percent use the platform daily and 55 percent use the application multiple times per day (Smith \& Anderson, 2018), indicating a stronger likelihood for more frequent connections to the potential participants.

Similarly to the initial interview solicitations, the researcher used the Instagram search tool to find the potential participants by name to identify available accounts attributed to the likeness of the former student-athletes. Similarly to Twitter, the direct message function was not always available, however, if it were, the researcher sent the potential participant a message describing the study and an inquiry about connecting to conduct the interview from the researcher's personal Instagram account with information supporting the legitimacy of the researcher. Of the first ten names searched, five identifiable Instagram accounts were uncovered, all with the direct messaging function 
available. The researcher sent messages and received an answer from two of the five former student-athletes within a two-day window. Moving forward, the next ten were searched, then the next ten, and the next. Groups of potential participant names were generated from the aforementioned list until the researcher secured and executed interviews fulfilling the appropriate sample size to complete this phenomenological study as indicated by data saturation (Creswell, 2013). Of the 33 identified Instagram accounts representing potential participants that were sent direct messages and followed as well as the three accounts that were just followed, the researcher secured and conducted 13 more interviews, accounting for a 36.11 percent success rate from December 2018 to January 2019.

Sample size. A heterogeneous group of people who have all experienced the phenomenon may vary in size from 3 to 15 individuals (Creswell, 2013; Moustakas, 1994; van Manen, 1990). Steeves (2000) recommends a necessary sample size estimated between 10 to 15 participants, as empirical knowledge drives sample size. Saturation, or the repeat of similar instances so that no additional data are found, alerts the researcher that data collection is complete (Creswell, 2013). As the data from each interview was coded shortly following the completion of the interview, the researcher could identify patterns in codes and themes, thus identifying when the data reached saturation. The researcher collected data until saturation was reached, as participants provided similar information and did not expand upon the identified codes and themes. Therefore, there is no numerically particular sample size for which the researcher aimed, but rather, a sample appropriate to capture the phenomenon in question. 
According to Creswell (1998) a phenomenological study should include a minimum of five and a maximum of 25 participants. Lazarowicz (2015) conducted a phenomenological study to examine the transfer experience of community college students to 4-year institutions via Schlossberg's (1981) Transition Theory with a sample size of $n=12$. In the present study, the researcher executed interviews with $\mathrm{n}=15$ participants. The researcher's role is to develop and maintain active control in the development of the sample through communication (Faugier \& Sargeant, 1997; O’Connor et al., 2013).

Access and entry. Permission to conduct a study involving human subjects was obtained through the University of Louisville Institutional Review Board (IRB) in November 2018. In compliance with IRB protocol, each participant was asked if he wanted access to documentation of the research, but otherwise, as the study presented no more than minimal risk or harm to participants, written consent from participants to participate in the study was not required. The principal risk associated with the study, according to IRB, was any harm associated with a breach in confidentiality. Therefore, the researcher took appropriate measures to protect participant identities by assigning pseudonyms and removed any other identifiers from this data, including institutional and conference affiliations from all universities attended and current locations of participants. Participants were informed of the anonymity of the study prior to the interview and the researcher ensured their identifiers would be removed from the study. The researcher stored electronic transcripts of interviews and all identifiable correspondence on a password-protected computer. 


\section{Data Collection}

According to phenomenological research standards in data collection, in-depth interviews focus attention on gathering data to capture information to understand common experiences of participants (Creswell, 2013). Moustakas (1994) supports asking broad, general questions about the phenomenon. Critical race methodology, through the encouragement of storytelling and counter-storytelling, with an approach anchored within phenomenological research, was used to capture the essence of participants' experiences through the transfer experience (Creswell, 2013; McCoy, 2014). The researcher, through broad interview questions, encouraged the participants to explain the essence of their perceptions and experiences (Glesne, 2016).

Before data collection began, the researcher conducted a pilot study. A pilot study is a methodological test conducted on a small-scale level to inform the main study (Kim, 2010; Prescott \& Soeken, 1989). A beneficial quality of the pilot study is its ability to provide researchers an opportunity to execute the study in order to identify areas for improvement and revision prior to initiating the study (Kim, 2010). Given the fact that the candidate pool of qualified, contactable participants was very small, the researcher identified a subject possessing many similar qualities to the participants per the selection criteria but was disqualified from the study due to the criteria.

The subject for the pilot study was a former men's basketball student-athlete of color who did transfer laterally from one Division I institution to another in the 2013-14 to 2018-19 time frame. However, the subject did not attend a Power Five institution at any point throughout his career and was therefore excluded from the study. Since the available sample population considered for the study was so limited, the researcher did 
not want to utilize a potential participant for the pilot study and not obtain usable data from the interview. The researcher instead obtained an interview with a participant with extremely similar experiences. The participant provided feedback on questions he was asked through the interview protocol. After the pilot interview, the interview protocol was revised and shortened, as questions produced redundant answers or did not accurately solicit the proper and necessary response to answer the research questions. The interview protocol was contracted after the pilot interview, by the researcher, from 20 initial questions to 13 final questions.

Prior to each in-depth interview, demographic data available through the institutional athletic website biographies on each respondent was collected. While identifying information was used to organize and schedule the interview, prior to the interview being conducted, a code name and number were assigned to the participant. Any identifying information on the participant thereafter was kept on a locked, passwordprotected computer in the researcher's office.

The interview guide consisted of a set of 13 pre-determined and pre-tested interview questions with the intent to examine the former student-athletes' experiences with the transfer process and redshirt year requirement. The interview protocol was developed with provided guidance from The Conceptual Model (Taylor \& Ogilvie, 1994) as well as other similar studies (Pendleton, 2007; Powers, 2010; Stoltenburg, Kamphoff, \& Bremer, 2011). Asking fewer, more expansive questions, rather than many small, specific questions, allowed the interview to flow more smoothly and encouraged the participant to take the question in the direction of his choosing (Jacob \& Furgerson, 
2012). Fifteen participants who responded to the soliciatation for interview were interviewed for the study.

Schlossberg et al.'s (1995) 4 S's system for coping with transition served as a useful model for understanding the personal and social dimensions and interpretations of the transfer transition. The 4 S's include four major categories, or variables: (a) the situation, (b) the self, (c) the supports, and (d) the strategies (Schlossberg, 1995). The 4 S's framework strengthens the understanding of processes an individual experiences through transition (Goodman, Schlossberg, \& Anderson, 2006; Schlossberg, 2011; Schlossberg et al., 1989; Schlossberg et al., 1995). In accordance with garnering themes framed from Schlossberg's (2011) 4 S's, prompts included questions framed around the situation, self, supports, and strategies (see Appendix A).

The interview questions were constructed and framed to better examine the influential contexts and impactful situations of the participant experiences with the phenomenon of lateral transfer (Creswell, 2013). Interview questions were constructed and framed to determine the nature of the $4 \mathrm{~S}$ variables within the context of the transition from native to receiving institution (Pappas \& Goodman, 1997). Participants were encouraged to recall and share stories and counter-stories of their lived experiences through the transfer and redshirt processes of their college experiences from a situation, self, supports, and strategies perspective. Additionally, participants were encouraged to recognize and explain perceived results and opinions of their experiences through the transfer redshirt process. This reflection allowed the researcher to examine the impact of the NCAA redshirt year requirement and its subsequent perceived effectiveness as a policy in current NCAA men's basketball. 
Storytelling and counter-storytelling. Critical race methodology focuses on race and racism in all aspects of the research process of research while simultaneously challenging race, gender, and class as intersectionalities to explain the experiences of students of color (Cooper \& Hawkins, 2014; Solórzano \& Yosso, 2001). Critical Race Theory (CRT) frames the what, why, and how of human behavior as it pertains to race, racism, and the socially constructed qualities of racism in society (Glesne, 2016; Matsuda, Lawrence, Delgado, \& Crenshaw, 1993; Scheurich \& Young, 1997; Solórzano \& Yosso, 2001). Storytelling and counter-storytelling are central to critical race methodology and focus on the experiences of people of color living in a predominantly white world (McCoy, 2014; Solórzano \& Yosso, 2001).

Counter-storytelling is the method of telling stories and exposing majoritarian experiences of marginalized individuals with racial privilege, as such experiences are not often shared (Solórzano \& Yosso, 2001). By combining phenomenological interview techniques and encouraging counter-storytelling, the researcher aimed to capture the essence of the experiences of the Division I Black men's basketball transfer redshirt with methods anchored in both Schlossberg et al's (1995) 4 S's and Critical Race Theory (Creswell, 2013; McCoy, 2014; Solórzano \& Yosso, 2001). Anticipation of counterstorytelling and how it was to enter into the study was difficult to measure, however, once data was collected, it provided insight into how counter-storytelling reflected the experiences of the Black Division I men's basketball student-athlete through the redshirt process and status as an NCAA Division I student-athlete in each of Schlossberg et al.'s (1995) 4 S categories. 


\section{Data Organization}

Notes were kept during each interview conducted throughout the study. Notes included dates, times, and any specifics of note during the interview. Although data was collected over the phone and therefore, body language was not obtainable to analyze, the researcher took note of any inflections of voice, frustrations, or other emotions during the interviews. Writing memos during interviews allows the researcher to identify any triggered thoughts, emotions, or opinions on the interview as well as identified themes and concepts (McCormack, 2000; Rubin \& Rubin, 2005).

Interviews with participants were conducted over the phone, or via internet-based telephone applications and programs. Over half the participants in the study were located abroad in various countries around the world and they requested the use of such applications to avoid international calling charges. Interviews were recorded via audio recording software and exported in .mp3 format. Audio-recorded interview files were transcribed via a professional, paid, independent, external transcription service as soon as each interview was completed.

\section{Data Analysis}

Interview transcripts were checked for errors in transcription before analysis by listening back to the audio-recorded interview while reading along to the transcript. The data collected through the interviews resulted in dozens of pages of transcriptions, and therefore, memos taken during the interviews were integral to analyze and interpretation of the data. In addition, the fast turn-around of the transcription service and review of each interview before preparing for the next was integral to understanding concepts, themes, and coherence of the phenomenon (Rubin \& Rubin, 2005). 
Categorization and coding. Qualitative research analysis involves the categorization of data to evaluate its representation of an instance of the phenomenon being evaluated (Spiggle, 1994). Codes, then, are applied to the data categories to organize analysis and interpretation (Blair, 2015). The researcher analyzed and organized the transcribed data through interpretive phenomenological analysis (Creswell, 2013). Emergent strategy is the first principle of analysis of phenomenological data as it allows analysis to follow the nature of the data, as themes through data analysis can emerge and change (Waters, 2017). Significant statements were highlighted and grouped into clusters of meaning, or codes, to identify themes and categories within the phenomenological data (Creswell, 2013). Codes were generated both deductively as they have presented a priori from prior research and inductively as they emerge from the present data (Spiggle, 1994). Additionally, data was organized and presented according to the research questions.

Themes were framed by and compared to Schlossberg's 4 S's framework, and included codes falling in line with the (a) situation, (b) self, (c) support, and (d) strategies (McCoy, 2014; Schlossberg, 2011). Emergent themes were compared from the collected data with themes emergent from the literature and theoretical framework. Additionally, the researcher elicited the processes of phenomenological reduction in efforts to open oneself to the phenomenon as it possesses its own meaning and structure, thus promoting objectivity (Merleau-Ponty, 1964).

Schlossberg's first category of the 4 S's framework, the situation, refers to the circumstances of the individual at the time of the transition (Schlossberg, 2011). Eight factors are considered situational: 1) trigger, or what precipitated the transition, 2) timing, or how the transition impacts the social clock of the individual, 3) control, or what is or is 
not controllable by the individual, 4) role change, or how the role of the individual shifts through transition, 5) duration, or the permenance of the transition, 6) previous experience with a similar transition, 7) concurrent stress accompanying the transition, and 8) assessment of the transition (Evans, Forney, Guido, Patton, \& Renn, 2010; Goodman et al., 2006; Lazarowicz, 2015). Themes garnered from the data analysis were compared and attributed to the eight factors when applicable.

The second category of the 4 S's framework, the self, refers to the psychological and demographic characteristics of the indivual experiencing the transition (Workman, 2015). Demographic characteristics, such as race, gender, and age, as well as psychological characteristics such as self-efficacy, level of optimism, and self-esteem, have a direct impact on the capability of the individual to cope with transition (Schlossberg, 2011). Themes garnered from the data analysis were compared and attributed to demographic and psychological factors of self when applicable.

The third category of the 4 S's framework, the supports, refers to the people, organizations, systems, or institutions to which an individual can or cannot turn through transition (Workman, 2015). According to Evans and colleagues (2010), four specific types of social support affect the transition and include intimate relationships, family, friends, and institutional communities. Strong support systems often result in an indivual smoothly navigating the transition process (Sclossberg, 1981; 2011). Themes referring to support garnered from the data analysis were compared and attributed to the four types of supports when applicable.

The final category of the 4 S's framework, the strategies, refers to the ways the individual experiencing the transition copes with the transition itself. The plan of action 
to cope with events and factors of the transition includes strategy choice, creative capabilities, assertion, and reactions to stress (Sargent \& Schlossberg, 1988). Themes referring to strategies garnered from the data analysis were compared and attributed to the four types of supports when applicable.

Specific factors are often attributed to groups and individuals who approach the transition from differing perspectives, however, using a generalizable model to better understand transition as an overall concept allowed the researcher to discern the transition experiences of Black Division I men's basketball transfer student-athletes. The more disruptive the transition to the life of the individual experiencing the transition, the more resources the individual needs to cope with the transition (Schlossberg, 1984). The focus upon the $4 \mathrm{~S}$ 's framework is to provide a btter understanding of the resources employed by the individual experiencing the transition.

\section{Trustworthiness}

Credibility and Dependability. Several techniques were utilized to ensure the credibility and dependability of the data analysis. Transcripts of recorded interviews were available to participants for member checking (Glesne, 2016). Asking participants to review entire transcripts can make them feel awkward or misrepresented, therefore, the researcher asked participants to review drafts of the data analysis to confirm interpretations (Glesne, 2016). The process of obtaining feedback from research participants can be cumbersome and time-consuming, but reactions are shown to either verify or constructively challenge the data analysis (Glesne, 2016). Additionally, the researcher used peer-debriefing by committee members who also have research focuses in student-athlete issues and experiences (McCoy, 2014). Glesne (2016) suggests the use 
of logical auditors in the validation of chosen interpretations of data, particularly in qualitative research.

Tringulation is the method of obtaining the most pure and true understanding of a situation by combining different methodological resources (Silverman \& Marvasti, 2008). Methodological triangulation strengthens the credibility of data and data collection (Maggs-Rapport, 2000). The phenomenologist, and in this case the researcher, can secure an indepth understanding of the phenomenon through triangulation (Denzin \& Lincoln, 2003). Triangulation of the data was obtained through the interviews, peer debriefing, and member checking of the data. The triangulation using multiple data collection methods, and in this case, the evaluation of the current NCAA policies, structures, and potential changes as well as the qualitative interviews with 15 student-athletes providing lived experiences and analyses, ensures strength in substantiation of data (Huberman \& Miles, 2002).

\section{Researcher Positionality}

In qualitative research, it is often common for the researcher to include a positionality statement to shape any influence of the researcher in executing the research (Atkinson \& Sohn, 2013). Reflexively examining positionality allows the researcher to ground him/herself through evaluation of how he or she may influence the data collected and codes inducted thereafter (Rose, 1997). Issues of positionality often persist through the data collection process, and therefore, being mindful about the influence the researcher's positionality has upon data collection and analysis will provide better richness of data (Bourke, 2014). 
I, as the researcher, understand that along with the participant, my identity has potential to impact the research process (Bourke, 2014). I, the researcher, identify as a White female, I played Division I women's basketball from 2005 to 2010, and transferred laterally between two non-Power Five Division I institutions during my time. My experience through the transfer process, from an academic perspective, did not include many large changes in terms of loss of credits or major change, but rather, I stayed the course with my intended major and the majority of my earned credits at my initial institution transferred to my receiving institution. I finished my undergraduate degree requirements and graduated after my fourth year of college and therefore had the opportunity to begin a Master's degree during my last season of eligibility. I attribute much of my continuing academic pursuits to that opportunity and believe that without it, I likely would not have pursued a Master's degree.

From an athletics perspective, the redshirt year allowed me to grow as an athlete, focusing primarily upon myself and my development as a player both on the court and in the weight room. I transformed my game throughout my redshirt year and believe my production once I regained eligibility benefitted tremendously from such growth. From a social perspective, I used the redshirt year to settle into my new surroundings and foster strong friendships with teammates and non-teammates. Therefore, from what I know to be true from my experiences as a transfer student-athlete, the redshirt year is greatly beneficial to the student-athlete transition. This experience is likely the norm rather than the exception, as many of my transfer student-athlete former teammates as well as many of my transfer student-athlete former players also took advantage of the redshirt year 
from an academic perspective as well as a basketball perspective and have since completed master's degrees.

In addition to my time as a student-athlete, I also have experience as a Division I women's basketball coach and have first-hand knowledge of the recruiting process of both traditional and transfer student-athletes. From the perspective of coach, I witnessed the transfer student-athlete acclimation and growth through the redshirt process. Therefore, from what I know as a former Division I women's basketball coach, the redshirt year is greatly beneficial to the student-athlete transition. In addition, I observed Black student-athletes have a particularly difficult time on the PWI campus. Therefore, from what I know, the transfer process is likely to be more difficult for Black studentathletes.

I identify as a White person, and therefore, it is impossible for me to reject my cultural and racialized positionality through the research process to better the production and outcome throughout the inquiry (Milner, 2007). While it is impossible to remove my lens completely from the phenomena, by being aware of my biases and experiences, I can add perspective to the interview process and dive deeper with participants. Positionality is a space within which objectivism and subjectivism meet, and finding the proper mix of the two is integral to the research process (Bourke, 2014).

Bracketing. Prior to conducting the participant interviews, the researcher has described fully her own experiences in relation to the phenomenon in focus (Marshall \& Rossman, 2011). Thorough preparation of bracketing is necessary before data collection and analysis (Chan, Fung, \& Chien, 2013). Qualitative researchers must engage in reflection upon their own roles in the research to be aware and sensitive to their own 
lived experiences and biographies and how those can shape the research (Marshall \& Rossman, 2011). Husserl (1931) believed it was possible to bracket one's beliefs and assumptions in order to bracket oneself to attain pure, transcendental consciousness. As a former NCAA Division I basketball player who is a White woman who laterally transferred and experienced the redshirt year process, I, as the researcher, have set aside my beliefs and assumptions to discover a truly fresh and unbiased perspective of the phenomenon (Creswell, 2013). This phase of inquiry is also referred to as epoche, or the gaining of clarity from preconceptions of the ongoing processes (Marshall \& Rossman, 2011).

\section{Summary}

The purpose of this study was to explore the transition experience of the Black student-athlete through the lateral transfer process and redshirt year-in-residence requirement in Division I men's basketball. In order to acquire as much information as possible, the qualitative research paradigm produced rich, descriptive data to develop a deeper understanding of the phenomenon (Bogdan \& Taylor, 1975; Creswell, 2013; Glesne, 2016). Purposive sampling was used in this study (Beamon, 2008) and the researcher used social media platforms, Twitter and Instagram, to contact eligible participants. Telephone interviews were conducted either over the phone or through internet-based telephone applications, as access to the population of participants was very limited (Tausig \& Freeman, 1988), as participants currently reside in locations all over the world.

Schlossberg et al.'s (1995) 4 S's system for coping with transition provided a model for understanding the individual dimensions and interpretations of the transfer 
transition. Additionally, the phenomenological interview techniques and encouragement of counter-storytelling aimed to capture the essence of the experiences of the Division I Black men's basketball transfer redshirt transition. The researcher analyzed and organized the transcribed data through interpretive phenomenological analysis (Creswell, 2013). Emergent strategy was used to allow analysis to follow the nature of the data as themes emerge and change (Waters, 2017). Codes were generated both deductively as they have presented a priori and inductively as they emerge from the present data (Spiggle, 1994). Themes were then framed by Schlossberg's (1995) 4 S's framework. Researcher positionality was integral to the study, as the researcher is a former Division I basketball player who had experience transferring laterally during her NCAA intercollegiate athletics career. Reflexively examining positionality grounds the researcher in how he or she may influence the data collected and codes inducted thereafter (Rose, 1997). Therefore, the researcher set aside her beliefs and assumptions to discover an unbiased perspective of the phenomenon through bracketing (Creswell, 2013). Although limitations were present, richness of the data was adequate and the population was fairly homogenous, therefore it is likely this study will have transferability in the future. 


\section{CHAPTER IV}

\section{ANALYSIS}

The purpose of this study was to explore the Black basketball student-athlete transfer experience through the redshirt year-in-residence in Division I men's basketball. Using Schlossberg's (1981) transition theory, the study aimed to provide a better understanding of the advantages and disadvantages experienced during the redshirt year for laterally transferred student-athletes. The transition experience was examined by utilizing Schlossberg's (1995) 4 S's (i.e., situation, self, supports, strategies) framework. In addition, this study also employed Critical Race Theory (CRT) to frame the what, why, and how of human behavior as it pertains to race and racism (Glesne, 2016; Matsuda, Lawrence, Delgado, \& Crenshaw, 1993; Scheurich \& Young, 1997; Solórzano \& Yosso, 2001). By employing counter-storytelling in data collection and analysis, this study caputerd the experiences of the Black Division I men's basketball student-athlete through the redshirt process and status as an NCAA Division I student-athlete in each of Schlossberg et al.’s (1995) 4 S categories.

The key to applying Schlossberg's (1981) transition theory is to place priority upon the individual's perception of the transition rather than the transition itself. Similarly to Flowers et al.'s (2014) study, the participants have already completed their transition through the redshirt year and therefore are providing a complete reflection of their experiences. It should be noted that had the interviews occurred during the 
transition, results may differ. The reflective method was chosen by the researcher, however, to obtain a holistic understanding of the entirety of the situation, as studentathletes presently in the transition phase may have less reflective opinions of the redshirt policy. For instance, Henderson (2013) found the interview of student-athletes during the moments of transition led to a lack of obtaining an accurate reflection on the experience.

The two research questions guiding the study were as follows:

RQ1. What are the transition experiences of Black Division I men's basketball transfer student-athletes with the redshirt year?

RQ2. What are the perceived benefits or drawbacks of the redshirt year requirement experienced by Black Division I men's basketball players?

Fifteen former student-athletes meeting the criteria of the study participated in semi-structured interviews. Interviews lasted, on average, 17 minutes, and ranged between 10 and 27 minutes. Each interview inquired about the participant's (a) situation, (b) self, (c) supports, and (d) strategies through the transfer transition and redshirt yearin-residence, and encouraged counter-storytelling.

\section{Demographics}

Fifteen participants were interviewed for the study. Table 2 provides a demographic summary of the study participants (pseudonyms were used to protect participants) and includes mode of social media through which they were contacted, final year of athletic eligibility, how many calendar years the student-athlete resided at each institution, information on major change, graduation status, graduate degree status (if applicable), and reason for transfer. More detailed participant biographies can be found in Appendix C. 
Table 2

Demographic Summary of Study Participants

\begin{tabular}{|c|c|c|c|c|c|c|c|c|c|c|c|}
\hline \multirow[t]{2}{*}{ \# } & \multirow[t]{2}{*}{ Name } & \multirow[t]{2}{*}{ Social } & \multirow{2}{*}{$\begin{array}{l}\text { Final year of } \\
\text { eligibility }\end{array}$} & \multicolumn{3}{|c|}{ Years at Institutions } & \multirow[t]{2}{*}{ Major change } & \multirow[t]{2}{*}{ Grad? } & \multirow[t]{2}{*}{ Masters? } & \multirow[t]{2}{*}{ Reason } & \multirow[t]{2}{*}{ Doing now } \\
\hline & & & & First & Second & Third & & & & & \\
\hline 1 & Jason & Twitter & $2015-16$ & 1 & 3 & 1 & Yes - - - Business to Political Science & Yes & .5 & Basketball & Working \\
\hline 2 & Trevor & Twitter & 2016-17 & 2 & 2 & 1 & Yes - - -Communications to Sociology & Yes & .5 & Basketball & G League \\
\hline 3 & $\mathrm{AJ}$ & Instagram & $2015-16$ & 2 & 3 & & No & Graduated in 5 & & Basketball & Overseas \\
\hline 4 & Gerald & Instagram & $2016-17$ & 2 & 3 & & $\begin{array}{l}\text { Yes - - - Business Management to Sports } \\
\text { Management }\end{array}$ & Graduated in 5 & & Basketball & Overseas \\
\hline 5 & Aaron & Instagram & 2013-14 & 2 & 2 & 1 & No & Yes & .5 & Basketball & Overseas \\
\hline 6 & Toby* & Instagram & $2017-18$ & 2 & 3 & & $\begin{array}{l}\text { Yes - - - Sport management to leisure } \\
\text { studies }\end{array}$ & Graduated in 5 & & Basketball & G League \\
\hline 7 & Avery & Instagram & $2016-17$ & 2 & 2 & 1 & No & Yes & .5 & Basketball & G League \\
\hline 8 & Marcus & Instagram & $2018-19$ & 1 & 4 & & No & Yes & .5 & Basketball & Overseas \\
\hline 9 & Greg* & Instagram & $2015-16$ & 1 & 3 & 1 & Yes - - -Agriculture to Business & Yes & .5 & Basketball & Overseas \\
\hline 10 & John & Instagram & 2016-17 & 2 & 2 & & No & Yes & & Basketball & G League \\
\hline 11 & Will & Instagram & $2016-17$ & 1 & 3 & 2 & $\begin{array}{l}\text { Yes - - - Sport Management to } \\
\text { Communication }\end{array}$ & Yes & .5 & Basketball & Overseas \\
\hline 12 & Michael & Instagram & 2013-14 & .5 & 3.5 & & No & Graduated in 5 & & Basketball & $\begin{array}{l}\text { Coaching in } \\
\text { NCAA }\end{array}$ \\
\hline 13 & Stephen & Instagram & $2013-14$ & 3 & 2 & & Yes - - Advertising to communication & Graduated in 5 & & Basketball & Overseas \\
\hline 14 & Anthony & Instagram & $2015-16$ & 2 & 3 & & Yes - - - marketing to agricultural business & Yes & .5 & Basketball & Overseas \\
\hline 15 & Miles & Instagram & $2017-18$ & 3 & 2 & & Yes - - - marketing to social work & Graduated in 5 & & Family & Overseas \\
\hline
\end{tabular}

* denotes international student-athlete 
Other demographic characteristics, such as gender and race, were qualifications for the study, therefore each participant in the study identifies as a man of color. Institutions to and from which participants transferred were removed from the data as they are identifiers; however, the institutions at which participants ended their careers represented each of the Power Five conferences across the country. Two of the 15 participants identified as international student-athletes and the other thirteen participants were born and grew up in the United States. Thirteen of the 15 participants are currently playing professional basketball either domestically, in the NBA G League, or internationally, in a variety of professional leagues across the globe. One participant is currently pursuing Law School and one participant is currently a Division I graduate assistant men's basketball coach in the United States.

Although participants were directly prompted to discuss their experiences as Black men's basketball transfer student-athletes on predominantly White campuses, covert, subtle descriptions of their experiences were also uncovered through the interviews in a variety of ways through descriptions of Schlossberg's 4 S's framework. It is important to note participants directly denied any particular experiences they had attributed to their race when prompted to specifically explain if they had any recollections, however, all participants described issues they faced through the redshirt year with covert issues of racism. Such covert, societally-ingrained experiences with race and racism fall more in line with Critical Race Theory (Glesne, 2016; Matsuda, Lawrence, Delgado, \& Crenshaw, 1993; Scheurich \& Young, 1997; Solórzano \& Yosso, 2001). 
Through the interview protocol, participants were overtly prompted to describe their experiences as Black men's basketball transfer student-athletes on predominantly White campuses. Overt mentions and expressions of race-related or racially-charged experiences occurred only when prompted by the researcher. However, more covert, microaggressive racial experiences were evident throughout the interview process through other questions and prompts inquiring about the student-athlete experience through the transfer transition. This emergent strategy allowed the interview to follow the nature of the data (Waters, 2017) so as to not direct or guide the participant in any specific direction.

\section{RQ \#1: The Transition Experiences of Black Division I Men's Basketball Transfer \\ Student-Athletes}

The fifteen interviewed former student-athletes had fifteen separate, yet relatable, experiences through the transition process through the transfer redshirt year. Each individual transfer student-athlete transition contained a specific set of situations, strategies and coping mechanisms to cope through the transition. However, it is important, in the context of this study, to link similarities of concepts and themes to discover patterns and connections for a better understanding of the phenomenon (Rubin \& Rubin, 2005). The following section is an integrated analysis of the codes and themes that emerged from the interviews in accordance with Schlossberg's (1981) 4 S's system of coping with transition: 1) the situation, 2) the self, 3) the supports, and 4) the strategies. Table 3 provides a summary of the thematic findings in relation to the 4 S's as well as attributed factors in relation to the deducted codes from Schlossberg's 4 S's 
framework. Accuracy and consistency in interpreting the data was paramount to the researcher's analysis.

Table 3

Thematic Findings in Relation to Schlossberg's (1995) 4 S's themes

\begin{tabular}{|c|c|c|c|}
\hline Situation & Self & Supports & Strategies \\
\hline $\begin{array}{ll}\text { - } & \begin{array}{l}\text { Transfer reason } \\
\text { (trigger) }\end{array} \\
\text { - } & \text { Academic } \\
\text { issues } \\
\text { (concurrent } \\
\text { stress } \\
\text { accompanying } \\
\text { the transition) }\end{array}$ & $\begin{array}{ll}\text { - } & \text { Following } \\
\text { dreams (self- } \\
\text { efficacy) } \\
\text { - } \\
\text { Isolation } \\
\text { (demographics, } \\
\text { self-esteem, } \\
\text { self-efficacy) }\end{array}$ & $\begin{array}{ll}\text { - } & \text { Family (family) } \\
\text { - } & \text { Coaches and } \\
\text { athletics support } & \text { staff } \\
\text { (institutional } \\
\text { community) } \\
\text { - Teammates and } \\
\text { other student- } \\
\text { athletes } \\
\text { (friends) }\end{array}$ & 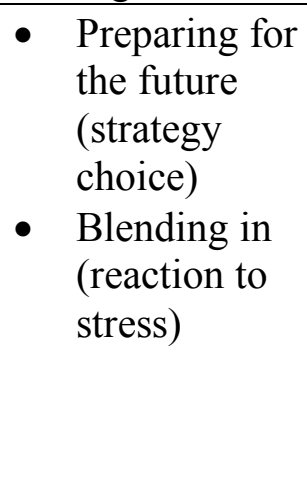 \\
\hline
\end{tabular}

Situation. The situation refers to the circumstances surrounding the individual during the transition (Schlossberg, 2011). The situations faced through the transfer transition and reflected upon by the participants in the study varied, yet presented some similarities. The situations surrounding the student-athletes provide specifics as to their own processes through the transition phase of their transfer and subsequent redshirt year.

The decision by the student-athletes to leave their initial institution without a guaranteed landing space at another institution was described by participants as scary, inciting nerves and worries. Before student-athletes asks for a release from their commitment to their initial institution with intent to transfer, they are, by NCAA rules, restricted from contacting other institutions or coaching staff members to inquire about their interest (NCAA, n.d.c.). Therefore, when student-athletes asks for and are granted their release from their initial institution, they do so without security of obtaining another full, Division I scholarship at another institution. However, each of the fifteen 
participants did, in fact, find a receiving institution where they were granted another full scholarship.

Transfer reason. The theme of transfer reason aligns with Evans and colleagues' (2010) factor of 'trigger', or the precipitation of the transition. In line with previous research by Flowers et al. (2014), the vast majority of participants described a facet of their collegiate athletics careers as the primary driver of their transfer decision. All but one $(n=14)$ of the participants in this study described basketball-related reasons as the catalyst, including issues with a coach, issues with level of play, and concerns for a future professional playing career, with the outlier attributing his transfer decision to family issues. According to Alexander (2011), attributions to basketball as the catalyst to the decision to transfer also align with the most cited reasons for Division I men's basketball transfer. These reasons are to (a) move closer to home, (b) pursue potential to earn more playing time, (c) play at a higher level, (d) pursue potential to earn a role with increased scoring options, and (e) pursue a team with more potential for success.

Jason, for instance, who left his initial institution after just one academic year to transfer to another program, explained his reason for transfer:

My transfer was more about the relationship I had with the coach that was there and how he was handling certain situations as far as playing time. It was just extremely unpredictable. For me as a freshman, I wasn't expecting to go in and get all the playing time, but once he gave me the opportunity, I was playing extremely well. Then, when we started playing conference games, I only averaged, maybe, two minutes per game...I didn't want to sit and stay here and be confused as to why I'm not playing. 
The situation Jason experienced aligns with Barnhill and Turner's (2013) study findings. Student-athletes who perceive their coach has failed to fulfill a promise or obligation reported an altered relationship with their coach and are therefore more likely to depart the institution. Jason opted against spending the entirety of his career at his initial institution with a coaching staff he did not trust, and instead, pursued a situation with a new coaching staff in hopes of finding a more suitable situation.

It is important to note that of the 15 participants, two identified as international student-athletes who came to the United States to play college basketball. Popp (2007) found international student-athletes exhibited lower social adjustment and institutional attachment than domestic student-athletes, as evidenced by Greg, who transferred twice during his career. Additionally, Popp, Pierce, and Hums (2011) found international NCAA Division I student-athletes valued the amount of their scholarships and head coach personality as most valuable when choosing a college or university, differing from domestic student-athletes' valuing degree strength and school reputation. Meadows, Pierce, and Popp (2011) found international student-athletes to struggle with homesickness, adjustments to the U.S. culture, and language barriers. Additionally, international student-athletes cannot all be combined into one group, but rather, each individual international student-athlete must be understood and assisted on a unique basis (Newell, 2015).

Toby, one of the international former student-athletes included in this study, indicated the degree strength and academic prowess of the university had absolutely nothing to do with his decision. Rather, he chose his second school based on his potential basketball career going forward. Greg indicated an interesting situation with the coaching 
staff influencing his reason for transfer, saying the situation at his initial institution "was not good. I did not really get along with the coaching staff. That was the major reason why I transferred...the coach there wasn't the one who recruited me.” Although Toby and Greg are international student-athletes, their reasons for transfer were similar to the participants born domestically.

Student-athletes disappointed with playing time or level of play are acutely aware of their four years of athletics eligibility. Instead of remaining at their initial institution, they decided to seek transfer to what they perceived to be better situations for them athletically. AJ left his initial institution after playing for two seasons. He explained how he felt mislead as a prospective student-athlete, saying, "During the recruiting process, coaches sell you on things, but once you get to campus, it's not that. I felt I wasn't put into a successful basketball situation." This aligns with previous research finding studentathletes are often met with realities differing from their expectations that were often built up by coaches unrealistically selling their programs (Rossouw, 2010).

One of the fifteen participants, Miles, described his decision to transfer based on family reasons, saying, "There were a lot of things I had to be home with my family for. My coach was actually really understanding and was really helpful when I was transferring. He kind of knew it was coming." When prompted to explain specifically whether his decision to transfer had anything to do with the basketball component, he denied any involvement or swaying whatsoever, but did describe his relationship with the head coach of his initial institution as amicable and helpful in his pursuit of a receiving institution on the transfer market. While Division I men's basketball players do attribute transfer decisions to moving closer to home (Alexander, 2011), the decision is also likely 
driven by the decision to play basketball while being located closer to home (Associated Press, 2017). Therefore, playing with a team closer to home provides advantages to the student athlete in both areas.

In addition to the aforementioned reasons student athletes transferred, geographical location of the participants' initial institutions also affected their experiences. Student athletes described experiences with race and racism before deciding to transfer to another institution. For instance, Aaron discussed how his experiences with race were dictated by geographical location within the country and cultural beliefs and perceptions of race rather than the actual institution he attended. Aaron indicated that the initial institution he attended before transferring was in the southern region of the United States. The state in which his initial institution was located was, "as a whole is very, I'm going to say, racist" (Aaron). He said he remembered seeing Confederate flags in or on cars driving around the city. However, Aaron also indicated he did not let any of the experiences he had off campus, around the city, or in this state affect him or his experiences on campus as a student-athlete in any way. Aaron transferred to a school located in a more liberal area of the country on the west coast which could be attributed to his main experiences with race and his basketball career occurring at his initial institution. He did not indicate the transfer was due to any issues or experiences he had with his race, but rather, indicated the decision to transfer was based solely on basketball.

Though not necessarily related to geography, Trevor expressed his first-hand experience with his decision to attend, and play basketball at, a predominantly White institution: 
The best basketball schools are predominantly White schools. You know, us Black athletes, there are a lot of historically Black colleges that are also options, but just all of the, you know, Black basketball players, they have these dreams of playing at the biggest schools which are full of White people.

Trevor was correct in saying the biggest basketball schools in the United States are full of White people -- all 65 NCAA Power Five institutions have predominantly White student bodies. Moreover, prior research suggests that PWIs are often considered unfit to meet the needs of Black male students (Cooper \& Hawkins, 2014). While historically black colleges and universities might provide better educational and social environments for Black students, HBCUs lack resources and exposure for players seeking professional careers (Allen at al., 1991; Brown, 2011; Brown et al., 2001; Cooper et al., 2014; Davis, 2008).

Academic Issues. The theme of academic issues aligns with Evans and colleagues' (2010) factor of concurrent stress accompanying the transition, as such academic issues incited stress among the participants. Inquiry into the academic situation facing the student-athletes before, during, and after the transfer transition produced many alarming and concerning responses from the participants. As mentioned in the demographic data, nine of the 15 participants maintained a traditional, four-year academic course toward graduation through the transfer transition and graduated in four years, beginning graduate work during their final season of eligibility. One of the 15 participants reported he did not utilize his fifth year of eligibility after transfer and instead opted to pursue a professional basketball career after graduating in four years. Additionally, nine participants were forced to change their undergraduate majors at their 
receiving institutions due to one of two reasons: a) the receiving institution did not offer the major the student-athlete was previously pursuing at his initial institution, or b) the student-athlete did not have enough transferrable credits to continue to pursue the same major at the receiving instition and was therefore not admitted. Five of the nine participants who were forced to change their majors still graduated in four years. Of these five participants, three elected to transfer after just one year at their initial institutions and two transferred after spending two years at their initial institutions.

The fifth year of athletic eligibility provides an opportunity for student-athletes to remain oncampus at their receiving institution to exhaust eligibility while beginning coursework in a master's program. Therefore, there is an advantage to maintaining an academic course toward a four-year undergraduate graduation and subsequently earning a traditional, four-year undergraduate degree, as indicated by the nine student-athletes who had the ability to do so. After the undergraduate degree is earned, student-athletes can elect to cease their collegiate basketball career and pursue other opportunities. John, for instance, was the only participant in this study to transfer, graduate in four years, and elect to leave without finishing his eligibility. He is now playing professional basketball in the NBA G League. Additionally, per NCAA guidelines (NCAA, 2016), studentathletes who have earned an undergraduate degree have the ability to transfer, without penalty or in the case of transfer student-athletes, another redshirt season, to another Division I institution with immediate eligibility. This process is discussed in the next section.

According to the NCAA policy, if a student-athlete graduates with any eligibility remaining, he or she can transfer to another institution to pursue a graduate degree of 
interest that may not be available or offered at their undergraduate institution (NCAA, 2016). Student-athlete advocates refer to the graduate transfer rule as one of the only proplayer NCAA regulations in existence, as the student-athlete with an earned degree and remaining eligibility has earned options for their graduate-level academic endeavors (Story, 2018). Division I men's basketball has seen a significant uptick in the number of graduate transfers, growing from just 15 in 2011 to 87 in 2016 (Story, 2018). According to Flowers et al. (2014), student-athletes going through the transfer transition were often motivated in the classroom to either catch up academically or gain ground to get ahead in their studies.

Six participants took advantage of the NCAA Graduate Transfer policy, allowing student-athletes with eligibility remaining to transfer without penalty if they earn their undergraduate degree. One of the graduate transfer participants, Avery, did not have to change majors upon his initial transfer and graduated with his Bachelor's degree in four years from his receiving institution. Since he redshirted at the receiving institution, he was then able to transfer again, laterally, to another Division I institution. Since Avery earned his undergraduate degree prior to his second transfer, he was immediately eligible to participate in games while he began work on his graduate degree. In his one year of graduate work, he completed approximately 50 percent of required courses toward degree. After his professional playing career, he plans to finish the degree, as he was informed through his receiving institution it would be paid for by the institution upon his return.

Will transferred from his initial institution after one year of playing, then spent three years at his receiving institution before taking advantage of the graduate transfer 
rule to finish his career at another institution. Aaron spent two years at his initial institution before transferring to finish his undergraduate degree, followed by a graduate transfer, saying he "saw the benefit of just being able to sit out that year." Similarly, Greg spent one year at his first institution before transferring, finishing his undergraduate degree then leaving for a third institution; however, he faced a particularly difficult situation while doing so:

I had to change my major, and I lost a lot. I felt like I had to start over again...I really had to study hard, you know, I lost so many credits. I was trying to get everything back and graduate on time, and I did. I got it done.

When participants moved from Division I institution to Division I institution, issues arose with transferrable credits and course transfers. As indicated by Greg, credit transfer contributed heavily to the academic situations the participants were placed in after transferring to their receiving institutions. Credit loss, by numbers, fluctuated with each interview and was primarily reliant upon two things: (a) degree progress of the participant at his initial institution and (b) the academic situation faced at the receiving institution. Stephen had to switch majors and lost many credits when he transferred after spending three years at his initial institution, saying:

I was actually an advertising major at [the initial institution] and [the receiving institution] didn't have, or didn't offer that as a major. The closest thing to advertising was a communications degree, so I did that. Some of my credits didn't transfer over so I had to make those up, and with that redshirt year I think I made it up during that year and in the summer...I just kind of spread it out, just spread it out to get it done over the five years. 
Although Miles had a smooth decision-making process before his transfer, the academic situation he faced at his receiving institution was dire after spending three years at his first school before departing. When asked how many credits he lost through his transfer to a more highly touted academic institution than he previously attended, he said, Probably 60 percent of my credits didn't transfer. Going into a higher acknowledged school, there was a big difference, so there were some classes they didn't take because it was, I guess, a different level of what they needed...I had to take some classes for a second time, a few classes I had to re-do.

Additionally, Miles was required to change his major after completing three years of degree progress at his initial institution as his receiving institution did not carry the major.

Six of the 15 participants took all five of the NCAA-allotted five year clock to complete their undergraduate degrees. Four out of the six participants who took the full five allotted years to earn their undergraduate degrees were required or chose to switch their majors upon transfer. For them, the redshirt year allowed them academic flexibility to switch majors without losing the opportunity to ultimately earn their undergraduate degree.

Few participants indicated that while they lost credits, it did not impact their degree progress. Trevor was required to change his major from communications to sociology, however, in doing so, he did not lose an abundance of credits, graduated in four years, and began his master's degree during his fifth year of eligibility. Trevor explained his transfer situation, saying, "As far as my classification and all that stuff, I was still good to graduate in four years...For me, it was great. I was able to get two 
degrees for free." Trevor did, however, choose to switch his majors in order to salvage as many earned credit hours as possible, saying:

I knew I wanted to graduate in four years, so I went in and I was trying to figure out what field of study most of my credits would transfer to. It ended up being what it was because I could have gone to that school and have done anything, but I would have had to dip into that fifth year in order to complete it...I was kind of looking forward, saying that I'd rather get whatever degree I can in this amount of time so that I can go ahead and get that second one.

In terms of NCAA policies and procedures, loss of credits can lead to ineligibility, as student-athletes are required to have earned increased percentages towards degree progress throughout their careers (NCAA, n.d.c.). If student-athletes, and specifically transfer student-athletes, do not meet minimums, they can be faced with losing eligibility they cannot recover.

In addition to loss of credits, academic clustering was another theme that was presented throughout the interviews. Academic clustering is present when $25 \%$ or more of a team is enrolled into a single select major (Fountain \& Finley, 2011). Minority student-athletes are more often clustered into specific majors regardless of future goals to maintain eligibility (Beamon, 2008; Fountain \& Finley, 2009). Academic advisors or coaches sheparding student-athletes representing specific demographic groups to enroll in specific majors or degree progress tracks can be detrimental to the lives of studentathletes of color in the long-term (Comeaux, 2010).

Will, for instance, not only changed majors after his transfer, but was then clustered into a major at his receiving institution due to it housing the majority of his 
men's basketball teammates, saying, "Most of the basketball players at [my new school] had communications as a major...Since [school] didn't have my [previous] major, [sport management], it was similar enough in the aspect where I could get the skills if I ever wanted to do anything with basketball." While it did not happen to him directly, Jason stated, "A lot of the time, the academic advisors just kind of throw some of the players into whatever major, and some of these majors aren't even really helpful once you get out." Transfer student-athletes have potential to be academically clustered not just one time, but twice; both at their initial institution and again at their receiving institution. The systematic encouragement of student-athletes representing specific demographic groups, and in this case, Black men's basketball student-athletes, to enroll in specific majors not once, but twice, can be doubly detrimental not just to the academic progress of the student-athlete, but to their future professional careers outside of basketball (Comeaux, 2010).

In summary, the situational circumstances of the transition of the participants presented similarities in the study. Participants expressed basketball-related reasons for transfer, in line with previous literature (Flowers et al., 2014), leading student-athletes to land in both good and bad situations with their receiving institutions. The academic situation of the participants through the transfer transition provided both advantages and disadvantages, however, the fifth year of eligibility afforded to student-athletes through transfer provided 14 of 15 participants with either the flexibility to finish their undergraduate degree or the advantage of beginning graduate coursework. Still, Black student-athletes at PWIs cite academic under-preparedness and race-based stereotypes as the main reasons for academic challenges and lack of interest in social engagement on 
campus (Sato et al., 2017). For example, Gerald explained when he worked in group projects, "I treated everybody with respect...they probably looked at it, and probably looked at me like, oh he plays basketball." Aaron explained the lack of interest in social engagement of himself and fellow athletes on campus, saying:

The basketball schedules and stuff are so tight that you're around those guys 80 percent of the time while you're in school. I mean, you can find time, but I mean, for, I know the men's basketball teams, you're generally, and especially at the bigger schools, you're generally kind of stuck with those guys...it's very hard to find different social groups.

Further, when Black men's basketball transfer student-athletes experience race-based stereotypes and suffer from under-preparednes, they are more at risk for academic failure. Specifically, Black men's basketball players may encounter issues with credit transfer, degree progress, and acclimation to a receiving institution after transfer.

Self. According to Schlossberg (2011), the self refers to the psychological characteristics of the individual experiencing the transition and incorporates strengths, weaknesses, experiences, options, and coping capabilities (Sargent \& Schlossberg, 1988). Participants were asked to reflect upon the evolution and characteristics of their own thoughts, feelings, and mindsets throughout the transfer transition and redshirt year. Better understanding the self and what was important or apparent to the student-athlete through transfer was integral to understanding the ability of the student-athlete to cope through the transition. Participants reported varying reflections of self throughout the interviews and gave insight into the positives and negatives of the transfer transition and redshirt year. 
Following dreams. The theme of following dreams as reflected in the data analysis aligns with the factor of self-efficacy, a psychological characteristic of the self through transition according to Workman (2015). Participants pursued the transfer transition in order to follow dreams and aspirations they set for themselves either before or during their playing career at their initial institution. Transfer transitions allowed student-athletes to pursue better situations for them from the perspective of their basketball careers, including increased opportunities to play professionally in the future. For instance, Jason pursued the transfer to compete against the best opponents in the country in order to improve his game, saying:

It was obviously playing at the higher level, it was always extremely, extremely competitive...you're playing against some of the best talent and individual basketball. I'm playing in an arena that I've always dreamed of. Of course, for me, I've always dreamed of playing at a high major school. Once I was able to kind of show what I can do on that level is kind of more when I started to get more notoriety...At the end of the day, the experience was amazing because the reputation is a big thing.

Aaron pursued similar dreams and goals through his transfer transition to his receiving institution. He indicated his decision to pursue the remainder of his basketball eligibility at a bigger, more nationally prominent school in a larger, more successful conference allowed him to play against historic programs as well as increase his stock for a professional career in basketball after graduation. Michael, for instance, understood in order to follow his dreams, he had to maintain his focus on basketball through his transfer 
transition and redshirt year, indicating throughout the process he was "focused on getting back onto the court."

The mindset and focus upon basketball-related goals by the student-athlete played a significant role in their decision to transfer. Basketball was in the decision-making driver seat and often took precedence over any academically-conscious decisions, as many participants put themselves in academic jeopardy with the decision to transfer. However, as stated, 13 of the 15 participants are currently playing professional basketball, at various levels, and are likely to make lucrative livings doing so. Therefore, the focus placed upon basketball and not on academics throughout the transfer process did not hinder their pursuit of a professional sport career that will provide them with a career, at least for the short-term. From a CRT perspective, Black male athletes are more likely to pursue professional sport careers than their White counterparts because they believe they will be treated fairly in the professional sport industry (Donnor, 2005). Subsequently, Black student-athletes invest into and interpret their interscholastic sport careers as a pathway to achieving their career goals (Donnor, 2005).

Isolation. The theme of isolation was attributed to both demographic and psychological characteristics of the self through transition, including demographics, selfesteem, and self-efficacy (Workman, 2015). Demographic characteristics of the self, including race and socioeconomic status, led participants to feel isolated, as well as low self-esteem and self-efficacy through the transition and redshirt year. Participants reported facing feelings of isolation and loneliness during the redshirt year. Participants were confronted with new social groups, social dynamics, and unfamiliar social structures on their receiving campuses. The feelings of isolation and loneliness especially 
hit hard for participants when their teams, who provide built-in social support and structure, left campus to travel for away games during the participants' redshirt seasons. As previously stated, according to the NCAA policy, transfer redshirt student-athletes are not eligible to travel with the team for away contests (NCAA, n.d.c.). AJ, for instance, described his feelings of isolation and his inability to cope at times during his redshirt season due to his team being on the road for away games, leaving him on campus alone. He said:

Actually, it was very tough on me. It wasn't bad at first because the season didn't start until November. Then travelling kicked in and [my teammates] weren't around. So like, December it really hit me because I wasn't travelling. I really was just ready to give up because that was the first time besides injury keeping me out of sports activities. It wasn't like I was ineligible for academics, it was selfimposed. It was frustrating. I really didn't have any friends or family who had gone through it, so it was all me just learning on my own on the fly. Luckily, Christmas break came and my coach gave me the entire break as if I were a regular student. It allowed me to go home, be around friends and family, and just come back with a better attitude and state of mind to push through the second semester.

AJ had a uniquely beneficial experience after his coach allowed him to depart campus during Winter Break to recollect his thoughts and re-center himself to finish the year successfully. Many coaches would likely not do so, as redshirt transfer student-athletes are often looked upon to play in practice and challenge the currently eligible players on the team. The time AJ was afforded to take care of himself at home was likely the reason 
he sustained his commitment to his receiving institution and finished his career successfully.

Greg expressed feelings of loneliness during his redshirt year, specifically describing feelings of isolation while his team was on the road as well. He said, "Most of the time I was in my room just chilling." Greg said he did not necessarily put himself in positions to interact with others, but instead, took care of himself during his redshirt year. John also had similar issues, explaining he felt most alone and isolated on campus when his team had road games. He said, "For me, I was by myself. I was alone when they left...I didn't have a car to go to the gym, it was definitely difficult." It is important to note that at the time of his redshirt year, the 2014-15 season, the NCAA policy stated John was not able to obtain employment during the season, even as a redshirt studentathlete (NCAA, 2016). Thus, he could not purchase his own transportation. John would have been able to obtain employment during the off-season, but would have only been able to earn up to the institution-calculated "incidental expenses" amount, typically falling in the $\$ 1,200-\$ 2,500$ range (NCAA, 2016). NCAA policy changed in August 2017, stating student-athletes are able to obtain part-time employment during the academic year, so long as earnings do not eclipse the same "incidental expenses" amount (NCAA, 2019).

Stephen, who transferred after three seasons at his initial institution, expressed a large change in his interaction with teammates into a much more isolated state at his receiving institution, saying, "I mean, for three years, I was used to doing everything with the team, so it was a little tough, I'll admit...I did everything at practice when the team was at home, but when they were on the road for long periods of time, it was a bit weird 
of a transition that first year." Additionally, Stephen had to cope with his transition away from his initital institution being in close proximity to his hometown and family to a new institution taking him out of his home state for the first time. He indicated his isolation and feelings of loneliness may have also been due to being far away from family and friends.

The transfer process was often approached and executed by the participants with little to no direction or knowledge of the processes, rules, and policies involved in transfer and transition from one Division I institution to the next. This placed studentathletes in a position of isolation through the process. A lack of direction is expected, as when the transfer student-athlete requests the release from his commitment to his initial institution, that institution is no longer required to provide any assistance whatsoever through the re-recruitment process, either logistically, academically, or otherwise. It is up to the transfer student-athlete to navigate the transfer process. Additionally, the studentathlete is forbidden by NCAA policy from contacting other institutions prior to receiving his release while still contractually bound to his initial institution to gauge interest (NCAA, 2016). This rule is in place to prevent institutions from poaching players from other institutions and enticing them to transfer.

Gerald described how his decision-making process to transfer led him to feel confused and isolated throughout the transition process. During his interview, he indicated his under-preparedness and lack of direction:

During that time my Sophomore year, going into my Junior year, I wasn't really at peace with myself because I was kind of in a young state of mind. I was 
listening to and had a lot of people on the outside feeding me things, you know, telling me what I should do, what I shouldn't do.

Gerald knew it was best for him to depart from his initial institution; however, once he was released, he no longer had the direction and support from his former coaches and university. He then indicated he leaned on others in his narrow network of support which did not help his situation when transferring.

Michael described a unique case of isolation through the transfer process. Michael departed his initial institution after just one semester and described the experience at his initial institution as being very volatile after a coaching staff change occurred prior to him arriving on campus as a freshman:

I had to come to the realization that it just wasn't the place for me...It just wasn't a good fit for me, I didn't feel like they cared about me as a person outside of basketball. It was just a whole bunch of me being mislead.

The coaches who recruited Michael from high school were no longer employed at his initial institution, and Michael knew it was time to look elsewhere to continue his career. Michael went on to describe how once he realized he was not loved and cared for at his initial institution by the new coaching staff and decided to transfer at the end of his first semester, he stopped going to class, putting his situation in deeper jeopardy and need of direction and guidance. He was alerted by academic support at his initial institution that in order to be eligible to successfully transfer to another Division I institution, he had to earn passing grades in his classes. Michael said he then accomplished the bare minimum to be able to depart with his eligibility intact to attend another Division I institution. 
Michael's situation through transfer was worsened due to both his lack of feeling cared for and subsequent lack of care.

The isolation of Black transfer student-athletes is particularly concerning due to issues of and experiences with racism in relation to the geographical location of the institution reported through the interviews. John described a geographical location-based set of experiences with race and racism at his receiving institution. He described his encounters with racism and indicated that due to the transparent nature of how members of the community presented their racially-fueled ideals and actions, he knew who to avoid and how to avoid any issues around campus:

If they're racist, they'll let you know...I knew that if they were rude to me, they were just being real...I don't mess with disrespect...but the fact that they are just upfront about it instead of acting like they're not...they'll let you know...they were taught to be like that...you can feel the tension.

The outward, transparent displays of racism by the community members surrounding John's campus puts Black student-athletes in danger if they are not aware of their surroundings or are not safely guided around the community by teammates or staff at their receiving institution.

When John entered his transfer situation, he was focused on finding a BCS, or Power Five, institution to play out remainder of his career. He indicated that once he became eligible on the transfer market, he was recruited by many schools, but received interest from only a small pool of Power Five institutions. His options to continue his career at a Power Five institution were limited and he decided to attend his receiving institution without obtaining useful information, like issues with race on and around the 
PWI campus. Had he received more direction and guidance through the transfer process, he may have had the ability to take advantage of other opportunities to avoid the environment of racism he ultimately entered with his transfer.

In contrast to the reported negative feelings of isolation and loneliness, some participants reported a sense of agency (Flowers et al., 2014) as well as relaxed comfort and confidence during the redshirt year on the campus of their receiving instition. Miles described his redshirt experience after his transfer as being very positive and enriching, saying:

I actually loved it. I was able to be a somewhat normal student for a couple of months. It was fantastic...I didn't have to travel so I was able to focus on school for the first time in years. So it was like, in my view, I actually really, really enjoyed it and thought I really needed it.

Trevor discussed his experiences as a Black student-athlete on a predominantly White campus, explaining the necessity to have a strong awareness of his surroundings: Obviously you go in and you're conscious of what's going on around you, but I mean, more times than that, there's more good people than bad people. Especially as an athlete, you get more favor if it came down to it, racially, like a color situation, more than likely you'll get a little bit of a different experience being an athlete and somebody that's in the spotlight. I feel like you have to be conscious of what's going on around you. If it's ten White people in a room and myself, I'm going to stand out. No matter what, you're the odd man out just in terms of looks, so to people you're going to stand out...you just have to be conscious of that reality. 
It is important, in this circumstance, to note the campus community has been found to appreciate and value athletes when they perform on the field more than when they participate in the classroom (Frazier, 2012). When Trevor's experience is considered in comparison to John's, who experienced overt racism on campus and in the community, both acknowledged they are appreciated for their athletic feats, but not necessarily for academic achievements. This mindset and environment could perpetuate issues of Black student-athletes lack of focus on academics. Additionally, it could lead Black studentathletes, like John, to over-identify with and strive for athletic achievements in order to appease the campus environment where they live. Such strong racial stereotypes associated with the Black male student-athlete lead to racist implications, thus further perpetuating the perception of their sole purpose on campus being for athletics (Harper, 2009). Even if the Black male student-athlete is interested in receiving an education while competing intercollegiately, other university stakeholders are often more interested in the personal or institutional gain through the exploitation of the athletics abilities of the student-athlete (Donnor, 2005).

The need the participants expressed to possess a heightened awareness of their surroundings on their respective campuses indicated they feel different, excluded, and isolated from the general population on campus due to their race. Through the CRT method of counter-storytelling, the participants had the opportunity to assert the truth of their experiences as such experiences impacted their time on campus and the truth that their race impacted not only their daily lives and experiences on campus, but their professional careers thereafter. Societal perceptions of race fundamentally sustains 
inequitable conditions that disproportionally affect the experience of Black studentathletes (Bimper, 2015).

The requirement Trevor conveyed of a necessary heightened awareness of his race on campus is indicative of the same post-racial narrative gleaned from the comments Jason made about his heightened awareness on campus (Bimper, 2015). What is most alarming about the experiences and opinions Trevor shared is the fact that instead of the four years student-athletes traditionally have to acclimate to their campus and perhaps feel more comfortable even in a predominantly White environment, transfer studentathletes have to acclimate all over again at their receiving institution with a new set of predominantly White students, faculty, and community members.

In summary, the psychological characteristics of the participants' self through their transition experiences from their initial to receiving institution were integral to understanding the ability of the participant to cope through the transition phenomenon. Transfer transitions allowed student-athletes to pursue better situations for them from the perspective of their basketball careers, leading 13 of the 15 participants, at the time of the study, to enjoy professional basketball careers. Although the pursuit of the transfer focused on basketball, many participants reported feelings of isolation during the redshirt year. New social environments at the predominantly White receiving institution accompanied by NCAA policies restricting transfer student-athletes from travel inhibited the participants from being received smoothly. Isolation also occurred due to the transition away from the social structures of the participants' initial institutions. Black student-athletes transferring to a new campus expressed needing to have a heightened sense of awareness of their surroundings through the transition, as heightened awareness 
indicated participants felt different, excluded, and isolated from the general population on campus due to their race.

Supports. Supports, according to Schlossberg (2011), refer to the people, organizations, institutions, and systems to which the individual experiencing the transition can or cannot turn during the transition experience. Relationships are of utmost importance to both the academic and athletic career of the student-athlete, and their success depends primarily upon how such relationships can provide support (Wylleman \& Lavallee, 2004). Support structures, both from a systematic and personnel perspective, present at the receiving institution during the redshirt year allow student-athletes to adjust and transition to their new receiving institution with the aid of family, friends, teammates, athletics support, and other support structures and personnel around campus.

Student-athletes experience a unique campus environment much different than the average student. Therefore, student-athletes are more likely to forge relationships with other student-athletes in the campus community who can understand their environments and time commitments to their sport. Student-athlete social networks, most often comprised of parents, siblings, and extended family, provide support in many forms for Black student-athletes at PWIs (Carter-Francique, Hart, \& Cheeks, 2015). According to Flowers et al. (2014), transfer student-athletes often pursue and make use of their narrow support network in sport, including parents, coaches, teammates, or other athletics department employees. From an academic support perspective, faculty, staff, and support members of the campus and athletics community should embrace Black student-athletes and stand up for for their holistic well-being on campus (Harper, 2009). Through their interviews, participants indicated heavy use of narrow support networks provided to them 
through sport. The following sections explore the participants' experiences with support either received or not received from various goups through their transition from initial to receiving institution.

Family. The theme of family aligns directly with Evans and colleagues' (2010) four social support categories of intimate relationships, family, friends, and institutional communities. Family members were credited for being the most effective means of support for the student-athletes through the transiton and redshirt year regardless of proximity of the instititution to the geographic location of the families to the studentathletes. Jason, for instance, leaned on his family for support during his transition and redshirt year and described the most effective member of his family providing support, saying, "I would say my dad... and others in my family as well...I felt like having the support system allowed me to not only think about basketball but to take my education more seriously." Aaron had a strong core of family members helping him through the transition as well, indicating his father, mother, and brother were available to support him during tough times. Anthony described a unique experience where he transferred to a school much closer to home where his parents were available to conveniently visit more often which allowed them to provide support in a much more physically present manner. Family members providing support to the participants were not just parents, but also included brothers, sisters, cousins, aunts, uncles, and grandparents.

Coaches and athletics support staff. The theme of coaches and athletics support staff aligns directly with Evans and colleagues' social support category, institutional communities. Coaches and athletics support staff are often placed on the front lines of the transfer student-athletes' transition to their receiving institution, as they can provide 
resources and informed answers to questions. The successful coach in the intercollegiate setting is in charge of informing the student-athlete about any important issues regarding his or her role on the team as well as any expectations of them as a student-athlete (Rezania \& Gurney, 2014). Student-athletes reported lower levels of stress when also reporting their head coach as likeable (Weathington, Alexander, \& Rodebaugh, 2010). Therefore, in general, student-athletes are heavily influenced by their relationship with their head coach and it is likely transfer student-athletes require just as, if not more, of a solid relationship foundation with their head coach at the receiving institution.

An elemental component of the successful player-coach relationship is trust (Stein, 2018). If a coach violates the psychological contract that exists with the establishment of the player-coach relationship, student-athletes trust in the coach is lessened, leading to heightened intentions to leave their institutions (Barnhill \& Turner, 2013). Such contract violations, occurring with mistreatment or abuse by the coach, indicates many transfer student-athletes may enter their new team structure with trust issues and reluctance to establish a new player-coach relationship. If a coach possesses the ability to build trust with student-athletes who may already possess such trust issues, they can likely assist in successfully navigating transition and redshirt experience for the student-athlete.

A successful player-coach relationship at a transfer student-athlete's receiving institution is key to smooth transition. Gerald, for instance, credited his coaching staff for aiding him through his transition and redshirt year. He described his coaching staff by saying, "They were really, really welcoming when I got there and told me everything was going to be cool, everything was going to be okay, just make sure you keep working 
hard...you have to have a good supporting cast of good, good people in your circle. That's what I had, fortunately." Gerald even had a basketball staff member available to spend time with him whenever the team was at a road game, accompanying him when he went to the gym or spending time with him watching basketball in the locker room.

Aaron had a particularly pleasant exeperience during his redshirt year with building his relationship with and getting to know his new head coach, saying, "His door is always open, so he made the redshirt year. We got time to like, get to know each other for a full year intensely, without him having to yell at me for practice or anything. So I think he was my go-to." This relationship between head coach and athlete, although traditionally built up over a student-athlete's four seasons of eligibility, can benefit the transfer student-athlete immensely if prioritized. Although such relationships are often built during the traditional recruiting process of the student-athlete during their high school career, the recruiting process through the release and transfer can also foster such close relationships between coach and student-athlete.

Teammates and other student-athletes. The theme of teammates and other student-athletes aligns directly with Evans and colleagues' social support category, friends. Social groups that aided participants that aided them throughout their transition were often teammates and other student-athletes around campus. Student-athletes have strict and specific schedules and routines that often set them apart from the general student population. A transfer student-athlete who does not have the traditional time to experience the campus like native students, is likely to gravitate to others who have similar experiences. Trevor, for instance, said he spent most of his time with teammates 
and other athletes during his redshirt year. Aaron had a similar experience during his redshirt year on his receiving campus, saying:

I just hung out with the basketball team more than anybody. I think it's just that the basketball schedules and stuff are so tight that you're around those guys 80 percent of the time while you're in school. I mean, you can find time, but I mean, I know the men's basketball programs, especially at bigger schools, you're generally kind of stuck with those guys. Not in a bad way, but it's very hard to find different social groups...you're with your team and there's no getting out of it because you're in practice so much or in meetings. Your schedule is pretty dictated.

John echoed similar sentiments, saying his basketball teammates at his receiving institution "were really welcoming...they always made things easier." Although Stephen felt isolated during his redshirt year when his team was travelling for games, he indicated he did his best to reach out to other athletes on campus, including football and baseball players who were in their off-seasons during the bulk of the travel calendar for men's basketball.

Michael decided to commit to transfer to his receiving institution the first day he was on campus for a visit after seeing a team member who was a former friend of his in high school, saying, "I had committed the first day I got there because I ended up seeing a high school friend of mine. We played in a couple tournaments and gained a friendship with basketball at random tournaments in different cities. We just had a really good connection." He went on to describe a strong sense of team leadership at his receiving institution that helped with his transition. Michael also said he gravitated toward other 
athletes on campus for social support as well, indicating student-athlete "schedules are different than the general population of students."

While the majority of participants attributed positive qualities to their social support systems during the transfer and redshirt process, a few had a much more negative experience with social support. Jason admitted his social support was a bit lacking throughout his transfer, saying:

I didn't really have as many friends as I did when I was at [former school]. I was also a bit older than everyone else. I would say when I was at [receiving school], I was a little bit more to myself. I had friends that I would hang out with on the team here and there, which was a lot of the older guys, but I was kind of to myself.

Marcus echoed a similar sentiment, describing his transfer process and redshirt year as "more isolated. You're kind of sequestered into the athletics facilities...you're kind of, like, a celebrity." The transfer to a Power Five institution, as each participant experienced, presented differences for the participants, like a heightened celebrity status and an increase in athlete sequestering, differing from what they experienced at their previous non-Power Five institutions.

While many participants denied experiencing any overt experiences with race on campus, others did express specific experiences that influenced their perceptions of their receiving institutions. Jason shared his encounters with race at his receiving institution, expressing some various issues through his experiences with his predominantly Black team: 
I would say at [receiving school]...of course there were a lot of white kids there, but I mean the majority of our entire team was pretty much for the most part Black. Then there's still a lot of diversity even with the team as well...I never really had any types of discrepancies or any issues as far as the whole race thing goes...but it's funny, I know some people kind of struggle. I had teammates who grew up in Chicago so they normally hung out with Black people. But where I grew up, some of my closest friends are White...depending on your environment or where you're from, that plays a huge role in how you transition in those environments.

The environment described by Jason that affected his Black teammates is what many Black student-athletes encounter when matriculating onto PWI campuses. Black studentathletes at PWIs must constantly negotiate their own identities to successfully navigate the Whiteness and privilege not afforded to them while simultaneously managing raceand athlete-related stereotypes impacting their social identity on campus (Bimper, 2015; Bimper et al., 2013). While not an experience solely attributed to transfer studentathletes, the Black transfer student-athlete must matriculate and negotiate such identities not once, but multiple times at each university attended.

Michael described his support community surrounding his receiving campus during his transfer transition, saying "I am a strong Black man, and I'm a leader, so I demand respect. [The community at his receiving institution] was conducive to everything I was going through and the people were great. I didn't have any bad experiences when it comes to all that or with anybody on campus." Stephen also credited his receiving institution for its diversity and indicated he did not experience any direct 
issues with his race during his time as a transfer student-athlete. Social networks of Black student-athletes on predominantly White campuses often provide strategies and pathways to successful navigation of any racialized circumstances toward academic and social success (Carter-Francique et al., 2015; Solórzano et al., 2000).

Although academic centers housing academic support for student-athletes further isolate student-athletes from the general student population (Huml, Hancock, \& Bergman, 2014; Rubin \& Moses, 2017), participants indicated academic support staff in athletics provided major assistance in their transfer transition. Athletics support staff members are often at the forefront of assisting student-athletes through their acclimation to campus (Gaston-Gayles, 2003). Trevor said he was provided support by an academic services employee at his receiving institution to guide him through study halls and tutor appointments. Marcus described an increase in required time with academic support during his redshirt year to help him adjust, including academic planning meetings and time with tutors. Stephen said the academic services available to him both through athletics and through his major helped with his academic transition and acclimation to his receiving institution.

Only two of the fifteen participants, however, indicated the use of non-athletics supports on campus to aid in adjustment to their receiving institution, particularly during their redshirt seasons. During the redshirt year, $\mathrm{AJ}$ went to the student recreation center to play basketball and interact with non-athlete students, particularly when his team was on the road for away games. He even decided to join a flag football team on campus with non-athlete students "to have fun and do things to make the time pass by." Anthony took advantage of his spare time during the redshirt season and joined an oncampus fraternity, 
saying, "basically, it was just like, a filler I guess. I felt like I had the opportunity to dive into something a little bit differently during the redshirt year." Anthony did indicate his obligations with and commitment to the fraternity came second to his commitments to basketball. His circumstance and role as a student-athlete on campus was something his colleagues in the fraternity just had to understand, as he explained, "you're really an athlete first."

In summary, the participants' support systems aided significantly in their transition experiences. Relationships are of utmost importance to both the academic and athletic career of the student-athlete, and the support structures provided by such relationships with family members, coaches, teammates, and other support staff on campus provided participants with tools to cope with their transition. The shift from one predominantly White institution to another presented a challenge to Black studentathletes' acclimation and acceptance onto their receiving campuses. As student-athletes are often segregated on high-level Division I campuses from the general population of students, however, participants leaned on a narrow support network comprised of those most closely affiliated with their basketball program for support. This support structure may have been more narrow for Black student-athletes due to a lack of diversity on the PWI campus.

Strategies. Strategies, according to Schlossberg (2011), are the actions an individual takes to cope with transition. Participants indicated the use of several different strategies, or plans of action to cope with the transition, when navigating the transfer transition and redshirt year. Reported strategies revolved around anticipation and preparation for the future, and the use of the redshirt as a tool for accomplishing goals 
either athletically or academically. The participants' preparation to execute a strategy to take advantage of the benefits afforded to them by the redshirt year is key to a beneficial experience.

Preparing for the future. The theme of preparing for the future refers to a strategy choice, one of the four plans of action to cope with the factors of the transition (Sargent \& Schlossberg, 1988). According to the literature (Flowers et al., 2014), transitions for some participants fall under the category of anticipation. In this case, anticipation means the participants attended an initial institution with the planned anticipation of transferring to a higher-level program. Jason explained his strategy for transferring and remaining on track to graduate in four years, thus utilizing his fifth year of eligibility to begin his master's degree. He explained how having a plan, and a solid general understanding of the processes and policies of the transfer transition and redshirt year, allowed him to take advantage of the benefits afforded to him through the decision to leave his initial institution. He explained how many student-athletes have professional aspirations and let their athletic dreams guide their decision-making processes. He provided insight into the process from his perspective, saying:

I feel like a lot of collegiate athletes want to play professionally, but the thing is that, you know, it's challenging and it's hard, especially if you get into a position where you're thinking whether it's good enough money to obtain your livelihood...I feel like it's best to start preparing for the real world just because you really want to have that back-up plan just in case playing doesn't work out. Similar to the mindset of Jason through his transfer transition, Trevor explained his mindset and understanding of his process allowed him to take advantage of the redshirt 
year, but rather than doing so from an academic perspective, he took advantage from a basketball perspective. He said:

I looked at it as an opportunity there. There's no pressure to play. You can train, and you can train a little bit differently when you're not relying on a fresh body for games. You can practice long, but you can also work out an hour before and an hour after practice. I can afford to be sore on game day.

Trevor took advantage of the opportunity to spend a full calendar year improving his basketball skillset without team-centered distractions and without the need to preserve any energy or function for his performance on game days. In turn, he became a better basketball player during his college career, and since exhausting his eligibility and graduating, he has enjoyed a professional basketball career in the NBA and NBA G League with plans to continue playing professional basketball until he no longer has an opportunity to do so.

The strategy of taking advantage of the opportunitites through transfer to improve level of play, and ultimately with the hope of also improving professional basketball career prospects, was evident through the interviews. John, for instance, elected to and pursued his transfer transition to a higher, more nationally recognized level in order to have a chance at being drafted by an NBA franchise. He explained how a strategy employed by a former teammate who had an extremely successful career at the same initial institution as John did not provide him an opportunity to play in the NBA. This former teammate gave John advice to take advantage of a different opportunity that would give him potential to move to the higher level, thus providing him with a better chance at playing in the NBA. He said, "I wanted to go to a bigger school at the high 
level where I'm able to perform and show my competitive side, and agents will find you out of college." John was not taken in the NBA draft, but is currently enjoying a career in the NBA G League in the United States with aspirations of eventually being brought up to an NBA roster.

Will, too, pursued the opportunity to play at his initial institution as a means to advance collegiate basketball career. He explained he had aspirations of playing at a higher level from the beginning, using his freshman year to play at a lower level to prove his capability as a basketball player before entering the transfer market with an anticipated transition to a receiving institution offering a higher caliber of basketball. Will explained he had anticipated his decision to go through the process of transfer transition from the very beginning. This anticipation allowed him to enter the basketball transfer market with a résumé filled with basketball accomplishments assisting him in finding the most appropriate receiving institution for what he could offer as a basketball player, saying:

I wanted to play at the highest level. Fortunately for me, I started as a freshman at [initial school] and was able to be on the All-Rookie team at the end of the year, which gave me leverage to transfer.

Will transferred because he had an "idea of leaving a legacy," and was successful in doing so, as he took advantage of the redshirt year to become a better basketball player at his receiving institution.

Blending in. The theme of preparing for the future refers to a reaction to stress, one of the four plans of action to cope with the factors of the transition (Sargent \& Schlossberg, 1988).Strategies were employed by participants during their transition and 
redshirt year to blend in to their new campus environment. As all 15 participants transferred to predominantly White institutions, a new environment meant that Black student-athletes were, once again, placed into the racial minority on a college or university campus. Thus, they were often faced with the tasks of acclimating and blending in. Gerald used his status as a notable Black student-athlete on campus to his advantage saying, "I treated everybody with respect and they treated me with respect. They probably looked at me like, “Oh, he plays basketball”, so you know, I really didn’t have any issues or any problems with anybody." Gerald's strategy to use his celebrity status as an athlete allowed him to, at least on the surface, negate awkward interactions on his receiving campus.

AJ tried to diffuse any race-affiliated situations whenever possible during the transition into the environment of his receiving institution, saying he did not allow himself to emotionally invest in any trivial experiences due to his race. Overall, however, AJ expressed an understanding of the realities of the campus culture at a predominantly White institution, saying, “Obviously being a student-athlete, you're pre-judged as a lazy student... and then just being a minority in the United States period, you're also prejudged." As Gerald and AJ explained, the perceptions accompanying the intersectionality of being Black and a student-athlete dictated their ability to cope with their transition and acclimate to their new campus. Employing the strategy of using athlete notoriety and oncampus fame while controlling what was controllable allowed for a smoother transition into a new, predominantly White, campus environment.

Overall, the strategies employed by the participants through their transition from initial institution to receiving institution helped them better cope with the transition 
experience. The preparation of executing a strategy was paramount to the success of the strategy itself, whether athletically or academically motivated. The redshirt year allowed participants to take advantage of benefits afforded through the policies in place.

However, if a strategy was not executed or not implemented whatsoever, the redshirt year provided the participants with a cushion in their transition to the receiving institutional climate. The participants who anticipated their transfer transition gave themselves a better likelihood of successfully transitioning, either athletically or academically, to a new predominantly White campus environment at their receiving institutions. In addition, participants who utilized strategies to better blend in as Black student-athletes at a new PWI had more success on campus in diffusing or avoiding any racialized or stereotypical issues.

To summarize, the key to applying Schlossberg's (1981) transition theory to the present study was to prioritize the individual's perception of the transition rather than the transition itself. Schlossberg's (1995) 4 S's provided an effective framework to better understand the transfer transition and redshirt year process of Black Division I men's basketball lateral transfers. Each individual transfer student-athlete transition brings a specific set of situations, strategies and coping mechanisms to navigate the transition. The integrated analysis of the inducted and deducted codes and themes that emerged from the interviews in accordance with Schlossberg's (1981) 4 S's system of coping with transition provided accuracy and consistency in data interpretation. In addition, covert, subtle descriptions of experiences with race and racism, in accordance with Critical Race Theory and counter-storytelling, illuminated through the interviews in a variety of ways through descriptions of Schlossberg's 4 S's framework. 


\section{RQ \#2: Perceived Benefits and Drawbacks}

All participants $(n=15)$ indicated they received direct benefits from their experiences with the redshirt year in a multitude of ways. The redshirt year provided student-athletes an academic buffer, cushion, or advantage; allowed student-athletes to mature from a personal or basketball-related perspective; and gave athletes an opportunity to develop both academically and athletically. Most importantly, all fifteen ( $n$ $=15$ ) former men's basketball student-athletes in the study explicitly expressed they received advantages supplied to them with the NCAA policy in place requiring the redshirt year after lateral, Division I to Division I transfer. Disadvantages of the redshirt year, though mentioned less frequently, were also addressed throughout the interviews and discussed in each of the following sections.

Holistic advantages and disadvantages. According to the participants, the redshirt year provided many advantages to the student-athletes. To holistically evaluate the student experience, it is important to focus on the intersections of the Black studentathlete rather than separate constructs (Magolda, 2009). Therefore, to understand the holistic advantage provided to the Black student-athlete, it is important to evaluate the academic, athletic, and cultural experiences of the participants. Jason indicated the redshirt year provided him with time to fine-tune an invaluable set of skills and benefits of which he took complete advantage. At the time of the interview, he was preparing for the LSAT with intentions of enrolling in law school in the future. Jason raved about his experiences with the redshirt process, saying:

I'm trying to get into law school next fall...just having the educational background as far as my undergrad and graduate degree as well as playing 
basketball, I'm just trying to use that to my advantage. I took my redshirt year as a gain because even in that year I feel like a lot if times, it gives players a chance to mature mentally, physically, and I think the extra year just does a lot depending on if the player takes advantage of it.

It is important to note the emphasis Jason placed on the success of the redshirt year being based on whether or not the student-athlete takes advantage of the benefits. In order to successfully complete a college degree, student-athletes must have a healthy interaction and engagement with their campus environment (Hendricks \& Johnson, 2016). Traditional, native four-year student-athletes report having a hard time managing their athletic commitments while simultaneously prioritizing an engagement with the campus from an academic and social perspective (Hendricks \& Johnson, 2016). Adding the increased stressors associated with the transfer transition, the availability of the redshirt year to assist in the transition provides lenience to the already strenuous academic and athletic pursuits of the student-athlete.

Similar to the experiences of Jason, Trevor echoed the redshirt year provided similar benefits to him and his career, saying his experience with the year-in-residence was "a significant gain...I looked at it as crunch time. But really, it was a year to develop myself... as long as you're being productive, it's hard not to benefit from it." Again, the experience requires the student-athlete take advantage of the time and resources provided by the redshirt policy. AJ had similar feelings and credited the redshirt process as a holistic benefit to his career as a student-athlete, saying, "For me, I think it helped me a lot as far as growing as a person.” Anthony attributed growth to the redshirt year in a very 
similar way, explaining, "You have the year to mature...you have the year to grow as a person."

Gerald recognized he did not have the picturesque career he envisioned as a prospective student-athlete, but did express his appreciation for having his experiences with the redshirt year. He said:

I feel like everything happens for a reason. Even though I didn't have the type of career I wanted, I was still able to touch a lot of people and impact people's lives, and meet people who were able to impact my life as well. I got to be a bigger voice in our community...those kinds of things are just priceless.

Transfering has been shown to negatively impact a student-athlete's ability to acclimate to campus and engage with the university community and limit sense of belonging (Flowers et al., 2014). Additionally, the campus community appears to primarily value athletes for their on-court performance (Frazier, 2012). Reputations of transfer students, as designated outsiders, have shown to negatively impact their confidence, expectations, and acceptance capabilities within the new campus culture and community (Goldrick-Rab \& Pfeffer, 2009). Fortunately for Gerald, such negative experiences with the campus community did not occur and rather, he appreciated the time afforded to him through the transfer redshirt year to impact the community surrounding his receiving institution in a positive manner.

Michael described how by transferring, he had the opportunity to make a significant positive change and evolve away from the hardships he experienced at his initial institution. He said, referring to his receiving institution, "I could create a new identity for myself." This new identity, or fresh start afforded to transfer student-athletes 
at their receiving institution, could serve Black student-athletes particularly well, as research has shown faculty, students, and academic support staff are more likely to have a negative perception of their academic pursuits than White students (Bimper et al., 2013; Carter-Francique et al., 2013; Comeaux, 2010; Davis, 1990; Harper, 2009; Jones et al., 2017; Sailes, 1993; Sato et al., 2013; Sato et al., 2017; Singer, 2016). Beginning again with a new identity, either academically, athletically, or socially, could allow the transfer student-athlete to have a completely different, and potentially much better, experience at the receiving institution.

Holistic disadvantages occurred mainly when participants felt as though they were not adequately prepared or not guided appropriately through the redshirt process. James, for instance, alluded to the fact that many student-athletes are misled through the transfer and redshirt year, saying, "If you transfer and you don't really understand how, [the knowledge of how to do so] is really vital." Similarly, Stephen said, "I think it's just the way it is viewed mentally. If you go into it and just kind of go into it, you will have a lot of extra time and I can see how some people just get off the beaten path and end up having a lot of extra time. But if you're locked in and working on stuff, I see it as a gain.” The necessity of the transfer student-athlete to have adequate ability to take advantage of the advantages provided through the redshirt year is vital to the success of the transfer student-athlete.

Academic advantages and disadvantages. Research has shown a positive relationship between athletic satisfaction and adjustment to college. The academic, athletic, and social experiences of the student-athlete are interconnected (Russell, 2015). As $n=14$ participants decided to depart their initial institutions for basketball-related 
reasons, it is likely and evident through the academic transition experiences of the student-athletes that transferring placed them at varying rates of academic disadvantage. Therefore, the redshirt year provides a cushion for adjustment.

Anthony, who decided to transfer after spending two years at his initial institution before asking for his release, described the redshirt year as an advangage, saying, "It's an advantage to sit out." Anthony was required to change his major upon transfer after two years of degree progress at his initial institution from business marketing to agricultural business. He graduated in four years and had the opportunity to begin graduate coursework. Miles, who decided to transfer after three years of degree progress at his initial institution, said, "I wasn't in that much of a rush...I enjoyed being able to sit out." Miles, too, was required to change his major, but after three years of degree progress, lost many credits. He shifted majors from business marketing to social work and needed his fifth year of eligibility to complete his undergraduate degree. While he stated his redshirt year provided him an academic advantage, the transfer process itself halted his overall academic progress. As previously indicated, due to NCAA policies and procedures, credit loss through the transfer process can lead to ineligibility, as student-athletes are required to have earned increased percentages towards degree progress throughout their careers (NCAA, n.d.c.).

Aaron expressed how he needed the advantage the redshirt year provided saying, "I think it honestly took me a year to fully adjust to the school... academically, I was able to catch up and keep my grades high. During my redshirt year I took about 20 credits per semester." The average student enrolls in anywhere between 12 to 15 credits per semester in order to graduate on time in the traditional four years (Belfield, Jenkins, \& Lahr, 
2016). Therefore, after transferring, Aaron was forced to enroll in approximately $2-3$ more classes per semester than the average student. With his athletic time commitments taken into consideration, the redshirt year requiring Aaron to remain on campus, not play in contests, and not travel to away contests, provided him with the needed time flexibility to not only graduate with his undergraduate degree in four years, but to begin graduate coursework during his fifth year of athletic eligibility. Thankfully, Aaron was not required to change his major after completing two years' worth of coursework at his initial institution before deciding to transfer.

Greg indicated he used the redshirt year "to focus on the classroom." Though Greg was required to change his major after transferring, he had only accumulated one year of degree progress at his initial institution and was not set as far back as he would have been had he elected to transfer at a later time in his academic career. He, too, graduated with his undergraduate degree in four years and began coursework on a graduate degree during his fifth year of athletic eligibility.

Anthony recognized the distinct academic advantage he was provided through the redshirt year requirement saying, "I would say I grew up in a lot of areas as far as being more informed about and being able to take advantage, as far as academics, it inspired me to be more knowledgeable. I was able to expand with my master's." Although Anthony elected to transfer after two years at his initial institution and was subsequently required to change majors, switching from marketing to agricultural business allowed for many of his earned credits in business marketing to be accounted for in agricultural business. He, too, graduated in four years and began coursework on his graduate degree during his final year of eligibility. 
Although the academic benefit of transferring to take advantage of the fifth year of paid tuition to begin to pursue a graduate degree is a distinctly alluring asset in the Division I transfer process, many student-athletes do not enjoy enough academic success to take advantage of the opportunity. Student-athletes who were not academically successful at their initial institutions, or those who cannot maintain academic success through the transfer transition, also enjoy the academic advantage of the redshirt year-inresidence in different ways. The redshirt year provides these students with an additional year to pursue their undergraduate degree at the expense of the receiving college or university. Many student-athletes, including six participants in this present study, required such academic flexibility and took advantage of the additional year provided to them through the redshirt process to better their academic careers as an undergraduate student. However, the transfer process in general presented participants with such a detrimental academic disadvantage they needed a complete calendar year of coursework to recover.

Black student-athletes at PWIs experience under-preparedness and race-based stereotypes causing academic challenges on campus (Sato et al., 2017). In the cases of Black men's basketball transfer student-athletes, the race-based stereotypes and underpreparedness places them more at risk academically than their White counterparts, as issues with credit transfer, degree progress, and acclimation to a receiving institution after transfer can have a more harsh effect on their progress through college. The redshirt year advantageously allows Black student-athletes to acclimate academically to the receiving institution with grace and flexibility. 
The academic pressures placed on student-athletes academically are high, as degree progress is integral to eligibility (NCAA, n.d.c.). Regardless of credit transfer, or academic major change, the redshirt year provides transfer student-athletes a buffer to acclimate to a new campus. Recognizing the academic advantages afforded to transfer student-athletes by the student-athletes themselves is key to ensuring academic success upon transfer.

Basketball advantages and disadvantages. As indicated by 14 of 15 participants in the study, the reasons for transfer were basketball-related and included playing time, coach relationships, and level of national prominence, among others. It is not surprising, therefore, that many participants attributed athletic advantages they enjoyed throughout the rest of their collegiate careers as well as their professional basketball careers thereafter to the redshirt year. As each of the participants ended their playing careers at a Power Five institution, the enormity and significance of sport to their stories shone through in the interviews.

Trevor saw athletics benefits and advantages coming from his redshirt year process, saying, "It was great for me because I got to learn and develop and just concentrate on myself and then be so well incorporated into the system that it was second nature...my main initiative for a whole year was just developing my game." Trevor left his initial institution after two years. He admitted he did not anticipate having to go through the process when he initially enrolled in college, but was pleasantly surprised with the results of the transfer transition from a basketball perspective. He is currently playing in the NBA G League after playing in the NBA last season, and said, “Transferring schools wasn't the plan, but to be able to do all of that in five years of 
college, then to play in the NBA, there was success in that." The advantages Trevor received during the additional year of college proved fruitful for his professional basketball career.

Marcus shared a similar experience with gaining a basketball advantage through the redshirt process, saying, "I was able to be able to play at a level where I always felt like I could play. If I didn't take that sit-out year, I wouldn't have been able to do that...for me, it taught me patience...you had to have a sort of level of patience and toughness to make it." Marcus transferred from a non-Power Five institution to a Power Five institution, allowing himself to grow and excel at the highest college basketball level available during his redshirt year. He is currently playing professional basketball overseas.

Michael echoed similar feelings about his development as a student-athlete. His transfer transition experience is unique, as he departed his initial institution after just one semester, then redshirting a full calendar year before being eligible to compete in contests. It took Michael time to adjust after arriving at his receiving institution, as he explained, "I wasn't ready to be out there my sophomore year after my freshman year." The time he spent during the redshirt year allowed him to grow as a basketball player without wasting his athletic eligibility. Although by transferring mid-season, he did not receive and experience the full four years of NCAA-allotted competition, he still had the opportunity to spend the redshirt year focusing primarily upon himself and his development from an athletic perspective.

It is important to note Will was presented the option by the head coach at his receiving institution to apply for an appeal to the NCAA for an exception to transfer 
without redshirt penalty and be immediately eligible to participate in contests. The NCAA Council makes decisions on whether to relieve certain student-athletes of the redshirt penalty due to certain documented and mitigating circumstances directly impacting the health, well-being, or safety of the student-athlete (DeCourcy, 2018). Reasons for waiver approval have often been attributed to family medical issues and tragedy (DeCourcy, 2018). Will indicated he had family in close proximity to his receiving institution. Will, however, chose not to appeal, saying, "I wanted to make sure I pay my dues and come in on a clean slate. It was great, I had coach working me out every day...when I was practicing with the team, I was always on the scout team so I would be able to work on skills I wouldn't normally work on.” The decision to serve the redshirt year-in-residence ultimately worked in Will's favor as he graduated on time from his receiving institution then had the opportunity to take advantage of the graduate transfer policy to finish his eligibility at a third institution. There, Will suffered an injury and ended up appealing to the NCAA for his sixth year of eligibility, which was granted. He is currently playing professional basketball overseas.

The benefits of the redshirt year from a basketball perspective are immesurable, as indicated; however, participants also offered disadvantages to spending an additional year in the college basketball system for consideration. Trevor discussed how, after spending an additional year at the college level and therefore entering the professional draft pool at an older age, takes away from the marketability and draft-ability of the athlete, explaining, "When you're playing professional ball, the younger you are, the more it helps. I am in my second professional year at 25 , which is not old, but you're considered relatively seasoned. That's the flip side." AJ echoed this same issue, 
explaining his experience and potential to play professionally in the NBA, saying, "Going to the Draft, they said the only negative is your age. Regardless of how well I did, I still wouldn't have been a lottery pick because I was in my twenties." According to Trevor and AJ, spending that fifth year in the college ranks was detrimental to the draft stock of student-athletes.

Some participants expressed a sense of regret about their experiences. Jason, for instance, stated he missed out on the special player-coach relationship as well as the atmosphere of the university. The bond that is formed between player and coach throughout a traditional four-year career at the same school left Jason envious; however, with both transfer student-athlete (Woods, 2017) and coach (Winn, 2015a) movement rates skyrocketing each year, this player-coach relationship has the capability to occur less and less often over time.

\section{Overall Impressions of the Redshirt Year}

Despite the fact that all participants in this study indicated they received benefits and were advantaged from the redshirt year, only three of the 15 participants agreed when specifically prompted that the redshirt year should be a requirement for Division I basketball student-athletes. Although participants expressed appreciation and gratitude for their personal experiences with the redshirt year, 12 of the 15 participants disagreed with the current NCAA policies.

One of the proponents of the redshirt policy, Anthony, said he appreciated the redshirt policy as it boosts the experience of the transfer student-athlete, and that "It might be a good policy the way it is implemented." Trevor, another proponent of the redshirt year, indicated the necessity of the redshirt year for a different reason, being due 
to an aversion of chaos in the college basketball recruiting marketplace from year to year, saying:

If you let everybody play right away, it is really going to become a circus. People are going to jump all over the place. I think by choosing to transfer, it already tests your commitment to that school a little bit just because you have to sit and wait. If it's just a problem with a coach or a school or a location, is it really worth me sacrificing a whole year worth of playing? Still, numbers are increasing to take that route. If you let them play right away...if you have a losing record, I would anticipate those teams would lose half their team every year.

Although Trevor did not attribute his feelings of redshirt year necessity to the academic, athletic, or social advantages afforded to student-athletes, his prediction of recruiting chaos would likely ensue if the policy were revoked.

Twelve of the 15 participants disagreed with the redshirt year policy as it is currently in place to varying extents. Reasons revolved solely around basketball and the control the NCAA and its member institutions has over student-athletes during their college careers. Each of the 12 participants opposing the redshirt year were not in complete opposition, but rather, felt as though the policy needed at least some type of change going forward.

Although he admitted to its array of benefits both from an athletic and academic perspective, Aaron indicated he did not think the redshirt year was a necessary requirement for the transfer student-athlete, saying:

I don't think it's necessary. I don't think it should be mandatory to the fact that the coaches are able to leave, but the players can't. Or, you know, if a coach gets 
fired, the players are kind of stuck. So no, I don't agree that you should have to sit out a year. I don't know what they should do to change it, but players should play right away...you can try to find the positives of it...but there are going to be some type of casualties on either side of the fence.

The indecisiveness Aaron expressed with what to do about the current redshirt year is something that is expressed across the country. The NCAA Division I Transfer Working Group is, as of Spring 2019, in the process of evaluating and examining alternatives (Hosick, 2018a).

Michael, a current coach in NCAA men's basketball, disagreed with the current redshirt penalty, saying student-athletes should be able to move freely and be eligible to play right away. During his interview, Michael was encouraged to take off his "coach hat" and put on his "student-athlete hat", and still, he insisted the redshirt penalty is an unnecessary part of the transfer student-athlete process. Gerald felt as though something should change, suggesting the addition of an academic component to waive the necessity of the redshirt year. He said:

You can't have bad grades, not going to class, and expect to transfer to another school and play right away. You should be a good student...you would need the student to reach a certain level before they could make any decision to play right away.

The current academic component requiring student-athletes pass at least 6 credits from their departing semester at their initial institution as well as degree progress qualifications for eligibility are in place to set academic standards for transfer student-athletes (NCAA, 
n.d.c.). However, Gerald felt as though the redshirt year qualifications process should be more streamlined.

In the same vein, $\mathrm{AJ}$ indicated there should be extenuating circumstances to allow a player to play right away if a coach were to depart the institution, because "if you get recruited by one culture, then [the coach] gets fired and you're stuck in a system with a coach that you didn't know or you don't want to play for, I believe then you should be able to transfer with no redshirt." Avery explained similar thoughts toward the redshirt year, saying, "as long as they're doing everything they can in school, I think they should be able to transfer and play right away. You can have a coach get fired and a player decide to transfer. What if he came for the coach? And he can't go play right away?" The head coach of a program is often the reason student-athletes choose an institution. With Division I men's basketball coach movement on the rise (Winn, 2015a), it is not shocking to find the participants place emphasis on this element of the student-athlete experience and reason for potential transfer.

Stephen disagreed with the requirement of a student-athlete sitting out for an entire redshirt year, suggesting players should be required to sit out only a handful of games, then be eligible to play. Marcus had a similar opinion, comparing sports requiring the redshirt year to other sports that do not, saying:

You should play right away. I think basketball and football are the only two sports that have that rule...I don't know what it is, but I have an idea that it is a control thing. If there was no rule, there would be Armageddon every year, so it is kind of like a given, but players should have the freedom of movement to be able to do what is best for them and their families. 
Marcus had similar feelings on the removal of the redshirt year to Trevor, as it would create chaos.

John indicated the redshirt year should be a choice for the transfer student-athlete, but not something that is required, especially if the student-athlete were coming off a successful basketball season and wanted to continue his momentum at his new institution. Even though Will chose not to appeal his redshirt year although his receiving head coach gave him an opportunity to do so, he still considers the redshirt requirement unnecessary, indicating similarly with others that a coach leaving a school should not handcuff a player, saying,

If I come to [a school] and I want to play and [the head coach] has been recruiting me since I was in high school, and then I get there as a freshman and he decides to leave for the next three years. I don't think that's fair at all. They should be able to leave penalty-free. If the coach leaves, I think they should be free as well. The trust and faith placed by the student-athlete on the head coach and the affiliation of the basketball program in the head coach indicates a major shift occurs when a coach departs an institution. Therefore, as previously indicated, the rise of the transfer studentathlete pool (Woods, 2017) occurring simultaneously alongside the increase in Division I men's basketball head coach movement (Winn, 2015a) creates a dilemma of causality in men's basketball.

\section{Summary}

The purpose of this study was to explore the transfer experience of the Black men's basketball student-athlete through the redshirt year-in-residence in Division I men's basketball. Schlossberg's (1981) transition theory was used as a framework to 
examine the advantages and disadvantages experienced during the redshirt year for transfer student-athletes. The transition experience was evaluated with Schlossberg's (1995) 4 S's (i.e., situation, self, supports, strategies) framework. The study was also framed by Critical Race Theory (CRT) to examine the what, why, and how of human behavior as it pertains to race and racism (Glesne, 2016; Matsuda, Lawrence, Delgado, \& Crenshaw, 1993; Scheurich \& Young, 1997; Solórzano \& Yosso, 2001).

Data provided insight into how counter-storytelling reflected the experiences of the Black Division I men's basketball student-athlete through the redshirt process. The key to applying Schlossberg's (1981) transition theory to the present study was to prioritize each participants' individual perceptions of the transition rather than the transition itself. Schlossberg's (1995) 4 S's provided the framework to do so. The integrated analysis of inducted and deducted codes and themes from the interviews through the lens of Schlossberg's (1981) 4 S's system provided accuracy and consistency in data interpretation.

Each of the 15 participants in the study expressed advantages they were afforded due to the redshirt year. Such advantages were identified from holistic, academic, and basketball perspectives. Disadvantages, although not as often described, were also apparent from holistic, academic, and basketball perspectives. Despite the abundance of advantages afforded to each of the participants through the current redshirt policy, just three of the 15 participants expressed support for the policy going forward. Twelve of the 15 participants suggested various improvements or expressed opposition altogether. The contrast between the advantages and the disapproval of the policy is of concern. 


\section{CHAPTER V}

\section{DISCUSSION \& CONCLUSION}

The current NCAA redshirt requirement for Division I transfer men's basketball student-athletes will likely be altered in the near future as the NCAA considers pleas for change from coaches, players, and fans (Ziller, 2016). The alteration or removal of the transfer redshirt requirement could result in disproportionately negative effects on Black student-athletes, as they will be pushed more quickly through an already discriminating exchange of academic benefits for athletic contributions at NCAA member institutions (Cooper \& Hawkins, 2014). Transition to new academic and social settings takes time for any student (Lazarowicz, 2015). In addition to the classroom and other campus social settings, student-athletes face an additional transition dynamic to a new athletic team, coaches, department, and fan base. Moreover, Black Division I men’s basketball players may face racial discrimination and other negative stereotypes at predominantly White institutions (Hawkins, 2010). Loosening or removing the transition-assisting redshirt year will likely perpetuate the already vast racial inequities of NCAA Division I athletics (Harper, 2018). Additionally, if the redshirt year were removed or loosened, rates of transfer would likely multiply.

Through the lenses of Schlossberg's (1981) Transition Theory and Critical Race Theory (CRT) (Glesne, 2016; Matsuda, Lawrence, Delgado, \& Crenshaw, 1993; Scheurich \& Young, 1997; Solórzano \& Yosso, 2001), the present study aimed to better comprehend the experiences and perceived advantages and/or disadvantages of the 
transfer experience and redshirt year experienced by Black Division I men's basketball student-athletes. Transition theory (Schlossberg, 1981) presents a useful framework with which to better understand the student-athlete experience while Critical Race Theory (Tate, 1997) simultaneously illuminates issues of systemic racism ingrained into Division I college athletics. Furthermore, counter-storytelling was encouraged during the interview process, as the researcher asked each participant if, and if affirmed, how, their race impacted their individual transfer transition and the redshirt year. As all participants $(n=15)$ transferred from one predominantly White institution to another, the researcher had the ability to inquire about the experience of each participant. The experiences and perceptions of Black Division I men's basketball transfer student-athletes were framed by two research questions:

RQ1. What are the transition experiences of Black Division I men's basketball transfer student-athletes with the redshirt year?

RQ2. What are the perceived benefits or drawbacks of the redshirt year requirement experienced by Black Division I men's basketball players? The research questions were answered through in-depth interviews with 15 former Division I men's basketball student-athletes who (a) identified as men of color, (b) exhausted eligibility between the 2013-14 and 2018-19 seasons, (c) transferred laterally during their undergraduate years, and (d) were required to participate in and completed an academic year-in-residence at the receiving institution. Purposive criterion sampling was used to access and solicit the eligible participants, and contacts were successfully made with participants through social media platforms, Twitter and Instagram. 
In this chapter, the researcher discusses the results from the study through the experiences and perceptions of Black Division I men's basketball student-athletes in two sections: a) the transfer transition, and b) perceived benefits and drawbacks. Implications for practitioners involved in the transfer transition processes of the student-athlete including coaches, athletics department staff, the NCAA, sport managers, and the student-athletes are also discussed.

\section{The Transfer Transition}

This study explored the experiences of Black men's basketball players from transfer to redshirt year through the lenses of Schlossberg's (1981) Transition Theory and Critical Race Theory (CRT) (Solórzano \& Yosso, 2001). Results of this study support Schlossberg's (1981) transition theory as an appropriate framework for examining the experiences of the student-athlete from one academic institution to another (Flowers et al., 2014). The key to successful application of Schlossberg's (1981) transition theory is the placement of priority on the individual's perception of the transition rather than the transition itself. To better understand the career of the student-athlete, it is necessary to focus on athletic, psychological, social, academic, and vocational development (Wylleman \& Lavallee, 2004). To discern the holistic development of the student-athlete, it is important to recognize the intersection of perspectives pertaining to the situation, self, supports, and strategies through the eyes and experiences of the student-athlete (Wylleman \& Lavallee, 2004).

According to Schlossberg (2011), transition factors include anticipation (situation), preparation (strategy), alteration capability (strategy), individual experience (self), and available support (supports). Transitions are significant when accompanied by 
shifts in roles, relationships, beliefs, or means of achievement (Schlossberg, 1984), all of which apply to the transfer student-athlete in Division I men's basketball. Participants reflected upon their transitions from initial institutions to receiving institutions by describing shifts to their own personal transition factors of situation, self, supports, and strategies (Schlossberg, 2005).

In accordance with Schlossberg's transition theory, to best conceptualize the individual transition experience of the student-athlete, it is vital to recognize the interactive nature of the situation, self, supports, and strategies (Wylleman \& Lavallee, 2004). Therefore, a single source of causality was often difficult to discern through the data. For instance, a situation affecting a participant's transition may be caused by a myriad of factors related to lack of support, an issue of self, and/or a failed strategy. However, it is difficult to identify a single precipitating factor for the transfer as all factors may be interrelated. Therefore, the interaction and fluidity between the four tenets of Transition Theory must be understood and appreciated when examining the following sections.

Athletes are in constant transition. Transition experiences for athletes include small, anticipated daily transitions from regular life into sport settings, to large transition events in the careers of athletes between teams or into retirement. Situations, according to Schlossberg's (1995) transition theory, involve the overall circumstances of the individual throughout the transition. The primary transition examined in this study occurred when a student-athlete was granted release from obligations with his initial institution, sought transfer, and subsequently attended another institution with the intention of playing basketball after a redshirt, or transition, year. Many observers 
unfamiliar with the transfer process might think that when a student athlete seeks transfer, he does so with a new school and scholarship offer in hand. However, this is one of the many often misunderstood processes of transfer. Instead, when a student athlete decides to transfer and is released by his initial team and university, the student athlete is no longer in possession of a full scholarship. He may be at further at risk as he is not guaranteed to receive a scholarship from another instition. The situation entered into by the transfer student-athlete is risky, uncertain, and often unguided.

Fourteen of the 15 participants identified reasons involving their basketball careers as factors contributing to the desire to transfer. These factors included coaching issues, level of play, and future professional basketball career aspirations. The lone participant who differed attributed his transfer decision to family issues; however, like all other participants, he transferred to a Power Five institution, suggesting he, too, had similar commitments to continuing of his basketball playing career. Flowers and colleagues (2014) had similar findings that participation in and experience with sport were primary catalysts for a decision to transfer. Moving closer to home, a higher level of play, and pursuit of a more notable team in a higher profile conference with increased potential for future success also align with prior research by Alexander (2011).

While the decision to transfer was often motivated by experience with basketball at the initial instituion, the process of transferring may have negative academic repercussions for the student-athlete (Beamon, 2008). Often these consequences are not discussed with the student athlete at the initial institution or receiving institution. Student athletes may lose credit hours, be required to change academic majors, and/or may experience negative racial stereotypes in the classroom setting. Any or all of these 
experiences may result in a student athlete spending more time (e.g., a fifth

undergraduate year) at an institution to earn a degree.

From an academic advantage standpoint, six participants enjoyed the ability to transfer a second time without penalty due to the NCAA Graduate Transfer policy. These student-athletes earned their undergraduate degree in four years and were then, according to the policy, allowed to transfer again, without requirement to redshirt again, and play right away while pursuing graduate coursework. Additionally, two participants graduated in four years and elected to stay at their initial institution while beginning graduate coursework. The redshirt year gave eight of the 15 participants the opportunity to begin coursework toward a graduate degree while finishing up their athletics eligibility and still on their full athletic scholarship. This is a clear advantage to the transfer redshirt policy as it is currently in place.

In terms of academic concerns, participants described a plethora of issues. The stress associated with participating in Division I athletics significantly affects studentathlete academic performance (Stansbury, 2003), which was also evident in the present study. Instead of facing NCAA eligibility issues that could have been present with degree progress requirements, participants opted, when possible, to switch majors and maintain eligibility after their redshirt years-in-residence. This additional process of sacrificing academic interests to pursue athletic eligibility at the receiving institution the transfer student-athlete has potential to lead student-athletes to be considered less marketable in the future, as such majors provide student-athletes with limited future occupational relevance (Beamon, 2008). Members of the Knight Foundation Commission on Intercollegiate Athletics believe the NCAA stipulations on degree progress strongly 
influences the chosen field of study of student-athletes, as choices are now likely made to preserve academic eligibility instead of future career-related aspirations (Kulics, Kornspan, \& Kretovics, 2015; Wolverton, 2005).

The psychological characteristics and mindset of the person experiencing a transition affects the decision-making processes and abilities to cope through the transition. Through participation in intercollegiate athletics, student-athletes are afforded social, academic, and physical benefits (Singer, 2008). However, student-athletes also experience unique psychological issues throughout their college sport careers (Kissinger \& Watson, 2009). Transfer student-athletes must be self-reliant through the process (Flowers et al., 2014). The more control the individual has over decisions being made through the transition, the more positive he will consider the transition experience (Coakley, 2006).

Transfer student-athletes motivated to transfer by the pursuit of a professional sports career place themselves in jeopardy of failing academically (Robbins, 2015). Aspirations of professional sport careers are a main goal of student-athletes in revenuegenerating sports, although focusing on educational pursuits would likely and more dependably serve the student-athlete lifelong (Bimper et al., 2012). Participants in this study pursued the transfer transition to follow dreams they set for themselves either before or during their college basketball career. The opportunities afforded to participants if they elected to transfer opened doors to professional sport careers not likely to open if they remained at their initial institutions.

Attending an institution, and therefore playing basketball in a Power Five conference provides student-athletes an elite environment to develop and a national stage 
from which to shine. For instance, of the 30 first-round draft picks in the 2018 NBA Draft, 21 (70\%), hailed from Power 5 institutions (Forgrave, 2018). If playing the odds, playing basketball at a Power 5 institution can be beneficial for a college basketball player with aspirations to play in the NBA. However, as indicated throughout the interviews, it is a balancing act, as players must also have the ability to show their skills and abilities on the court and statistically. In terms of the current study, the professional aspirations applied, as 13 of 15 participants are currently playing professional basketball either domestically or overseas.

The longevity of a professional basketball career is, in reference to the span of a lifetime, fairly short. The average NBA career is approximately five seasons (Coon, 2011), and even though players then have options to continue either in the G League or overseas, the time away from family and friends can be taxing, particularly when the pay is not as enticing as the NBA. Therefore, although a professional basketball career can pay off immensely, a college degree can provide post-professional sport career former student-athletes with more options. Although all 15 participants in the present study were fortunate to find a receiving institution, hundreds of student-athletes each year depart from their initial Division I institution and are not received at another Division I institution. Those athletes must settle for either attending a Division II, Division III, NAIA, or NJCAA institution, or otherwise do not have the opportunity to continue their college basketball career at all (Cleveland, 2017).

When specifically focusing upon Black men's basketball student-athlete transfers, specific factors come into play with the student-athlete experience. According to the NCAA, a core value of its collegiate model of athletics promotes a space where student- 
athletes are supported in their balance of academic, social, and athletics experiences (NCAA, n.d.c.). However, NCAA rules and policies simultaneously reflect a racial and cultural bias, as Black male student-athletes, when compared to their White teammate counterparts, consistently underperform academically as indicated in APR and graduation rates (Baker \& Hawkins, 2016; Bolen, Rezek, \& Pitts, 2017). For instance, the NCAA uses a six-year scale when evaluating graduation rates of student-athletes. However, the NCAA simultaneously restricts student-athletes to a five-year window to compete in four seasons of sport (NCAA, n.d.c.). Therefore, the data according to the NCAA is often skewed (Donnor, 2006). Additionally, social isolation can further perpetuate such biases and underperformance issues in Black transfer student-athletes.

Emphasis placed upon student engagement social activities for transfer students is a necessary component of transfer student assimilation; however, such engagements are rare and almost non-existent for Black students on predominantly White campuses (Nuñez \& Yoshimi, 2016; Wang et al., 2017). As transfer student populations are on the rise, on-campus personnel must focus upon providing and promoting events celebrating and including diversity. Career intervention programs can be beneficial in assisting the facilitation of career transition for athletes when supplied at the organizational level (Gordon \& Lavallee, 2012). Additionally, athletics departments must place more value upon the on-campus experience of the student-athlete and provide support for those wishing to attend such events.

Sport is a social experience; therefore, the perceptions of other people during the transition of the individual, including fans, peers, coaches, and family members, have an impact on the transfer student-athlete experience (Pearson \& Petitpas, 1990). Student- 
athletes have a strong need for support when transitioning into a campus environment (Workman, 2015). Black male student-athletes report experiences participating in sport at PWIs that directly impact their academic success and social support (Carter-Francique et al., 2013). Although Flowers et al. (2014) found transfer student-athletes to be self-reliant through the transfer transition, the present study provides evidence that transfer studentathletes employ a strong, albeit narrow, network of supports during the transfer and redshirt process.

Although the support networks reported through the interviews were narrow by choice, it is alarming to note how little the participants sought or received support from non-athletics personnel on campus. Additionally, participants often did not socialize with non-athlete students on campus and chose to keep their social support circles small. This issue can also potentially be attributed to a causality dilemma as to whether studentathletes choose such narrow networks due to choice or lack of availability, and whether or not the lack of availability is due to the frequency of student-athlete choice. According to Frazier (2012), the campus community appreciates and values athletes when they perform on the field more than when they participate in the classroom. Faculty, staff, and support members often embrace Black student-athletes and fight for their rights while simultaneously expecting recognition with potential for personal gain (Harper, 2009). Transfer student-athletes, who are acclimating to a campus for the second time, are likely to choose even more narrow non-athletics support networks. Thirteen of the fifteen participants indicated they did not branch out from their narrow network through athletics. 
The most frequently credited support entity throughout the interviews was family. Credited family members included parents, siblings, and extended family members who provided support for the transfer student-athletes. According to Carter-Francique et al. (2015), social networks, most often comprised of parents and extended family, provide emotional and instrumental support for Black student-athletes at PWIs. According to Hawkins (2010), family structures have a direct influence upon the transition experience of a student-athlete. Family members, regardless of physical proximity to the receiving campuses of the participants, provided moral support through the transition.

As previously stated, when transfer student-athletes request their release and begin the transfer process, they lose guidance and direction from coaches and athletics support staff members at their initial institutions. The support from the coaches and athletics staff members at the receiving institution is integral to the transition of the student-athlete. According to Weathington et al. (2010), student-athletes report lower levels of stress when also finding their head coach likeable. As indicated throughout the interviews, coaches who were available to their student-athletes during transition provided a safe space for them to acclimate. The support of coaches during the redshirt year was extremely valuable to the participants, as it gave them the coaching and resources needed to improve their skillsets.

Participants reported feeling a gravitation toward socializing with teammates and other student-athletes when they arrived at their receiving institutions. Teammates in particular were credited with welcoming the transfer student-athletes and making their acclimation easier. The more accepting and supportive the team welcoming the studentathlete is through providing socialization, the more successful his acclimation to the team 
will be (Lewis, 1980). Student-athletes have regimented schedules and lack the flexibility and freedom non-athlete students possess, and therefore, participants explained studentathletes often stick together. Additionally, according to the participants in this study, transfer student-athletes arrive on campus older than traditional freshmen and are not afforded the same socialization opportunities.

Participants used strategies, or plans of action, to assist in their navigation of the transfer process and redshirt year. The more quickly a student-athlete transitions and acclimates to a new environment, the easier and more positive the transition experience (Coakley, 2006; Louis, 1980). Therefore, the more successful the strategy of the studentathlete, the better their transition experience. Participants described executing basketballrelated strategies to advance their college basketball careers and increase their likelihood to play professional basketball in the future. Participants also utilized strategies were also utilized by participants to blend into their new, predominantly White campus environment as seamlessly as possible.

Anticipated transitions are the easiest to navigate for transfer student-athletes (Flowers et al., 2014). The more the participants expressed an understanding of the transfer transition processes and how to utilize the redshirt year to their advantage, the better their experience with the transition. All 15 participants explained that the decision to transfer was made by them, and while they may have consulted support systems, the decision was theirs to make. Therefore, participants in this study had the opportunity to anticipate their transfer transition. Anticipating the events, issues, and roadblocks that may occur during the transfer transition 
Participants were relieved of pressures to fight for playing time or play in games and travel during the redshirt year. Some participants had the opportunity to take advantage of a year to develop their individual abilities. Although in hindsight it is difficult to discern if the redshirt year was a necessity for the participants to play professional basketball, 13 of the 15 participants are currently professional basketball players.

\section{Perceived Benefits and Drawbacks of the Redshirt Year}

As of Spring 2019, the NCAA Division I Transfer Working Group is gathering data and analyzing the effectiveness of the current policies requiring the lateral transfer redshirt year-in-residence (Hosick, 2018a). However, the Transfer Working Group is inquiring about the redshirt year by evaluating perceptions of current student-athletes and coaches who have valid opinions. The implicit biases that are associated with both groups to ensure student-athletes have immediate eligibility for competitive advantage likely overshadows the incorporation of the opinions of the transition experiences of the transfer student-athlete through the redshirt year. Therefore, the present study aimed to fill such gaps by interviewing former Division I basketball players who laterally transferred and experienced the redshirt year. None of the 15 participants indicated they had been contacted by the Transfer Working Group, indicating the opinions and experiences of recent former transfer men's basketball student-athletes are not obtained or utilized in the examination of the redshirt policies. It is therefore likely this study fills gaps in the current understanding and evaluation of the transfer policies and processes in Division I men's basketball. This study has immediate implications with the Transfer Working 
Group as it provides a perspective not otherwise included in the analysis of the NCAA redshirt policies.

It is difficult to measure the present study against other research, as no other studies which evaluated the benefits or drawbacks of the redshirt year for student-athletes were found in the literature search. Understanding of the transition experiences of the transfer student-athlete provides context to the perceptions of the benefits and drawbacks of the participants as well. In addition, the complete focus on the experiences and perceptions of Black transfer student-athletes through the transfer transition and their reflections of situation, self, supports, and strategies as well as their reflection upon their cover and overt experiences with race gave a voice to an underserved population on the predominantly White campus.

A holistic evaluation of the Black men's basketball transfer student-athlete experience requires an evaluation of the academic, athletic, and cultural experiences of the participants (Magolda, 2009). Although not always planned or expected, the participants reported many advantages of the redshirt year related to the interactions of their academic, athletic, and cultural experiences interacted. For instance, academic advantages gleaned from the redshirt, like the ability to begin a graduate degree, also provided participants the time and flexibility to develop their basketball skills. Basketball advantages gleaned from the redshirt, like the time to work exclusively to develop from an individual perspective, allowed participants time to acclimate to campus socially and culturally.

Participants expressed the redshirt year gave them time to heal from unfortunate circumstances with teammates or coaches at their initial institutions. Beginning again 
with a new overall identity allowed student-athletes to shed old bad habits and start fresh with the adjustment period the redshirt year provided. What is often not acknowledged when discussing the student-athlete experience is that they, too, experience the same, ordinary problems as other non-athlete students or those similar in age (Watson, 2003). Young adulthood presents many problems and issues, and a monumental shift in daily routine is likely to impact any college-age person in many ways. The redshirt year is provided to student-athletes and required by NCAA policy to assist student-athletes with this significant shift (NCAA, 2017b).

Participants expressed how the redshirt year gave them the ability to grow and develop personally from a self-maturation standpoint. However, advantages and disadvantages also mixed from a holistic perspective. The redshirt year provided time for academic flexibility for student-athletes while also requiring an additional basketball season which could have been spent at the professional ranks. Therefore, from a holistic perspective, the advantages and disadvantages of the redshirt year varied with each of the 15 participants and depended on the productivity of the participant.

Each participant $(n=15)$ in the study was placed at various levels of academic disadvantage through the transfer process. Although 4 of the 15 participants did not elect or were not required to change their majors through the transfer transition and still graduated in four years, they too were met with academic obstacles of credit transfer and academic acclimation. NCAA policies of progress-toward-degree requirements likely affect the eligibility of the transfer student-athlete (NCAA, n.d.c.; Townsend, 2012), and student-athletes making decisions aiding in the pursuit of a professional sport career are more at risk to compromise on academic decisions to ensure eligibility. 
The additional redshirt year gives the student-athletes options and opens doors to academic success. There is an advantage to maintaining a four-year academic course to earning a degree, as the fifth year then provides an opportunity for student-athletes to begin coursework in a master's program. Additionally, a four-year undergraduate graduation gives the student-athlete the option of transferring again without penalty as a graduate transfer.

During the recruiting process as high school students, prospective student-athletes are wooed by college coaches selling their basketball programs and universities, leading most recruits to choose a university for athletics-related reasons (Schneider \& Messenger, 2012). Therefore, it is not shocking that 14 of 15 participants in this study were motivated to transfer from their initial institution due to basketball-related reasons. As previously indicated, $n=14$ participants decided to depart their initial institutions and transferred for basketball-related reasons. Basketball as the catalyst for decision-making also supports the perception of the pampered student-athlete motivated solely by athletics participation (Ferrante et al., 1996).

Each participant indicated he benefitted from a basketball perspective from the redshirt year; however, participants also explained there were disadvantages to the redshirt year from a basketball perspective. The redshirt year keeps student-athletes in the collegiate ranks an additional year, causing them to enter the NBA draft pool at an older age which, as indicated by the participants, takes away from the marketability and draftability. The student-athlete, however, is not required to spend his fifth year playing college basketball and can, in fact, leave at any point after one calendar year after his high school graduation date to pursue a professional basketball career in the NBA. The 
calendar year is not required for a professional career overseas. Therefore, the redshirt year provides a give-and-take to the student-athlete to support any academic troubles with the transfer and support the student-athlete to grow from an athletics perspective while simultaneously placing him at a disadvantage from an NBA draft perspective.

Each of the 15 participants in the study expressed advantages they were afforded due to the redshirt year. Such advantages were identified from holistic and personal, academic, and athletic perspectives. Disadvantages, although not described as often, were also apparent from holistic, academic, and basketball perspectives. Despite the explanation of the benefits afforded through the current redshirt requirement, 12 of the 15 participants expressed opposition to the policy and expressed a need for alteration or removal altogether. The disconnect between experiencing the benefits while simultaneously opposing its necessity is attributed to a larger issue in the perception of Division I men's college basketball disproportionately impacting Black student-athletes.

The focus placed upon basketball as a catalyst for the decision to transfer without regard for academics, for the participants in the present study, did not hinder the pursuance of a professional sport career, as 13 of 15 participants are currently playing professionally. The perception of the lack of necessity or support of the redshirt year from a Power 5 perspective is alarming, as the Power 5 conferences are in the position to change policy. However, the likelihood of a lucrative professional sport career is lower for mid- to low-major NCAA student-athletes and therefore the perception of the redshirt year and subsequent potential alteration could disproportionately impact the majority of student-athletes in the US. From a CRT perspective, Black male student-athletes are already more likely to pursue and expect professional sport careers than their White 
counterparts (Kennedy \& Dimmick, 1987) because Black male student-athletes often believe they will be treated more fairly in the professional sport industry than other career industries (Donnor, 2005). Black student-athletes are more likely to invest into and interpret their interscholastic sport careers as a pathway to achieving their career goals (Donnor, 2005). Therefore, the transfer process could disproportionately impact Black student-athletes.

Critics, like the participants in the present study, question the legitimacy and effectiveness of the NCAA core values placed upon the holistic experience of the student-athlete (Davis, 1996). What is most alarming through the present study, however, is the disconnect between the benefits and the support of the redshirt year. As indicated in the results, Black transfer student-athletes have unique transition experiences on PWI campuses. Black student-athletes are failed academically by their institutions (Smith et al., 2016) and yet, a current policy in place to assist the transition of the student-athlete, according to 12 of the participants, is not necessary for the Black student-athlete experience even though it provides countless benefits.

The redshirt year provides holistic, academic, and athletic benefits to the studentathlete, and particularly to the Black student-athlete. Reestructure of current NCAA policies requiring the redshirt year is imminent; however, as the Division I Transfer Working Group is, as of Spring 2019, gathering information and examining alternatives to the redshirt year (Goodman, 2016). Therefore, it is crucial and timely to better understand the experiences of the redshirt year from the perspective of the studentathletes who experienced it first-hand. 


\section{Critical Race Perspectives}

According to Cooper and Hawkins (2014), NCAA Power Five institutions have predominantly White student bodies and are often considered unfit to meet the needs of Black male students. By transferring to and from PWIs, Black student-athletes likely repeatedly expose themselves to campus environments in which they may experience racism or other stereotypes often attributed to Black student-athletes. As evidenced by participants' stories, often experienced racism occurring at either their initial or receiving institutions. With basketball as the main catalyst for the transfer transition, Black studentathletes are likely putting themselves in situations lacking diverse and inclusive communities or ideals. Although not the solution, the redshirt year provides a buffer for the transitioning student-athlete to find comfort and safety at his receiving institution, even if it presents an uncomfortable, unwelcoming, or hostile racial situation for the student-athlete.

Statistically, Black male students represent $2.5 \%$ of the undergraduate student population at the 65 Division I Power Five institutions. Men's basketball rosters are approximately 61\% Black (Harper, 2016). Academically, Black male student-athletes graduate at a lower rate $(53.6 \%)$ than Black male non-athletes $(58.4 \%)$. The general student population at Power Five institutions boasts a 75.4\% graduation rate (Harper, 2016). The overall Division I men's basketball graduation rate, as reported by the NCAA (2016), is 78\%. All fifteen participants in the present study earned, at the very least, their undergraduate degrees, and at most, earned credits toward a graduate degree. However, in the absence of the redshirt year, $n=6$ participants would have exhausted their NCAAallotted eligibility before successfully graduating with an undergraduate degree, setting 
the four-year graduation rate of the transfer student-athlete participant pool at $60 \%$. While this rate is significantly higher than the graduation rate of Black male studentathletes (53.6\%), it is significantly lower than the graduation rate of Division I men's basketball student-athletes (78\%). The academic cushion provided by the redshirt year, therefore, alleviates issues with transferrable credits and academic acclimation vital to the transition process (NCAA, n.d.c.).

It is necessary to examine the academic experiences of Division I Black men's basketball student-athletes to conceptualize how to improve and better attain more inclusive practices on predominantly White campuses (Cooper \& Hawkins, 2014). Although each of the fifteen participants did, in fact, earn an undergraduate degree, as it was included in the criteria for the study, six participants did not do so without the help and addition of the fifth year of athletic eligibility. As not a single participant in the study $(n=0)$ attributed academics as the catalyst in their decision to transfer, participants did report both academic advantages and disadvantages throughout their transfer transition. To varying degrees, the transfer put participants' paths to academic success in jeopardy, as they were subjected to issues with credit transfer, degree progress, major availability, and NCAA academic standards for eligibility. As student-athletes in revenue-generating sports like Division I men's basketball are more likely to fail academically due to emphases placed on sport over academics (Simons et al., 1999), the 14 participants attributing their transfer to their basketball careers presented heightened risk of academic failure. Additionally, Bahr (2009) found lateral transfer resulted in a lower likelihood of obtaining a credential or degree. 
As evident in this study, the nine participants who elected to change their major either did so because their receiving institution did not offer the major in which they were already progressing, or they switched majors to maintain academic eligibility through degree progress qualifications set by the NCAA. Major selection disproportionately affects Black student-athletes negatively if athletics is the primary catalyst for choice of major due to practice times and level of "athlete-friendliness" (Bimper, 2015). In a study by Bimper (2015), Black student-athletes at PWIs identified their major not as their choice, but instead as a process directed by athletics. As also indicated in the present study, Black student-athletes are more likely to pursue a major that allows them to participate in sport over pursuing a major of interest for their future career (Beamon, 2008). Although 53.6\% of Black student-athletes do, ultimately, earn a degree (Harper, 2016), they also report not fully reaping the benefits of their education (Beamon, 2008). The hindrance and lack of support for pursuing academic interests leaves Black studentathletes ill prepared for careers outside professional sport and perpetuates and reproduces inequalities on the PWI campus (Beamon, 2008).

The past and present White patriarchy in the United States has disproportionately failed, and continues to fail, Black men (Smith et al., 2016). The stereotypes of Black Division I male student-athletes are detrimental to their academic experience and performance (Beamon, 2014; Beamon \& Bell, 2006; Bimper et al., 2013; Martin et al., 2010; Sailes, 1993). Additionally, Black student-athletes are more likely to experience academic probation, suspension, and academic ineligibility than White student-athletes (Beamon \& Bell, 2006). Adding in the transfer transition to an already clouded and 
detrimental perception of the Black student-athlete on campus adds unique roadblocks to the matriculation to a new campus and pathways to graduation.

Academic clustering occurs when 25 percent or more of the roster of one specific athletics team is enrolled into a particular major on a single campus. It occurs most frequently in two Division I revenue sports, men's basketball and football (Fountain \& Finley, 2011). Fountain and Finley (2009) found academic clustering included both White and Minority football student-athletes; however, the phenomenon occurs more frequently with Minority student-athletes. Although academic clustering impacts native student-athletes most often, it has the capability to doubly impact transfer student-athletes who may be academically clustered at their initial institution, transfer to their receiving institution, then be academically clustered again. The second academic clustering likely occurs most often, as again, Black student-athletes are more likely to choose a major that allows them to participate in sport over their major of interest (Beamon, 2008).

As an oscillating migrant laborer navigates internal colonial relationships while they pursue the most viable opportunities available (Hawkins, 2010), so too does the Black Division I transfer student-athlete navigate his transfer transition from one predominantly White institution to another. Prior to the men's basketball transfer studentathlete requesting his release, he cannot contact other institutions to gauge interest and must take the risk, when requesting his release, that he may not find another institution to attend (NCAA, n.d.c.). When the transfer student-athlete requests his release from his initial institution, that institution can, and will likely, cease to provide any logistic or academic assistance through the process. Once released, the transfer student-athlete is on his own, with the exception of his personal support network, until he successfully 
navigates the re-recruiting process and commits to his receiving institution. Therefore, when a transfer student-athlete is released, he loses structure and guidance that had been provided by the institution. Not until he is re-committed does he re-gain guidance and direction through the process.

Although Black male student-athletes are underrepresented on the predominantly White campus, they experience hypervisibility and are subject to hyper-surveillance during their athletics careers (Smith, Mustaffa, Jones, Curry, \& Allen, 2016). These student-athletes are also given high-quality support systems by athletics departments to manage their academic and athletic tasks while on campus (Gayles, 2009). When they request their release to transfer, they are excluded and excommunicated from this guidance at their initial institutions. They then must navigate and pursue the transfer processes without access to guidance or direction. The drastic drop in support due to the transfer is likely to impact Black student-athletes disproportionately, as Black studentathletes must then navigate the predominantly White campus without the status of student-athlete and the subsequent benefits (Hawkins, 2010). Additionally, Black transfer student-athletes feel like outcasts (Cooper \& Hawkins, 2014), and as the value of the Black student-athlete is often based solely upon athletic performance (Hawkins, 2010), the disappearance of athletics guidance for the Black student-athlete can be devastating. Black student-athletes reported feelings of under-preparedness for the transfer transition which often occurred after an unfortunate or negative experience at their initial institutions. The lack of preparedness puts transfer student-athletes at risk for academic failure, athletics ineligibility, or the inability to find a receiving institution. Additionally, 
participants in the study experienced hostile situations based on their race on both initial and receiving campuses.

Athletes often experience the "transition blues" during the transfer process, as emotions and feelings can be unexpected (Saxe et al., 2017). Black student-athletes describe feelings of detachment, exclusion, and separation from other students and teammates on campus (Sato et al., 2017). Isolation on predominantly White campuses has a disproportionately negative impact on students of color and leads Black student-athletes to drop out or achieve little to no academic success (Simiyu, 2012). Transfer studentathletes, in particular, are confronted upon arrival at their receiving institution with unfamiliar social groups and dynamics and may lack the ability to cope with their transition.

Coakley (2009) identified six factors of isolation, as experienced by the transitioning transfer Black men's basketball student-athlete, that erode academic commitment and capability: 1) Racial and athletic stereotypes compromise social relations supporting academic success; 2) The amount of time consumed by athletics takes away time for academics; 3) Campus activities on PWI campuses fail to accommodate Black students, leading to further isolation; 4) Campus life is not appealing to Black students and leads to withdrawal; 5) White students' discomfort with Black students due to lack of experience with diversity; and 6) White students' perception that Black students are privileged, creating tension and undermining any natural social interactions. Adding the layer of the transfer transition into the isolation already felt by Black students on campus creates a much harder road for Black Division I transfer men's 
basketball players to feel welcome, and not isolated, on the campus of their receiving institution.

Murty and Roebuck (2015) also reported Black student-athletes felt unwanted at non-athletic events on campus, including after-class meetings with faculty and fellow students. Participants also echoed this fact, saying they did not feel welcomed and would rather keep to themselves than to force social interactions on campus. This often leads Black student-athletes to create their own peer groups, as indicated by participants who identified fellow student-athletes as primary sources for friend groups. This social isolation perpetuates feelings of inferiority and stigmatization on predominantly White campuses (Murty \& Roebuck, 2015).

Participants described a heightened awareness on campus when socializing with other students and community members. Black student-athletes at PWIs are constantly in negotiation with their identities to navigate the Whiteness, privilege, and stereotypes impacting their social identity on campus (Bimper, 2015; Bimper et al., 2013). Therefore, it is not shocking to discover Black men's basketball student-athletes prefer to socialize with fellow teammates, who are 61\% Black (Harper, 2016).

Of the 36 total institutions attended by the 15 participants in this study, all 36 were predominantly White institutions. Each of the 15 participants in the study transferred to and from predominantly White institutions throughout their careers. Transferring into a new environment placed Black student-athletes into the minority, time and time again, and presented participants with the task of acclimating and blending in. Participants utilized strategies of diffusing any race-related instances on campus during their transition into their new environment. They expressed an understanding of the 
White campus culture and their actions were dictated by how their perceptions influenced their presence on campus.

Generally, team sport athletes are expected to blend in, as creating and fostering a sense of team and community within the team structure is paramount to the success of the team (Warner \& Dixon, 2011). Sport teams generate a "pack mentality" and thrive on cohesion and unity (Warner \& Dixon, 2011). However, the Whiteness of the team structure, particularly on the PWI campus, can overshadow the Black male identity, thereby generating disconnectedness and racial misplacement of the Black athlete (Armstrong \& Jennings, 2018).

Lewis, Chesler, and Forman (2000) found Black students face a paradox of blending in at PWIs while simultaneously being racially stereotyped and challenged, thus illuminating their group characteristics and differences from the White student body. Race, either covertly or overtly, often structures discourse surrounding sport in the United States, as racialized assumptions and expectations shape perception (Love \& Hughey, 2014). A decrease in overt, publicly expressed racism in sport in the United States has been evidenced (Hylton \& Lawrence, 2009; Love \& Hughey, 2014), as the racial terrain of sport has followed societal evolutions (Bimper, 2015). However, the minimization and dismissal of the existence of racism as it applies solely to overt expressions disqualifies the subtle, covert, and more modern forms of racism that still exist in abundance in US sport (Bimper, 2015). For instance, AJ explained, "I don't feel like, with the people I did meet, my race really mattered." Trevor explained his perceptions of his race on campus, saying, "My experiences with these predominately White schools in different regions of the country was pleasant. I have nothing but positive things to say about the whole, you 
know, racial divide." Therefore, such discourse and disqualification of racism was evident through the interviews in the portrayals of experiences with race of the participants in the present study.

From a holistic perspective of Black transfer student-athletes, the redshirt policy required Black student-athletes to remain on a predominantly White campus for an additional year. All but one $(n=14)$ participants in the present study elected to spend their allotted fifth year on campus. While the redshirt year provided flexibility and adjustment for the transition experiences of the Black student-athletes, it also kept student-athletes on campus an additional year. The choice to transfer was freely made by each of the participants; however, the policies of the redshirt requiring the year in residence and ultimately another year in a PWI campus environment. This additional year may be detrimental to the holistic wellbeing of the Black student-athlete as it alienates the Black student-athlete and distorts visibility within either his home community or university community (Hawkins, 2010), likely perpetuating a year longer than what is potentially necessary if he remained at his native institution for the entirety of his career and graduated in four years.

Academic clustering can aid in the eligibility of student-athletes (Fountain \& Finley, 2009). As Black student-athletes are more often clustered academically than their White counterparts, it is likely academic clustering has a disproportionately negative impact on the Black student-athlete population. In the case of the present study, as $n=9$ participants were required to change their majors upon transferring to their receiving institution, academic clustering can happen to transfer student-athletes each time they transfer. As indicated by participants, academic decisions were made to ensure athletic 
eligibility. Therefore, with the NCAA transfer policy in place as it is, Black transfer basketball student-athletes can use the redshirt year to either maintain their majors, as $n=$ 6 participants in the present study were able to do, or allow flexibility in choosing another major with the aid of the additional undergraduate year.

Student-athletes in the high-profile sports of football and men's basketball do not perform as well academically as the general student body population (Eitzen, 2016). Additionally, student-athletes in revenue-generating sports like men's basketball are more likely to fail academically than non-revenue generating sports (Simons et al., 1999). If the redshirt policy were rescinded, the transfer student-athlete graduation rate, and more specifically, the Black transfer student-athlete graduation rate, would likely plummet.

\section{Limitations}

There are a few limitations to the present study. Transferability relies upon richness of descriptions through the capture of the essence of a phenomenon and how applicable it is to another setting or group (Marshall \& Rossman, 2011). While the selected population of Black former Division I men's basketball transfer student-athletes was necessary for accessability purposes, the results of this study may not be transferable to, for instance, female transfer student-athletes or transfer student-athletes representing other sport populations. This study, however, provides a baseline framework for an otherwise unexplored phenomenon affecting a rapidly growing population of studentathletes not previously examined. The method of the present study provides a framework for future research of student-athlete transfers in other intercollegiate sports (Marshall \& Rossman, 2011). 
Utilizing social media to establish a connection with the participants presented many challenges. Representation on social media is not guaranteed in terms of legitimacy, and an abundance of fake profiles involving misrepresentation or impersonation exist, calling into question the authenticity of users (Smith, Smith, \& Blazka, 2017). Fake social media accounts can lead to users being catfished, or deceived through false online representation (Harris, 2013). Therefore, it was imperative for the researcher to represent herself as legitimately as possible through her social media profile which included institutional affiliations, basketball affiliations, and current occupation. Additionally, to establish rapport, the researcher exhibited an understanding of the background of the participant (Denzin \& Lincoln, 2003) as a former Division I basketball player who transferred. Once participants responded to the inquiry for an interview, the researcher began to build rapport by making responses as personable as possible, using shared language from the researcher's experience in college basketball, and accommodating any necessary schedule conflicts to ensure the interview was conducted. This included scheduling and conducting interviews at all hours of the night, as participants were living in many different time zones around the world.

Data collection was limited in its scope, as the study included one interview per participant as well as any affiliated demographic information. However, the purpose of the study was to explore the Black basketball student-athlete's transfer experience and examine their experiences through the redshirt year. To do so, interviews provided the most direct insight into the phenomenon. Morse (1994) recommends at least six participants for a phenomenological study, and since the present study included 15 interviews, the richness of the data is present, as the population of this study was fairly 
homogenous, and interview questions were considerably structured (Guest, Bunce, \& Johnson, 2006).

\section{Potential Implications}

As the climate of NCAA Division I men's basketball changes, there exists an increase in the need to explore new aspects in sport management research. Although NCAA rules and policies change each year, others have remained stagnant and have not improved or evolved with the changing climate of college athletics and the shifts in the makeup of the student-athlete population. The focus the NCAA places on the growth, well-being, and support of the student-athlete is evident in its mission and vision, however, athletics departments and affiliated employees are often more concerned with wins and losses than the futures of the student-athletes.

The vast majority of higher education literature examining the college transfer student focuses upon community college, or 2-year transfer to 4-year traditional institutions (Harper, 2009; Jain et al., 2016; Nutting, 2008; Swigart \& Murrell, 2010; Wassmer, Moore, \& Shulock, 2004; Wood \& Palmer, 2016). With the meteoric rise in numbers of transfer student-athletes in Division I men's basketball and the implementation of the Division I Transfer Working Group presently reviewing and analyzing the policies of the redshirt year, it is timely to present the current research. The voices and stories of those most affected by the policies, the transfer student-athletes themselves, have not been heard.

Focusing on the Black men's basketball student-athlete experiencing the transfer brings to light many inequities in NCAA college athletics. Although participation opportunities are plentiful for Black student-athletes in men's basketball, the academic 
and social climate on the PWI campus puts them at a distinct disadvantage (Davis, 1996). With the addition of the transition support necessary for Black student-athletes to successfully acclimate to their new campus, transfer student-athletes, as indicated by the present study, are in dire need of time to adjust academically and socially. Removing the transfer redshirt rules could result in Black student-athletes losing even more academic return on their athletic investment as the NCAA academic system would push them through even faster (Cooper \& Hawkins, 2014).

This study gave a voice to the Black men who have first-hand experience with the redshirt policy as it currently stands. Results of the study showed 15 of the 15 participants received direct benefits from the redshirt year. Each individual transfer student-athlete transition is different, and therefore, the needs and requirements of the student-athlete differ. It is important to understand how the transfer transition as well as the studentathlete's race impact the ability for the transfer student-athlete to cope from both the researcher and practitioner standpoints.

\section{Implications for Research}

The present study provides a unique perspective not otherwise explored in sport management literature---the four-year to four-year transfer student-athlete. By examining the transition experiences of Black Division I men's basketball players with focus upon the transfer redshirt requirement, this study is the pioneer exploration of a phenomenon not otherwise present in the literature. The gaps in both available higher education and sport management literature, as identified in previous sections, are vast, as studies have not examined the lateral transfer student or the lateral transfer student-athlete. Particularly as the transfer student and student-athlete population continues to grow each scholastic 
year, it is necessary for the research base to continue to expand to better understand the transition needs of the population.

The findings in the present study support Schlossberg's (1995) Transition Theory as an appropriate framework to examine the transition experiences of Black Division I men's basketball lateral transfers through the transfer and redshirt year. The individual person's interaction from the perspective of the situation, self, supports, and strategies indicates transition to a new academic and social setting takes time for any student (Lazarowicz, 2015). Additionally, the framework supplies data that captures the transition experience. This framework is likely to serve research focusing on other transfer student and student-athlete populations such as Division I women's basketball players (Flowers et al., 2014) in the future to identify differences from and similarities with the present study.

The overarching goal of critical race theory (CRT) is to eliminate racial oppression (Matsuda et al., 1993). If used effectively, CRT can generate a theoretical vocabulary to better comprehend racial ideologies (Hylton, 2005). The added layer of CRT in the present study strengthens the research and provides a lens to evaluate the Black transfer student-athletes on a PWI campus through counter-storytelling. The use of CRT in the present study illuminates the presence of racism in Division I college athletics as it impacts the growing population of Black transfer men's basketball student-athletes. Given the permanence of racism and Whiteness as the norm on the PWI campus (Cooper et al., 2014), it is important for researchers to properly utilize the lens of CRT, as the experiences of the Black student-athlete population cannot be generalized or understood without CRT. 
Though not the focus of the study, the use of social media sites for purposive sampling was a success and allowed the researcher to recruit a hard-to-reach sample. The researcher found success by representing herself legitimately through the use of her social media profiles and included institutional affiliations in her messages to the potential participants. Both Twitter and Instagram, as well as potentially other social media sites, give researchers a direct link to specific people. Previously, O'Connor and colleagues (2013) found Twitter provided access to participants and real-time responses; however, the specificity of the population for this study lent itself to Instagram. Both platforms, however, have the function of direct messaging along with Facebook, and can be used to send information and solicit potential participants. As the use of social media continues to increase, particularly in the millennial and Generation Z generations, it is likely these populations will continue to be accessible in this manner.

\section{Implications for Practitioners}

The present study has immediate and timely implications, as NCAA men's basketball representatives, along with the NCAA Division I Transfer Working Group are currently evaluating the redshirt policies (Hosick, 2018a). The present study provides a large piece currently missing from the puzzle: the experiences of former Division I transfer student-athletes with the redshirt year. Data collection required participants to recall their experiences from recent memory and provided experiences from a population who can fully reflect on their careers and how the redshirt year impacted their lives. The Transfer Working Group is collecting data from current student-athletes; however, Henderson (2013) found interviewing student-athletes during the moments of transition led to a lack of obtaining an accurate reflection on the experience. 
The exploration of the phenomenon as experienced by Black Division I men's basketball transfers will provide an indispensable perspective on the needs of this underserved population without agenda or pressure from media outlets or athletic departments. As a rules restructure allowing transfers without requirement of redshirt is imminent (Goodman, 2016), listening to the voices of those who have experienced the phenomenon will positively serve the future population.

Transitioning athletes are often placed in a neutral zone of unproductivity before initializing and embracing a fresh role in a new system with fresh responsibilities (Coakley, 2006). The more time it takes a student-athlete to acclimate to his new environment and surroundings, the less likely he is to find success (Louis, 1980). Therefore, the more quickly a student-athlete successfully navigates transition into a new environment, the better the transition (Coakley, 2006; Louis, 1980). It is the responsibility of the receiving institution, from athletics, academic, and social perspective, to support transfer student-athletes throughout the transition.

Institutions cannot perpetuate the post-racial narrative on campus (Bimper, 2015) as ignoring racial inequities will cause disproportionate damage to the Black studentathlete well-being both short- (Bimper et al., 2012; McCoy, 2014) and long-term (Comeaux, 2010). Black transfer student-athletes feel isolated from the campus community due to a lack of social support and acceptance on campus. Institutions must focus on improving racial diversity on campus and promoting inclusive environments and spaces for learning and collaborating (McCoy, 2014). Institutions must take the time to educate faculty on how to better promote inclusive environments for students. As faculty have shown to harbor stereotypes hurting the Black student-athlete (Comeaux, 2010), 
institutions must hold faculty accountable. Harper (2015) challenges institutions to push faculty to frequently examine their personal biases or assumptions about Black students. This concept, particularly on the Power Five campus, is necessary for the betterment of the faculty-student-athlete relationship.

Although athletics academic support centers further isolate student-athletes from the student population (Huml et al., 2014; Rubin \& Moses, 2017), the support provided by these centers is vital to the transfer transition. Support staff should be involved in the entirety of the transfer process, from the instant the transfer student-athlete contacts the coach with his release, and provide transparency and guidance from an academics perspective. Student-athletes should be educated and evaluate their transfer situation with all the academic details necessary to help with their decision. Once on campus, support staff must encourage transfer student-athletes to foster relationships with faculty, as developing social capital strengthens the experiences of Black student-athletes on PWI campuses (Bimper, 2017).

The initial institution the transfer student-athlete leaves must also improve its assistance to the transfer student-athlete. From a retention perspective, Division I institutions must do two things: 1) Put stronger value on keeping student-athletes native to their original institutions, and 2) Hold coaches accountable for losing student-athletes to transfer. Retention of student-athletes is key, as it presents an added expense to replace student-athletes through the recruiting process. In 2012, the NCAA reported that Division I institutions spent, on average per student-athlete, between $\$ 36,000$ (for NCAA Football Championship Subdivision schools) and \$102,000 (for NCAA Football Bowl 
Subdivision schools) (Fulks, 2013). Therefore, transferring student-athletes can cost athletics departments hundreds of thousands of dollars annually.

Generally, Division I institutions must value diversity when hiring positions of leadership across campus. People in power on the college campus can leverage their political capital to support initiatives and groups promoting diversity across campus (Harper, 2015). Black student-athletes need leadership in place to protect and promote them not just on the field or court, but in the classroom.

Black student-athletes are often exploited for their athletic abilities and academically failed by their institutions (Smith et al., 2016). It was troubling to discover, through this study, how former student-athletes felt about a current policy in place to assist in their transition. Although the redshirt year provides countless benefits to the transfer student-athlete, as it did for all 15 participants in this study, the athlete identity and sport-first mentality prompted 12 former student-athletes in this study to think the policy should change. The issue of putting sport over all is systemic and perpetuating the exploitation of student-athletes by removing the redshirt year would disproportionately impact Black student-athletes, as they are more likely to pursue professional sport careers and subsequently invest into and interpret their interscholastic sport careers as a pathway to achieving their career goals (Donnor, 2005).

Practitioners at all levels of sport have a responsibility to educate and promote the well-being of all student-athletes they serve through policy and practice. Athletic department employees directly associated with student-athlete development must remain diligent in their knowledge of current and proposed policies to better prepare studentathletes for any impending transitions. As the NCAA Division I Transfer Working Group 
will likely implement redshirt policy alterations in the near future (Hosick, 2018a), this responsibility is placed on student-athlete support staff members to educate both coaches and student-athletes on the changes and how they will affect the transfer transition going forward.

\section{Future Research}

The number of annual Division I men's basketball transfers is likely to continue to rise (Woods, 2017). As transfer student-athletes navigate the re-recruitment process and acclimation to a new campus, it is vital to better understand their transition to better support their experience. The lack of existing literature on the transition experiences of transfer student-athletes leaves room for an abundance of potential future research. Future research possibilities focusing on the transfer experiences of student-athletes are endless, and while this study serves as a starting point, it additionally establishes the importance of this line of research in sport management.

Specifically in Division I men's basketball, future research examining the experiences of White transfer student-athletes could serve as a comparison to better distinguish discrepancies in the experiences of Black student-athletes. The present study focused specifically on Power Five transfer student-athletes. Further research examining the mid- to low-major Division I transfer student-athlete transition for comparison would strengthen the understanding and practical application of the research. Additionally, future research examining the experiences and perceptions of the transfer and redshirt year of presently competing student-athletes for comparison with former student-athletes would strengthen the perception of the transition. 
The use of transition theory (Schlossberg, 1981) in the present study could easily translate into the college football structure as it, too, requires student-athletes to participate in a redshirt year (NCAA, n.d.c). Additionally, Black student-athletes likely face similar experiences across revenue-generating sports (Hawkins, 2010; Simons et al., 1999). Due to the larger sizes of college football rosters, it is likely the available pool of participants could be exponentially larger. Therefore, future research with college football transfers could pursue the use of a quantitative methodology.

Further research on female athlete transfer experiences in NCAA women's basketball might provide a more comprehensive understanding of the experience of college basketball student-athletes. According to the NCAA (2018), NCAA women's basketball student-athletes have a $0.9 \%$ likelihood of playing professional basketball in the United States. Women's basketball transfer student-athletes may have different experiences with the transfer and redshirt transition than the men in the present study which indicated Division I men's basketball transfers are driven by the pursuit of a professional basketball career.

Future research examining the processes experienced by community/junior college transfer student-athletes to a four-year institution is necessary to better support the transition path, particularly as there is no redshirt penalty for community college transfers to four-year institutions. Additionally, future research with a specific focus on "swirlers" (Flowers et al., 2014), or 4-2-4 transfer student athletes moving from a traditional four year institution into a community/junior college setting, then back to a traditional four year institution would provide additional insight into the transition experience and its subsequent effects impacting the student-athlete. Other populations of 
transfer student-athletes, including graduate transfers and transfer student-athletes at the Division II and III levels would provide stronger understanding of student-athlete transfer regardless of redshirt requirements.

\section{Summary}

This study was a necessity in the current transfer climate of NCAA Division I men's basketball. As the transfer student-athlete population continues to grow, so too does the need to supply appropriate support and make educated, appropriate decisions from a policy perspective. Regardless of the opinions of committees, coaches, news outlets, and fans, what should matter most in policy generation and revision is the experience of those directly affected by current policy - the student-athletes.

The purpose of this study was to explore the transfer experience of the Black men's basketball student-athlete through the redshirt year-in-residence in Division I men's basketball. Schlossberg's (1981) transition theory served as an effective framework to examine the advantages and disadvantages experienced during the redshirt year using Schlossberg's (1995) 4 S's structure. Critical Race Theory (CRT) served as an anciliary framework to examine the what, why, and how of human behavior as it pertains to race and racism (Glesne, 2016; Matsuda, Lawrence, Delgado, \& Crenshaw, 1993; Scheurich \& Young, 1997; Solórzano \& Yosso, 2001).

All 15 participants in the study expressed advantages they experienced due to the redshirt year. Despite the abundance of advantages described, just three of the 15 participants expressed support for the redshirt year. Twelve of the 15 participants suggested improvements or expressed opposition altogether. The distinct contrast 
between the experienced advantages and the expressed disapproval of the policy should be of major concern to NCAA policy makers.

Results gleaned from this study have potential to influence NCAA policies on an immediate basis. Additionally, results revealed specific needs of the Black student-athlete generated or intensified through the transfer transition requiring attention from Division I institutions. Ultimately, the study has provided a launching point to fill gaps in transfer transition research while simultaneously addressing a largely publicized current current issue within Division I men's basketball. 


\section{REFERENCES}

Albritton, T. J. (2012). Educating our own: The historical legacy of HBCUs and their relevance for educating a new generation of leaders. The Urban Review, 44(3), $311-331$

Alexander, E. (2011, March 4). College athletes turn to transfers in search of playing time. Cleveland.com. Retrieved from http://www.cleveland.com/sports/college/ index.ssf/2011/03/college_athletes_turn_to_trans.html

Allen, W. (1992). The color of success: African-American college student outcomes at predominantly White and historically Black public colleges and universities. Harvard Educational Review, 62(1), 26-45.

Armstrong, K. L., \& Jennings, M. A. (2018). Race, sport, and sociocognitive "place" in higher education: Black male student-athletes as critical theorists. Journal of Black Studies, 49(4), 349-369.

Associated Press. (2017, March 23). Duke says Chase Jeter to transfer to a school closer to home. APNews.com. Retrieved from https://apnews.com/45d15ec9444a48c7a5b57b5a20617cf4

Atkinson, D., \& Sohn, J. (2013). Culture from the bottom up. TESOL Quarterly, 47(4), 669-693.

Bahr, P. R. (2009). College hopping: Exploring the occurrence, frequency, and consequences of lateral transfer. Community College Review, 36(4), 271-298. 
Baillie, P. H. F. (1993). Understanding retirement from sports: Therapeutic ideas for helping athletes in transition. The Counseling Psychologist, 21(3), 399-410.

Baker, A. R., \& Hawkins, B. J. (2016). Academic and career advancement for black male athletes at NCAA Division I institutions. New Directions for Adult and Continuing Education, 150, 71-82.

Beamon, K. K. (2008). “Used goods”: Former African American college student-athletes' perception of exploitation by Division I universities. Journal of Negro Education, $77(4), 352-364$.

Beamon, K. K. (2012). “I'm a baller": Athletic identity foreclosure among AfricanAmerican former student-athletes. Journal of African American Studies, 16(2), 195-208.

Beamon, K. K. (2014). Racism and stereotyping on campus: Experiences of African American male student-athletes. The Journal of Negro Education, 83(2), 121-134.

Beamon, K. K., \& Bell, P. A. (2006). Academics versus athletics: An examination of the effects of background and socialization on African American male student athletes. The Social Science Journal, 43, 393-403.

Bekker, S. J., \& Cheater, F. (2011). Theoretical versus pragmatic design in qualitative research. Nurse Researcher, 119, 1-15.

Belfield, C., Jenkins, D., \& Lahr, H. (2016). Momentum: The academic and economic value of a 15-credit first-semester course load for college students in Tennessee. CCRC Working Paper No. 88. New York, NY: Columbia University Teachers College Community College Research Center.

Bell, L. F. (2009). Examining academic role-set-influence on the student-athlete 
experience. Journal of Issues in Intercollegiate Athletics, 19(4), 19-41.

Berg, B. L. (1995). Qualitative research methods for the social sciences (2nd ed.). Needham Heights, MA: Allyn \& Bacon.

Berger, J. B., \& Malaney, G. D. (2001). Assessing the transition of transfer students from community colleges to a university. NASPA, 40(4), 1-23.

Bimper, A. Y. (2015). Lifting the veil: Exploring colorblind racism in black student athlete experiences. Journal of Sport and Social Issues, 39(3), 225-243.

Bimper, A. Y. (2017). Mentorship of Black student-athletes at a predominantly White American university: Critical race theory perspective on student-athlete development. Sport, Education and Society, 22(2), 175-193.

Bimper, A. Y., Harrison, L., \& Clark, L. (2013). Diamonds in the rough: Examining a case of successful black male student athletes in college sport. Journal of Black Psychology, 39(2), 107-130.

Birnie-Lefcovitch, S. (2000). Student perceptions of the transition from high school to university: Implications for preventative programming. Journal of the First-Year Experience, 12(2), 61-88.

Blair, E. (2015). A reflexive exploration of two qualitative data coding techniques. Journal of Methods and Measurement in the Social Sciences, 6(1), 14-29.

Bogdan, R., \& Taylor, S. J. (1975). Introduction to qualitative research methods: A phenomenological approach to the social sciences. New York, NY: John Wiley \& Sons, Inc.

Bolen, J. B., Rezek, J., \& Pitts, J. D. (2017). Performance efficiency in NCAA basketball. Journal of Sports Economics, 1-24. 
Bourke, B. (2014). Positionality: Reflecting on the research process. The Qualitative Report, 19, 1-9.

Brown, M. C., \& Dancy, T. E. (2010). Predominantly white institutions. Encyclopedia of African American Education, 1, 523-526.

Brown, M. C., Donahoo, S., \& Bertrand, R. D. (2001). The black college and the quest for educational opportunity. Urban Education, 36(5), 553-571.

Brubacher, J. S., \& Rudy, W. (1997). Higher education in transition: History of American colleges and universities (4th ed.). New York, NY: Routledge.

Calmore, J. O. (1992). Critical race theory, Archie Shepp, and fire music: Securing an authentic intellectual life in a multicultural world. Southern California Law Review, 65, 2129-2230.

Carter-Francique, A., Hart, A., \& Cheeks, G. (2015). Examining the value of social capital and social support for Black student-athletes' academic success. Journal of African American Studies, 19(2), 157-177.

Carter-Francique, A., Hart, A., \& Steward, A. (2013). Black college athletes' perceptions of academic success and the role of social support. Journal of Intercollegiate Sport, 6, 231-246.

Chan, Z. C. Y., Fung, Y., \& Chien, W. (2013). Bracketing in phenomenology: Only undertaken in the data collection and analysis process. The Qualitative Report, $18(30), 1-9$.

Charmaz, K. (1996). The search for meanings: Grounded theory. In J. A. Smith, R. Harré, \& L. Van Langenhove (Eds.), Rethinking Methods in Psychology (pp. 27-49). London, UK: Sage Publications. 
Cheslock, J. J. (2004). Differences between public and private institutions of higher education in the enrollment of transfer students. Economics of Education Review, 34, 263-274.

Chickering, A. W. (1969). Education and identity. San Francisco, CA: Jossey-Bass.

Clark, A. (1998). The qualitative-quantitative debate: Moving from positivism and confrontation to postpositivism and reconciliation. Journal of Advanced Nursing, 27, 1242-1249.

Coakley, S. C. (2006). A phenomenological exploration of the sport-career transition experiences that affect subjective well-being of former national football league players. (Doctoral dissertation, University of North Carolina at Greensboro). Retrieved from https://libres.uncg.edu/ir/uncg/f/umi-uncg-1099.pdf

Cokley, K. (2002). The impact of college racial composition on African American students' academic self-concept: A replication and extension. The Journal of Negro Education, 71(4), 288-296.

Coon, L. (2011). Lockout: What will the players do next? ESPN.com. Retrieved from http://www.espn.com/nba/story?page=nextforplayers-111114\&_slug_=nbaplayers-do-next\&redirected=true

Cooper, J. N. (2016). Excellence beyond athletics: Best practices for enhancing black male student-athletes' educational experiences and outcomes. Equity \& Excellence in Education, 49(3), 267-283.

Cooper, J. N., \& Hall, J. (2016). Understanding black male student athletes' experiences at a historically black college/university: A mixed methods approach. Journal of Mixed Methods Research, 10(1), 46-63. 
Cooper, J. N. \& Hawkins, B. (2014). The transfer effect: A critical race theory examination of black male transfer student athletes' experiences. Journal of Intercollegiate Sport, 7, 80-104.

Cooper, J. N., Cavil, J. K., \& Cheeks, G. (2014). The state of intercollegiate athletics at historically black colleges and universities (HBCUs): Past, present, \& persistence. Journal of Issues in Intercollegiate Athletics, 7, 307-332.

Cooper, J. N., Davis, T. J., \& Dougherty, S. (2017). Not so Black and White: A multidivisional exploratory analysis of male student-athletes' experiences at National Collegiate Athletic Association (NCAA) institutions. Sociology of Sport Journal, $34,59-78$.

Cosh, S., LeCouteur, A., Crabb, S., \& Kettler, L. (2013). Career transitions and identity: A discursive psychological approach to exploring athlete identity in retirement and the transition back into elite sport. Qualitative Research in Sport, Exercise, and Health, 5(1), 21-42.

Cotomicalos, S. K. (2014). Issues and obstacles for lateral transfer students to selective colleges. Journal of College Admission, 3, 4-6.

Creswell, J. W. (1998). Qualitative inquiry \& research design: Choosing among five traditions. Thousand Oaks, CA: Sage.

Creswell, J. W. (2013). Qualitative inquiry \& research design: Choosing among five approaches. Thousand Oaks, CA: Sage.

Cummins, P., \& O’Boyle, I. (2015). Psychosocial factors involved in transitions from college to postcollege careers for male NCAA Division I basketball players. Journal of Career Development, 42(1), 33-47. 
Cuseo, J. B. (1998). The transfer transition: A summary of key issues, target areas and tactics for reform. (ERIC Document Reproduction Service No. ED 425 771).

Daniels, E. (2017, January 7). Star transfer Sam Cunliffe says he’s going to Kansas. FoxSports.com. Retrieved from http://www.foxsports.com/collegebasketball/story/sam-cunliffe-transferring-to-kansas-jayhawks-010717

Davis, T. (1996). African-American student-athletes : Marginalizing the NCAA regulatory structure? Marquette Sports Law Review, 6(2), 199-227.

Davis, T. (2008). Race and sports in America : An historical overview. Virginia Sports and Entertainment Law Journal, 7(2), 291-311.

DeCourcy, M. (2018, November 21). NCAA transfer waiver increase has coaches perplexed: 'It's a farce'. SportingNews. Retrived from http://www.sportingnews.com/us/ncaa-basketball/news/ncaa-transfer-waiverincrease-riles-coaches-its-a-farce/306x12duyq9w1km8k5mcy1xdq

Denzin, N. K., \& Lincoln, Y. S. Collecting and interpreting qualitative materials. $\left(2^{\text {nd }}\right.$ ed.). Thousand Oaks, CA: Sage.

Dixson, A. D., \& Rousseau, C. K. (2005). And we are still not saved: Critical race theory in education ten years later. Race, Ethnicity, and Education, 8(1), 7-27.

Donnor, J. K. (2005). Towards an interest-convergence in the education of AfricanAmerican football student athletes in major college sports. Race Ethnicity and Education, 8(1), 45-67.

Draucker, C. B. (1999). The critique of Heideggerian hermeneutical nursing research. Journal of Advanced Nursing, 30(2), 360-373.

Eitzen, D. S. (2016). Fair and foul: Beyond myths and paradoxes of sport. Lanham, MD: 
Rowman \& Littlefield.

Epps, E. G. (1995). Race, class, and educational opportunity: Trends in the sociology of education. Sociological Forum, 10(4), 593-608.

Evans, N. J., Forney, D. S., Guido, F. M., Patton, L. D., \& Renn, K. A. (2010). Student development in college: Theory, research, and practice. (2nd ed.). San Francisco, CA : John Wiley \& Sons.

Faugier, J., \& Sargeant, M. (1997). Sampling hard to reach populations. Journal of Advanced Nursing, 26, 790-797.

Ferrante, A. P., Etzel, E., \& Lantz, C. (1996). Counseling college student-athletes: The problem, the need. In E. F. Etzel, A. P. Ferrante, \& J. W. Pinkney (Eds.), Counseling college student-athletes: Issues and interventions. (2nd ed.), (pp.6578). Morgantown, WV: Fitness Information Technology.

Forgrave, R. (2018, June 22). 2018 NBA draft grades: Pick-by-pick results, analysis for all 60 picks in the first and second round. CBS Sports. Retrieved from https://www.cbssports.com/nba/news/2018-nba-draft-grades-pick-by-pick-resultsanalysis-for-all-60-picks-in-the-first-and-second-round/

Franklin, S. (2016). Black youth activism and the reconstruction of America: Leaders, organizations, and tactics in the twentieth century and beyond. Black History Bulletin, 79(1), 5-14.

Frazier, D. (2012). They only talk to me when they're drunk: The African American experience at small predominantly white institutions. SAGE Open, 2(2), 1-9.

Gardner, B. T. (1975). The educational contributions of Booker T. Washington. The Journal of Negro Education, 44(4), 502-518. 
Gasman, M., Baez, B., Drezner, N. D., \& Sedgwick, K. V. (2007). Historically Black colleges and universities: Recent trends. Academe, 93(1), 69-77.

Gaston-Gayles, J. L. (2003). Advising student athletes: An examination of academic support programs with high graduation rates. NACADA Journal, 23(1-2), 50-57.

Gayles, J. G. (2009). The student athlete experience. New Directions for Institutional Research, 44, 33-41.

Geanellos, R. (1998). Hermeneutic philosophy part I: Implications of its use as methodology in interpretive nursing research. Nursing Inquiry, 5(3), 154-163.

Glesne, C. (2016). Becoming qualitative researchers: An introduction (5th ed.). Boston, MA: Pearson.

Goldrick-Rab, S. (2006). Following their every move: An investigation of social-class differences in college pathways. Sociology of Education, 79, 61-79.

Goldrick-Rab, S., \& Pfeffer, F. T. (2009). Beyond access: Explaining socioeconomic differences in college transfer. Sociology of Education, 82, 101-125.

Goodman, J. (2016, September 8). Free agency would change college basketball forever. ESPN.com. Retrieved from http://www.espn.com/mens-collegebasketball/story/_id/17501805/will-free-agency-every-come-college-basketball

Goodman, J., \& Pappas, J. G. (2000). Applying the Schlossberg 4s transition model to retired university faculty: Does it fit? Adultspan Journal, 2(1), 15-28.

Goodman, J., Schlossberg, N. K., \& Anderson, M. L. (2006). Counseling adults in transition: Linking practice with theory (3rd ed.). New York, NY: Springer.

Gordon, S., \& Lavallee, D. (2012). Career transitions. In T. Morris \& P. Terry (Eds.)., 
The new sport and exercise psychology companion (pp. 567-582). Morgantown, WV: Fitness Information Technology.

Greer, J. (2017, April 11). Matz Stockman to transfer from Louisville. USAToday.com. Retrieved from https://www.usatoday.com/story/sports/college/louisville/2017/04/11/matzstockman-transfer-louisville-basketball-minnesota/100324064/

Groeschen, T. (2016, April 11). Broome on why he picked UC: 'Championships'. Cincinnati.com. Retrieved from http://www.cincinnati.com/story/sports/college/univ ersity -ofcincinnati/2016/04/11/uc-lands-high-scoring-transfer-broome/82884632/

Griffin, K. A., \& Gilbert, C. K. (2015). Better transitions for troops: An application of Schlossberg's transition framework to analyses of barriers and institutional support structures for student veterans. The Journal of Higher Education, 86, 7197.

Guest, G., Bunce, A., \& Johnson, L. (2006). How many interviews are enough? An experiment with data saturation and variability. Field Methods, 18(1), 59-82.

Guiffrida, D. A., \& Douthit, K. Z. (2010). The black student experience at predominantly white colleges: Implications for schools and college counselors. Journal of Counseling and Development, 88(3), 311-318.

Guillory, J., Wiant, K. F., Farrelly, M., Fiacco, L., Alam, I., Hoffman, L., Crankshaw, E., Delahanty, J., \& Alexander, T. N. (2018). Recruiting hard-to-reach populations for survey research: Using Facebook and Instagram advertisements and in-person 
intercept in LGBT bars and nightclubs to recruit LGBT young adults. Journal of Medical Internet Research, 20(6), e197.

Harper, S. R. (2018). Black male student-athletes and racial inequities in NCAA Division I college sports: 2018 edition. Los Angeles, CA: University of Southern California Race and Equity Center.

Harper, S. R. (2015). Black male college achievers and resistant responses to racist stereotyeps. Harvard Educational Review, 4, 646-674.

Harper, S. R. (2009). Race, interest convergence, and transfer outcomes for black male student athletes. New Directions for Community Colleges, 147, 29-37.

Harris, A. (2013, January 18). Who coined the term "catfish"? Slate. Retrieved from https://slate.com/culture/2013/01/catfish-meaning-and-definition-term-for-onlinehoaxes-has-a-surprisingly-long-history.html

Harrison, K. (2000). Black athletes at the millennium. Society, 37, 35-39.

Hassan, E. (2006). Recall bias can be a threat to retrospective and prospective research designs. The Internet Journal of Epidemiology, 3(2), 339-412.

Hawkins, B. (2010). The new plantation: Black athletes, college sports, and predominantly white NCAA institutions. New York, NY: Palgrave Macmillan.

Heddy, B. C., Sinatra, G. M., Seli, H., Taasoobshirazi, G., \& Mukhopadhyay, A. (2016). Making learning meaningful: Facilitating interest development and transfer in atrisk college students. Educational Psychology, 37(5), 565-581.

Heggins, W. J., \& Jackson, J. F. L. (2003). Understanding the collegiate experience for Asian international students at a Midwestern research university. College Student Journal, 37(3), 379-391. 
Henderson, M. M. (2013). Coming to terms: Career development experiences of NCAA division I female student-athletes in transition. (Doctoral dissertation, the George Washington University). Retrieved from https://search.proquest.com/docview/1346181178

Hendricks, S. P., \& Johnson, A. T. (2016). The athlete-student dilemma. Journal of Applied Sport Management, 8(4), 1-20.

Hilbert, E. (2017, November 2). New NCAA research: Team sports recruit earlier than individual sports. USA Today High School Sports. Retrieved from https://usatodayhss.com/2017/new-ncaa-research-team-sports-recruit-earlier-thanindividual-sports

Hockey, J., \& Collinson, J. A. (2007). Grasping the phenomenology of sporting bodies. International Review for the Sociology of Sport, 42(2), 115-131.

Hollings, S. C., Mallett, C. J., \& Hume, P. A. (2014). The transition from elite junior track-and-field athlete to successful senior athlete: why some do, why others don't. International Journal of Sport Science \& Coaching, 9(3), 457-471.

Hosick, M. B. (2018a, February 13). DI transfer group requests feedback on rule concepts. $N C A A$. Retrieved from http://www.ncaa.org/about/resources/mediacenter/news/di-transfer-group-requests-feedback-rule-concepts

Hosick, M. B. (2018b, June 13). New transfer rule eliminates permission-to-contact process. $N C A A$. Retrieved from http://www.ncaa.org/about/resources/mediacenter/news/new-transfer-rule-eliminates-permission-contact-process

Huberman, A. M., \& Miles, M. B. (2002). The qualitative researcher's companion. Thousand Oaks, CA: Sage. 
Huml, M. R., Hancock, M. G., \& Bergman, M. J. (2014). Additional support or extravagant cost? Student-athletes' perceptions on athletic academic careers. Journal of Issues in Intercollegiate Athletics, 7, 410-430.

Husserl, E. (1931). Ideas: General introduction to pure phenomenology (Gibson, W. R. B. transl.). London, England: George Allen \& Unwin Ltd.

Hylton, K. (2005). 'Race', sport and leisure; Lessons from critical race theory. Leisure Studies, 24(1), 81-98.

Hylton, K., \& Lawrence, S. (2009). 'For your ears only!' Donald Sterling and backstage racism in sport. Ethnic and Racial Studies, 39(15), 2740-2757.

Ishitani, T. T. (2006). How do transfers survive after "transfer shock"? A longitudinal study of transfer student departure at a four-year institution. Research in Higher Education, 49, 403-419.

Ispa-Landa, S., \& Conwell, J. (2015). “Once you go to a White school, you kind of adapt”: Black adolescents and the racial classification of schools. Sociology of Education, 88(1), 1-19.

Jacob, S. A., \& Furgerson, S. P. (2012). Writing interview protocols and conducting interviews: Tips for students new to the field of qualitative research. The Qualitative Report, 17(6), 1-10.

Jain, D., Bernal, S., Lucero, I., Herrera, A., \& Solórzano, D. (2016). Toward a critical race perspective of transfer: An exploration of a transfer receptive culture. Community College Journal of Research and Practice, 40(12), 1013-1024.

Johnson, D. R., Wasserman, T. H., Yildirim, N., \& Yonai, B. A. (2014). Examining the 
effects of stress and campus climate on the persistence of students of color and white students: An application of Bean and Eaton's psychological model of retention. Research in Higher Education, 55(1), 75-100.

Johnson-Ahorlu, N. (2017). Efficient social justice: How critical race theory research can inform social movement strategy development. The Urban Review, 49(5), 729745.

Jones, W. A., Liu, K., \& Bell, L. F. (2017). Examining the inclusiveness of intercollegiate team climate and its influence on student-athletes' cross-racial interactions. Journal of College Student Development, 58(4), 564-582.

Kaczorowski, R. J. (1987). To begin the nation anew: Congress, citizenship, and civil rights after the civil war. The American Historical Review, 92, 45-68.

Kantrowitz, M. (2011). The distribution of grants and scholarships by race. Financial Aid.org.

Retrieved from http://www.finaid.org/scholarships/20110902racescholarships.pdf Karkouti, I. M. (2016). Black students' educational experiences in predominantly white universities: A review of the related literature. College Student Journal, 50, 5970.

Katz, A. (2009, March 29). Curry will be eligible in 2010-11. ESPN.com. Retrieved from http://www.espn.com/mens-college-basketball/news/story?id=4026095

Kercheval, B. (2018, February 7). National signing day 2018: Multiple school Twitter accounts suspended at worst time. CBS Sports. Retrieved from https://www.cbssports.com/college-football/news/national-signing-day-2018multiple-school-twitter-accounts-suspended-at-worst-time/ 
Kerr, Z. Y., Marshall, S. W., Dompier, T. P., Corlette, J., Klossner, D. A., \& Gilchrist, J. (2015). College sports-related injuries - United States, 2009-10 through 2013-14 academic years. Morbidity and Mortality Weekly Report, 64(48), 1330-1336.

Kerry, D. S., \& Armour, K. M. (2000). Sport sciences and the promise of phenomenology: Philosophy, method, and insight. Quest, 52(1), 1-17.

King, C. R. (2005). Cautionary notes on whiteness and sport studies. Sociology of Sport Journal, 22, 397-408.

Kleiber, D. A., \& Brock, S. C. (1992). The effect of career-ending injuries on the subsequent well-being of elite college athletes. Sociology of Sport Journal, 9(1), $70-75$.

Koch, T. (1995). Interpretive approaches in nursing research: The influence of Husserl and Heidegger. Journal of Advanced Nursing, 21, 827-836.

Kodama, C. M., McEwen, M. K., Liang, C. T. H., \& Lee, S. (2002). An Asian American perspective on psychosocial student development theory. New Directions for Student Services, 97, 45-59.

Konsky, S. M. (2003). An antitrust challenge to the NCAA transfer rules. The University of Chicago Law Review, 70(4), 1581-1607.

Kulics, J. M., Kornspan, A. S., \& Kretovics, M. (2015). An analysis of the academic behaviors and beliefs of Division I student-athletes: The impact of the increased percentage toward degree requirements. College Student Journal, 49(1), 1-12.

Laanan, F. S. (1996). Making the transition: Understanding the adjustment process of community college transfer students. Community College Review, 23(4), 69-84.

Ladson-Billings, G., \& Tate, W. (1995). Toward a critical race theory of education. 
Teachers College Record, 97(1), 47-68.

Lapchick, R. (2016). Keeping score when it counts: Graduation success and academic progress rates for the 2016 NCAA Division I men's basketball tournament teams. The Institute for Diversity and Ethics in Sport. Retrieved from http://nebula.wsimg.com/6729bb35e3e2f1396de38f374d302a86?AccessKeyId=D AC3A56D8FB782449D2A\&disposition=0\&alloworigin $=1$

Lavallee, D. (2005). The effect of a life development intervention on sports career transition adjustment. The Sport Psychologist, 19, 193-202.

Lazarowicz, T. A. (2015). Understanding the transition experience of community college transfer students to a 4-year university: Incorporating Schlossberg's transition theory into higher education. (Doctoral dissertation, University of NebraskaLincoln). Retrieved from https://digitalcommons.unl.edu/cgi/viewcontent.cgi?article=1223\&context $=$ cehse daddiss

Leccesi, J. (2017, April 27). Five most common questions about verbal commitments. USA Today. Retrieved from http://usatodayhss.com/2017/five-most-commonquestions-about-verbal-commitments

Levine, J., Etchison, S., \& Oppenheimer, D. M. (2014). Pluralistic ignorance among student-athlete populations: A factor in academic underperformance. Higher Education, 68(4), 525-540.

Lewis, A. E., Chesler, M., \& Forman, T. A. (2000). The impact of "colorblind" ideologies on students of color: Intergroup relations at a predominantly White university. Journal of Negro Education, 69(1), 74-91. 
Li, D. (2010). They need help: Transfer students from four-year to four-year institutions. The Review of Higher Education, 33(2), 207-238.

Lipka, S. (2008). Survey finds transfer students disengaged, but some colleges are working to change that. Chronicle of Higher Education, 55(12), 31-33.

Long, J., Hylton, K., Dart, J., \& Welch, M. (2000). Part of the game? An examination of racism in grass roots football. London, UK: Kick It Out.

Louis, M. R. (1980). Surprise and sense making: What newcomers experience in entering unfamiliar organizational settings. Administrative Science Quarterly, 25(2), 226251.

Magolda, M. B. B. (2009). The activity of meaning making: A holistic perspective on college student development. Journal of College Student Development, 50(6), 621-639.

Mandel, S. (2014, August 7). With autonomy, will Power Five bust up NCAA sports as we know them? Fox Sports. Retrieved from https:/www.foxsports.com/collegefootball/story/ncaa-board-autonomy-power-5-division-i-future-080714

Marshall, C., \& Rossman, G. B. (2011). Designing qualitative research (5th ed.). Los Angeles, CA: Sage.

Martin, B. E., Harrison, C. K., Stone, J., \& Lawrence, S. M. (2010). Athletic voices and academic victories: African American male student-athlete experiences in the Pac-Ten. Journal of Sport and Social Issues, 34(2), 131-153.

Martinez, O., Wu, E., Shultz, A. Z., Capote, J., Lopez Rios, J., Sandfort, T., \& Rhodes, S. 
D. (2014). Still a hard-to-reach population? Using social media to recruit Latino gay couples for an HIV adaptation study. Journal of Medical and Internet Research, 16(4), e113. Retrieved from http://www.jmir.org/2014/4/e113/

Matsuda, M., Lawrence, C., Delgado, R., \& Crenshaw, K. (Eds.). (1993). Words that wound: Critical race theory, assaultive speech, and the first amendment. Boulder, CO: Westview Press.

Mayo, J. R., Murguia, E., \& Padilla, R. (1995). Social integration and academic performance among minority university students. Journal of College Student Development, 36, 542-552.

McCormack, C. (2000). From interview transcript to interpretive study: Part 1-Viewing the transcript through multiple lenses. Field Methods, 12(4), 282-297.

McCormick, A. C. (1997). Transfer behavior among beginning postsecondary students: 1989-94. Washington, DC: U.S. Department of Education.

McCoy, D. L. (2014). A phenomenological approach to understanding first-generation college students" of color transition to one "extreme" predominantly white institution. College Student Affairs Journal, 32(1), 155-169.

McGee, R. (2012, July 10). Every high school football star believes he's ready to handle the college game. Some must wait longer than others to prove it. ESPN.com. Retrieved from http://www.espn.com/espn/magazine/archives/news/story?page=magazine20091228-article22

McKnight, K., Bernes, K., Gunn, T., Chomey, D., Orr, D., \& Bardick, A. (2009). Life 
after sport: Athletic career transition and transferrable skills. Journal of Excellence, 13, 63-77.

Meadows, B., Piece, D., \& Popp, N. (2011). Qualitative analysis of international studentathlete perspectives on recruitment and transitioning into American college sport. The Sport Journal, 14(1).

Meleis, A. I., Sawyer, L. M., Im, E., Messias, D. K., \& Schumacher, K. (2000). Experiencing transitions: An emerging middle-range theory. Advances in Nursing Science, 23(1), 12-28.

Merleau-Ponty, M. (1964). The primacy of perception: And other essays on phenomenological psychology, the philosophy of art, history and politics. Chicago, IL: Northwestern University Press.

Miller, E. (2017, March 27). Wake Forest transfer a threat to score from 80 feet for ODU. The Virginian-Pilot. Retrieved from http://pilotonline.com/sports/college/olddominion/basketball/wake-forest-transfer-a-threat-to-score-from-feetin/article_fb1d4b4a-2c2d-5501-923e-cd24736ae2b0.html

Miller, K. (2016, December 9). Will Marcus Keene be college basketball's 1st 30 ppg scorer in 20 years? Bleacher Report. Retrieved from http://bleacherreport.com/articles/2680384-will-marcus-keene-be-collegebasketballs-1st-30-ppg-scorer-in-20-years

Milner, H. R. (2007). Race, culture, and researcher positionality: Working through dangers seen, unseen, and unforeseen. Educational Researcher, 36(7), 388-400.

Morrison, E. W. (2002). Newcomers' relationships: The role of social network ties during socialization. Academy of Management Journal, 45(6), 1149-1160. 
Moustakas, C. (1994). Phenomenological research methods. Thousand Oaks, CA: Sage.

Murty, K. S., \& Roebuck, J. B. (2015). Deviant exploitation of Black male student athletes on White campuses. Deviant Behavior, 36(6), 429-440.

Nasaw, D. (1981). Schooled to order: A social history of public schooling in the United States. Oxford, UK: Oxford University Press.

National Center for Education Statistics. (2018). Back to school statistics. Retrieved from https://nces.ed.gov/fastfacts/display.asp?id=372

National Center for Education Statistics. (2014). Degrees conferred by race and sex. Retrieved from https://nces.ed.gov/fastfacts/display.asp?id=72

National Collegiate Athletic Association. (2017, December 14). Tracking transfer in Division I men's basketball. Retrieved from http://www.ncaa.org/about/resources/research/tracking-transfer-division-i-men-sbasketball

National Collegiate Athletic Association. (n.d.a.). NCAA core values. Retrieved from http://www.ncaa.org/about/ncaa-core-values

National Collegiate Athletic Association. (n.d.b.). Playing and practice season rules. Retrieved from http://www.ncaa.org/playing-rules/playing-and-practice-seasonrules

National Collegiate Athletic Association. (n.d.c.). Transfer terms. Retrieved from http://www.ncaa.org/student-athletes/current/transfer-terms

National Collegiate Athletic Association. (n.d.d.). What is an academic redshirt? Retrieved from http://www.ncaa.org/student-athletes/future/eligibilitycenter/what-academic-redshirt 
National Collegiate Athletic Association. (2019). 12.4 Employment. NCAA LSDBi.

Retrieved from https://web3.ncaa.org/lsdbi/search/bylawView?id=8744\#result

National Collegiate Athletic Association. (2018, April 20). Estimated probability of competing in professional athletics. Retrieved from http://www.ncaa.org/about/resources/research/estimated-probability-competingprofessional-athletics

National Collegiate Athletic Association. (2017a). Estimated probability of competing in professional athletics. Retrieved from http://www.ncaa.org/about/resources/research/estimated-probability-competingprofessional-athletics

National Collegiate Athletic Association. (2017b). 2017-18 four-year transfer guide. Retrieved from http://www.ncaa.org/sites/default/files/201718_Transfer_Guide_4_Year_20170721.pdf

National Collegiate Athletic Association. (2016). Prevalence of Graduate Transfer in Division I. Retrieved from http://www.ncaa.org/about/resources/research/prevalence-graduate-transferdivision-i

Newell, E. M. (2015). International student-athlete adjustment issues: Advising recommendations for effective transitions. NACADA Journal, 35(2), 36-47.

Nuñez, A. M. \& Yoshimi, J. (2016). A phenomenology of transfer: Students’ experiences at a receiving institution. Innovative Higher Education, 42, 173-187.

Nutting, A. W. (2008). Community college transfer students' probabilities of 
baccalaureate receipt as a function of their prevalence in four-year colleges and departments. Education Economics, 19(1), 65-87.

O’Connor, A., Jackson, L., Goldsmith, L., \& Skirton, H. (2013). Can I get a retweet please? Health research recruitment and the Twittersphere. Journal of Advanced Nursing, 70(3), 599-609.

Ogbu, J. U. (2004). Collective identity and the burden of "acting White" in Black history, community, and education. The Urban Review, 36(1), 1-35.

Ogden, W. (2018, March 16). Redshirting made Gonzaga's Zach Norvell more hungry to help bulldogs to another NCAA tournament run. The Spokesman Review. Retrieved from http://www.spokesman.com/stories/2018/mar/16/redshirtingmade-gonzagas-zach- norvell-more-hungry/

Onwuegbuzie, A. J., \& Leech, N. L. (2005). Taking the "q" out of research: Teaching research methodology courses without the divide between quantitative and qualitative paradigms. Quality \& Quantity, 39, 267-296.

Oseguera, L. \& Rhee, B. S. (2009). The influence of institutional retention climates on student persistence to degree completion: A multilevel approach. Research in Higher Education, 50, 546-569.

Palmer, T. (2016, February 2). Texas transfer Jordan Barnett embraces coming home to Mizzou. The Kansas City Star. Retrieved from http://www.kansascity.com/sports/college/ sec/university-ofmissouri/article 58016788.html

Pappas, J. G., \& Goodman, J. (1997). When university faculty retire: A study of the 
transition process. Educational Resources Information Center. Retrieved from https://files.eric.ed.gov/fulltext/ED410772.pdf

Patino, A., Pitta, D., \& Quinones, R. (2012). Social media's emerging importance in market research. Journal of Consumer Marketing, 29(3), 233-237.

Patton, M. Q. (1990). Qualitative evaluation and research methods. (2nd ed.). Newbury Park, CA: Sage Publications, Inc.

Pearson, R. E., \& Petitpas, A. J. (1990). Transitions of athletes: Developmental and preventative perspectives. Journal of Counseling and Development, 69(1), 7-10.

Peirce, B. (1833). A history of Harvard university: From its foundation, in the year 1636, to the period of the American revolution. Cambridge, MA: Brown, Shattuck, and Company.

Pendleton, K. J. (2007). Using Schlossberg's transition theory to identify coping strategies of welfare recipients attending postsecondary institutions. (Doctoral dissertation, University of Louisville). Retrieved from https://ir.library.louisville.edu/cgi/viewcontent.cgi?article $=2109 \& a m p=\&$ context $=$ etd\&amp $=\&$ sei-

redir $=1 \&$ referer $=$ https $\% 253 \mathrm{~A} \% 252 \mathrm{~F} \% 252 \mathrm{Fscholar}$.google.com $\% 252$

Fscholar\%253Fstart\%253D10\%2526q\%253D4s\%252Bschlossberg\%2526hl\%253

Den\%2526as_sdt $\% 253 \mathrm{D} 0 \% 252 \mathrm{C} 18 \#$ search $=\% 224 \mathrm{~s} \% 20$ schlossberg $\% 22$

Popp, N. (2007). International student-athlete perception of college sport and its effect on adjustment to college. (Doctoral dissertation, University of Louisville). Retrieved from

https://ir.library.louisville.edu/cgi/viewcontent.cgi?article=2141\&context=etd 
Popp, N., Pierce, D., \& Hums, M. A. (2011). A comparison of the college selection process for international and domestic student-athletes at NCAA Division I universities. Sport Management Review, 14(2), 176-187.

Powers, M. S. (2010). Applying Schlossberg's transition theory to nontraditional male drop-outs. (Doctoral dissertation, University of Nebraska). Retrieved from https://digitalcommons.unl.edu/cgi/viewcontent.cgi?article $=1019 \&$ context $=$ cehse daddiss

Rall, R. M. (2016). Forgotten students in a transitional summer: Low-income racial/ethnic minority students experience the summer melt. The Journal of Negro Education, 85(4), 462-479.

Randles, C. (2012). Phenomenology: A review of the literature. Applications of Research in Music Education, 30(2), 11-21.

Raphael, K. (1987). Recall bias: A proposal to assessment and control. International Journal of Epidemiology, 16(2), 167-170.

Reeves, S., Albert, M., Kuper, A., \& Hodges, B. D. (2008). Why use theories in qualitative research? British Medical Journal, 337, 631-634.

Rezania, D., \& Gurney, R. (2014). Building successful student-athlete coach relationships: Examining coaching practices and commitment to the coach. SpringerPlus, 3, 1-11.

Robbins, P. A. (2015). The academic socialization and professional sport expectations of college athletes. (Doctoral dissertation, The University of Texas at Austin). Retrieved from 
https://repositories.lib.utexas.edu/bitstream/handle/2152/30942/ROBBINSDISSERTATION-2015.pdf;sequence $=1$

Rose, G. (1997). Situating knowledges: Positionality, reflexivities and other tactics. Progress in Human Geography, 21(3), 305-320.

Rossouw, A. (2010). The expectation-satisfaction relationship during the recruitment process in Division I basketball. (Doctoral dissertation, Northern Illinois University). Retrieved from https://search.proquest.com/openview/798b58bee0f2957a3d2a4b2f86151606/1?p q-origsite $=$ gscholar $\& \mathrm{cbl}=18750 \&$ diss $=\mathrm{y}$

Rubin, H. J., \& Rubin, I. S. (2005). Qualitative interviewing: The art of hearing data. ( $2^{\text {nd }}$ ed.). Thousand Oaks, CA: Sage.

Rubin, L. M., \& Moses, R. A. (2017). Athletic subculture within student-athlete academic centers. Sociology of Sport Journal, 34(4), 317-328.

Russell, B. C. (2015). An examination of the relationship between athletic satisfaction and student adaptation to college. (Doctoral dissertation, University of Tennessee). Retrieved from https://trace.tennessee.edu/cgi/viewcontent.cgi?article $=5033 \& \mathrm{amp}=\&$ context=utk graddiss\&amp $=\&$ seiredir=1\&referer=https $\% 253 \mathrm{~A} \% 252 \mathrm{~F} \% 252 \mathrm{Fscholar}$.google.com $\% 252 \mathrm{Fscholar} \% 2$ 53Fstart $\% 253 \mathrm{D} 30 \% 2526 \mathrm{q} \% 253$ Dsuccessful\%252Bstudent $\% 252$ Bathlete $\% 2526 \mathrm{hl}$ \%253Den\%2526as_sdt\%253D0\%252C8\%2526as_ylo\%253D2015\#search=\%22s uccessful $\% 20$ student $\% 20$ athlete $\% 22$

Sack, A. L., \& Staurowsky, E. J (1998). College athletes for hire: The evolution and 
legacy of the NCAA's amateur myth. Westport, CT: Praeger Publishers.

Sailes, G. A. (1993). An investigation of campus stereotypes: The myth of Black athletic superiority and the dumb jock stereotype. Sociology of Sport Journal, 10, 88-97.

Saxe, K., Hardin, R., Taylor, E. A., \& Pate, J. R. (2017). Transition blues: The experience of female collegiate student-athletes. Journal of Higher Education Athletics \& Innovation, 1(2), 25-48.

Scheerens, J. (1991). Process indicators of school functioning: A selection based on the research literature on school effectiveness. Studies in Educational Evaluation, 17, 371-403.

Scheurich, J., \& Young, M. (1997). Coloring epistemologies: Are our research epistemologies racially biased? Educational Researcher, 26, 4-16.

Schlossberg, N. K. (1966). Adults in transition. Presented at The Training of Counselors of Adults, May 1965, Chatham, MA.

Schlossberg, N. K. (1981). A model for analyzing human adaptation to transition. The Counseling Psychologist, 9(2), 2-18.

Schlossberg, N. K. (1987). Taking the mystery out of change. Psychology Today, 21(5), 74-75.

Schlossberg, N. K. (1989). Overwhelmed: Coping with life's ups and downs. Lanham, MD: Lexington.

Schlossberg, N. K. (2011). The challenge of change: The transition model and its applications. Journal of Employment Counseling, 48(4), 159-162.

Schlossberg, N. K., Lynch, A. Q., \& Chickering, A. W. (1989). Improving higher education environments for adults. San Francisco, CA: Jossey-Bass Inc. 
Schlossberg, N. K., Waters, E. B., \& Goodman, J. (1995). Counseling adults in transition (2nd Ed.). New York, NY: Springer.

Schneider, R., \& Messenger, S. (2012). The impact of athletic facilities on the recruitment of potential student-athletes. College Student Journal, 46(4), 805-811.

Seidman, I. E. (1998). Interviewing as qualitative research: A guide for researchers in education and the social sciences (2nd ed.). New York, NY: Teachers College Press.

Sheldon, P., \& Bryant, K. (2015). Instagram: Motives for its use and relationship to narcissism and contextual age. Computers in Human Behavior, 58, 89-97.

Sikkens, E., van San, M., Sieckelinck, S., Boeije, H., \& de Winter, M. (2017). Participant recruitment through social media: Lessons learned from a qualitative radicalization study using Facebook. Field Methods, 29(2), 130-139.

Silverman, D., \& Marvasti, A. (2008). Doing qualitative research: A comprehensive guide. Thousand Oaks, CA: Sage.

Simiyu, W. W. N. (2012). Challenges of being a Black student athlete on U.S. college campuses. Journal of Issues in Intercollegiate Athletics, 5, 40-63.

Simon, M. K., \& Goes, J. (2013). Dissertation and scholarly research: Recipes for success. Seattle, WA: Dissertation Success LLC.

Simons, H. D., Bosworth, C., Fujita, S., \& Jensen, M. (2007). The athlete stigma in higher education. College Student Journal, 41(2), 251-273.

Simons, H., \& Van Rheenen, D. (2000). Noncognitive predictors of student athletes' academic performance. Journal of College Reading and Learning, 30(2), 167181. 
Simons, H. D., Van Rheenen, D., \& Covington, M. V. (1999). Academic motivation and the student athlete. Journal of College Student Development, 40(2), 151-161.

Singer, J. N. (2016). African American male college athletes' narratives on education and racism. Urban Education, 51(9), 1065-1095.

Smith, A., \& Anderson, M. (2018, March 1). Social media use in 2018. Pew Research Center. Retrieved from http://www.pewinternet.org/2018/03/01/social-media-usein-2018/

Smith, L. R., Smith, K. D., \& Blazka, M. (2017). Follow me, what's the harm? Considerations of catfishing and utilizing fake online personas on social media. Journal of Legal Aspects of Sport, 27, 32-45.

Smith, W. A., Mustaffa, J. B., Jones, C. M., Curry, T. J., \& Allen, W. R. (2016). 'You make me wanna holler and throw up both my hands!': Campus culture, Black misandric microaggressions, and racial battle fatigue. International Journal of Qualitative Studies in Education, 29(9), 1189-1209.

Solórzano, D. G., Ceja, M., \& Yosso, T. (2000). Critical race theory, racial microaggressions, and campus racial climate: The experiences of African American college students. Journal of Negro Education, 69(1/2), 60-73.

Solórzano, D. G., \& Yosso, T. J. (2001). Critical race and latcrit theory and method: Counter-storytelling. Qualitative Studies in Education, 14(4), 471-495.

Sparkman, L., Maulding, W., \& Roberts, J. (2012). Non-cognitive predictors of student success in college. College Student Journal, 46(3), 642-652.

Spiggle, S. (1994). Analysis and interpretation of qualitative data in consumer research. Journal of Consumer Research, 21(3), 491-503. 
Stansbury, S. (2003). Evaluating academic success in student athletes: A literature review. Concept, 27.

Stein, A. (2018, January 8). How to keep a strong player-coach relationship. USA Basketball. Retrieved from https://www.usab.com/youth/news/2010/08/how-tokeep-a-strong-player-coach-relationship.aspx

Stokowski, S., Rode, C. R., \& Hardin, R. (2016). Academic advisors' perceptions of student-athletes at NCAA Division I institutions. The Journal of SPORT, 5(1), 5.

Stoltenburg, A. L., Kamphoff, C. S., \& Bremer, K. L. (2011). Transitioning out of sport: The psychosocial effects of collegiate athletes' career-ending injuries. Athletic Insight Journal, 3(2), 115-134.

Story, M. (2018, May 6). Coaches loathe it. Players like it. Who is right about the NCAA's graduate-transfer rule? Lexington Herald-Leader. Retrieved from https://www.kentucky.com/sports/spt-columns-blogs/markstory/article210483434.html

Strayhorn, T. L. (2014). What role does grit play in the academic success of black male collegians at predominantly white institutions? Journal of African American Studies, 18(1), 1-10.

Stubbs, R. (2017, December 21). With six redshirt players, Villanova basketball is more plus-one than one-and-done. The Washington Post. Retrieved from https://www.washingtonpost.com/sports/colleges/with-six-redshirt-playersvillanova-basketball-is-more-plus-one-than-one-and-done/2017/12/19/6c1e 7cdcdf76-11e7-89e8-edec16379010_story.html?utm_term=.faac5696e1ab

Sturges, J. E., \& Hanrahan, K. J. (2004). Comparing telephone and face-to-face 
qualitative interviewing: A research note. Qualitative Research, 4(1), 107-118. Surujlal, J., \& Zyl, Y. (2014). Understanding the dynamics of sport-career transition of Olympic athletes. Mediterranean Journal of Social Sciences, 5(20), 477-484.

Swain, D. A. (1991). Withdrawal from sport: Schlossberg's model of transitions. Sociology of Sport Journal, 8, 152-160.

Swigart, T. E. \& Murrell, P. H. (2010). Factors influencing estimates of gains made among African-American and Caucasian community college students. Community College Journal of Research and Practice, 25(4), 297-312.

Tate, W. F. Critical race theory and education: History, theory, and implications. Review of Research in Education, 22, 195-247.

Tausig, J. E., \& Freeman, E. W. (1988). The next best thing to being there: Conducting the clinical research interview by telephone. American Journal of Orthopsychiatry, 58(3), 418-427.

Tobolowsky, B. F. \& Cox, B. E. (2012). Rationalizing neglect: An institutional response to transfer students. The Journal of Higher Education, 83(3), 389-410.

Townsend, B. K. (2012). "Feeling like a freshman again": The transfer student transition. New Directions for Higher Education, 144, 69-77.

Tracey, T. J., \& Sedlacek, W. E. (1987). A comparison of white and black student academic success using noncognitive variables: A LISREL analysis. Research in Higher Education, 27(4), 333-348.

Tweksbury, R. (2009). Qualitative versus quantitative methods: Understanding why qualitative methods are superior for criminology and criminal justice. Journal of Theoretical and Philosophical Criminology, 1(1). 
Ungerleider, S. (1997). Olympic athletes' transition from sport to workplace. Perceptual and Motor Skills, 84(3), 1287-1295.

van Manen, M. (1990). Researching lived experience: Human science for an action sensitive pedagogy. Albany, NY: State University of New York Press.

Vogl, S. (2013). Telephone versus face-to-face interviews: Mode effect on semistructured interviews with children. Sociological Methodology, 43(1), 133-177.

Volkwein, J. F., King, M. C., \& Terenzini, P. T. (1986). Student-faculty relationships and intellectual growth among transfer students. Journal of Higher Education, $57(4), 413-430$.

Wang, X., Wickersham, K., \& Sun, N. (2017). The evolving landscape of transfer research: Reconciling what we know in preparation for a new era of heightened promise and complexity. New Directions in Institutional Research, 170, 115-121.

Warner, S., \& Dixon, M. A. (2011). Understanding sense of community from the athlete's perspective. Journal of Sport Management, 25(3), 257-271.

Wassmer, R., Moore, C., \& Shulock, N. (2004). Effect of racial/ethnic composition on transfer rates in community colleges: Implications for policy and practice. Research in Higher Education, 45(6), 651-672.

Waters, J. (2017). Phenomenological research guidelines. Capilano University Psychology. Retrieved from https:/www.capilanou.ca/psychology/studentresources/research-guidelines/Phenomenological-Research-Guidelines/

Watson, J. C. (2003). Overcoming the challenges of counseling college student athletes. Retrieved from https://www.counseling.org/resources/library/ERIC\%20Digests/2003-01.p 
Wawrzynski, M. R. \& Sedlacek, W. E. (2003). Race and gender differences in the transfer student experience. Journal of College Student Development, 44(4), 489501.

Weathington, B. L., Alexander, A. C., \& Rodebaugh, L. L. (2010). Coaching influences on student-athlete motivation, stress, and skill. Athletic Insight Journal, 2(2), 118.

Werther, E. (2012). College adjustment and burnout among undergraduate transfer and native students (Doctoral dissertation, University of Georgia). Retrieved from https://getd.libs.uga.edu/pdfs/werther_eckart_201208_phd.pdf

Wimpenny, P., \& Gass, J. (2000). Interviewing in phenomenology and grounded theory: Is there a difference? Journal of Advanced Nursing, 31(6), 1485-1492.

Winn, L. (2015a, July 29). Analyzing the movement of coaches and assistants across college hoops. SportsIllustrated.com. Retrieved from https://www.si.com/collegebasketball/2015/07/29/college-basketball-coaching-movement-transfer-study

Winn, L. (2015b, July 29). Analyzing the transfer \& commitment patterns of top 100 recruits. SportsIllustrated.com. Retrieved from https://www.si.com/collegebasketball/2015/07/29/top-100-high-school-recruits-transfer-behavior-study\#

Wolverton, B. (2005, November 9). Knight Commission members voice concerns about the NCAA's new academic expectations. The Chronicle of Higher Education. Retrieved from http:// chronicle.com/daily/2005/11/2005110906n.htm

Wood, J. L. \& Palmer, R. T. (2016). Determinants of intent to transfer among black male community college students: A multinomial, multi-level investigation of student engagement. Teachers College Record, 118, 1-28. 
Woods, D. (2017, November 7). College basketball transfers aren't new, but players and coaches cope with increase. IndyStar. Retrieved from https://www.indystar.com/story/sports/college/2017/11/07/college-basketballtransfers-arent-new-but-players-and-coaches-cope-increase/686784001/

Workman, J. L. (2015). Parental influence on exploratory students' college choice, major, and career decision making. College Student Journal, 49(1), 23-30.

Wylleman, P., \& Lavallee, D. (2004). A developmental perspective on transitions faced by athletes. In M. Weiss (Ed.) Developmental sport and exercise psychology: $A$ lifespan perspective (pp. 507-527). Morgantown, WV: Fitness Information Technology.

Yearwood, G. (2018). Playing without power: Black male NCAA student-athletes living with structural racism. Transforming Anthropology, 26(1), 18-35.

Yen, A. C. (2011). Early scholarship offers and the NCAA. Boston College Law Review, 52, 585-616.

Zhang, X., Kuchinke, L., Woud, M. L., Velten, J., \& Margraf, J. (2017). Survey method matters: Online/offline questionnaires and face-to-face or telephone interviews differ. Computers in Human Behavior, 71, 172-180.

Ziller, T. (2016, September 12). Would college basketball free agency really be so terrible? SBNation. Retrieved from https://www.sbnation.com/2016/9/12/12887258/college-basketball-transfer-rulelawsuit-fair-john-calipari 


\section{APPENDICES}

\section{Appendix A}

Interview Protocol

\section{Situation:}

1) Tell me about why you decided to transfer. (Powers, 2010)

2) What were the biggest differences in your two situations at [school 1] and [school 2]? (Pendleton, 2007; Powers, 2010)

3) What unexpected situations did you find yourself in during the redshirt year?

\section{Self:}

4) Think back to your redshirt year and your mindset during it. What did you personally go through during that year? (Powers, 2010)

5) What tools did you use to cope with the redshirt year? (Powers, 2010)

6) Did your race play a role, if any, (consciously or unconsciously) in transferring?

\section{Support:}

7) What social groups of people did you spend most of your time with during your redshirt year? (Stotlenberg et al., 2011)

8) Describe the support you received through your transition and redshirt year. (Pendleton, 2007)

9) Besides your sport, what other groups or support systems did you have on campus? (Stotlenberg et al., 2011) 


\section{Strategies:}

10) Do you view your transfer experience as a gain or loss, and why? (Powers, 2010)

11) What are you doing now? (Powers, 2010)
a) Work
b) Life

12) Looking back, is there anything you would have done differently? (Stotlenberg, 2011)

13) Do you personally think the redshirt year is necessary for student-athletes? 


\section{Appendix B}

Question Chart

\begin{tabular}{|l|c|c|c|c|c|c|c|c|c|c|c|c|c|}
\hline & $\mathrm{Q}$ & $\mathrm{Q}$ & $\mathrm{Q}$ & $\mathrm{Q}$ & $\mathrm{Q}$ & $\mathrm{Q}$ & $\mathrm{Q}$ & $\mathrm{Q}$ & $\mathrm{Q}$ & $\mathrm{Q}$ & $\mathrm{Q}$ & $\mathrm{Q}$ & $\mathrm{Q}$ \\
& 1 & 2 & 3 & 4 & 5 & 6 & 7 & 8 & 9 & 10 & 11 & 12 & 13 \\
\hline $\begin{array}{l}\text { RQ 1: What are the } \\
\text { transition experiences of } \\
\begin{array}{l}\text { Black Division I men's } \\
\text { basketball transfer student- } \\
\text { athletes with the redshirt } \\
\text { year? }\end{array}\end{array}$ & $\mathrm{X}$ & $\mathrm{X}$ & $\mathrm{X}$ & & $\mathrm{X}$ & $\mathrm{X}$ & $\mathrm{X}$ & $\mathrm{X}$ & $\mathrm{X}$ & & $\mathrm{X}$ & $\mathrm{X}$ & \\
\hline $\begin{array}{l}\text { RQ 2: What are the } \\
\text { perceived benefits or } \\
\text { drawbacks of the redshirt } \\
\text { year requirement } \\
\text { experienced by Black } \\
\begin{array}{l}\text { Division I men's } \\
\text { basketball players? }\end{array}\end{array}$ & & & & $\mathrm{X}$ & $\mathrm{X}$ & & & $\mathrm{X}$ & & $\mathrm{X}$ & $\mathrm{X}$ & & $\mathrm{X}$ \\
\hline
\end{tabular}




\section{Appendix C}

\section{Participant Biographies}

The following section briefly describes the college basketball careers of the participants through their individual transfer transitions. Additionally, information pertaining to their current careers is provided.

Jason. Jason began his college basketball career at a small, mid-major university. After one season, he decided to transfer to another institution because of the relationship he had with his head coach coach. He indicated the trust he had in this coach was broken because of issues he had with playing time inconsistency throughout his freshman year. Jason then spent his redshirt season at his receiving institution as well as his redshirt sophomore and redshirt junior playing seasons. He indicated he did not have any academic issues with the transfer, although he did have to change his major from business to political science.

After a successful playing career at his second institution, he graduated in four years, thus giving him the opportunity to elect a graduate transfer to another institution. From this transfer, Jason had the opportunity to play at a Power Five institution much closer to his home while he began work on his master's degree. After he exhausted his playing eligibility, Jason played professional basketball for one season. He then returned to his third institution to complete his master's degree. He is currently preparing to take the LSAT with hopes of being admitted to Law School soon.

Trevor. Trevor had an extremely unique experience throughout his collegiate basketball career, as he attended three different Power Five institutions. He spent his first two years at his initial institution, and after realizing there was another player in his position that was likely to take a large quantity of minutes at the position the following year. Trevor then decided to transfer and spent two seasons, one redshirt year and his redshirt junior season, at his second institution. He changed his majors when he got to his second institution and went from a communications major to a sociology major. He chose this major specifically so he could stay on track to graduate in four years. After remaining on track and graduating in four years from his second institution, Trevor decided to pursue a graduate transfer to finish his career at a third institution. There, he began work on his master's degree. Trevor played his final year at another Power Five institution while beginning graduate coursework.

Trevor indicated his redshirt year allowed him to grow as a basketball player as he was able to focus on his skills and physical development. After he exhausted his eligibility, he was drafted into the NBA and has since been a consistent NBA G League roster member while also having a few opportunities to be called up to an NBA roster. He sees the redshirt year as giving him invaluable benefits to be in the position he currently is in as a professional basketball player and plans to complete his master's degree after his playing career has culminated.

AJ. AJ attended two institutions during his collegiate basketball eligibility. He spent two seasons at his initial institution before electing to transfer, indicating basketball 
was not going as expected and that he had a different understanding of his circumstances during the recruiting process than what he was actually dealt when he arrived on campus. When he was going through the re-recruitment and selection process for his receiving institution, he was aware of his academic situation and did not want to select a school where he had to make up too many credits where it would impact his eligibility and ability to graduate.

$\mathrm{AJ}$ indicated the redshirt year helped him because he did not have to focus as intensely on basketball and could get back on track academically. He had a very tough time from a personal perspective during the redshirt year and indicated he felt very lonely. However, he was able to spend Winter Break at home to recollect and came back for the spring semester of his redshirt year with a refreshed mindset. He took the full five NCAA-allotted years to earn his undergraduate degree in Sport Management. He is currently playing professional basketball internationally and plans to do so as long as he can.

Gerald. Gerald indicated he had a fairly good and normal experience during his freshman year at his initial institution. However, during his sophomore year, he did not feel at peace with himself and felt as though he should continue his career elsewhere. He said he did not feel as though he had a great chance to have a successful finish to his basketball career if he stayed. He indicated he had professional basketball aspirations and knew that in order to have his best chance at a successful career professionally, he should pursue another institution. At his initial institution, he was majoring in business management. He indicated his academic growth in business management was his second favorite thing to do after basketball. When he was going through the transfer process, he chose his receiving institution over two others based on the fact that his credits transferred. However, he had to switch his major from business management to sport management.

Although Gerald should have had two full playing seasons at his receiving institution after his redshirt year in residence, he suffered a season-ending injury in the first game of his redshirt junior season. Although he applied to get his year back and obtain a waiver from the NCAA to participate in a sixth year, he was denied, and therefore only played one full season at his initial institution. He graduated in five years with his undergraduate degree and is currently playing professional basketball internationally.

Aaron. Aaron experienced a very interesting transition throughout his college basketball career. Prior to attending his initial institution, he attended a boarding high school, so he indicated his transition to the college setting was not as hard for him as it was for other freshmen. However, after spending two years playing at his initial institution, he decided to pursue his career in basketball and try to play professionally. $\mathrm{He}$ departed his initial institution, a very conservative, Christian-affiliated university, and transferred to a Power Five, large, public university, which he indicated was a big culture shock for him. He also had an interesting academic experience, as the curriculum at the Christian university did not offer certain requirements he needed to graduate from his receiving institution, so he said he was in very introductory, freshman-level courses as a senior. Regardless, he graduated on time and did not need to change majors. After 
graduating in four years, Aaron elected to take advantage of the graduate transfer option and transferred to another Power Five institution much closer to his home and family. During that year, he finished approximately 50 percent of his graduate coursework. He is currently pursuing a professional basketball career and is currently playing internationally.

Toby. Toby, an international student-athlete, spent two years at his initial institution before departing. He indicated his reason to transfer was purely basketball related and said he was one of many student-athletes to transfer that season. He said a big reason was that, at his position, his initial institution had a lot of depth and therefore, he was concerned with his playing time and ability to remain on the court. He transferred to a Power Five institution, but upon doing so, needed to change majors. He then spent his redshirt year along with two seasons of eligibility at his receiving institution and graduated in five years. He indicated he lost credits upon his transfer, but he said he did not have any issues catching up. He did, however, take a full five years to complete his undergraduate degree.

Toby said he did not socialize much at either campus and kept to himself. He said the redshirt year was a gain for him and allowed him to grow from a basketball perspective. However, he thinks each situation is different and if a student-athlete has the ability to play right away, they should have the ability to elect to do so. Toby is currently playing professional basketball in the United States and has hopes of making an NBA roster in the near future.

Avery. Avery spent two years at his initial institution before electing to transfer. He took a few official visits before electing to transfer to his second institution. $\mathrm{He}$ indicated that he did not lose any credits upon his transfer and did not need to change his major. His reason for transfer was completely basketball related. After spending his redshirt and redshirt junior seasons at his second institution and graduating on time, he elected to take advantage of the graduate transfer policy and finish his career at a Power Five institution. He was able to finish approximately have his graduate degree during his last season of eligibility and is currently in the process of finishing the program. $\mathrm{He}$ is currently playing professional basketball in he NBA G League.

Marcus. Marcus spent just one year at his initial institution before electing to transfer. He indicated the head coach who recruited him with plans of coaching him was not there his freshman year, and Marcus did not feel as though he should continue at that institution. He discussed how his redshirt year was the worst year of his career, as he could not play in organized basketball games. He said he had a very hard time sitting and watching the games during his redshirt season. Additionally, as he transferred from a mid-major institution to a Power Five university, he said he had a much harder time acclimating to campus at the Power Five institution, as he felt like his celebrity status deterred him from having a normal college student experience.

From an academic perspective, Marcus said his credits transferred and he was able to continue pursuit of his major and was able to graduate in four years. He then began graduate coursework during his fifth year of playing eligibility. Marcus indicated 
the redshirt year taught him patience and allowed him to develop as a player and as a student.

Greg. Greg was an international student-athlete, but indicated he spent his high school career in the United States. He decided to transfer after just one year at his initial institution. He said he did not get along with the coaches, and that the coaches who were at his initial institution were not the coaches who recruited him. He said the main reason he chose that institution was to play for a specific assistant coach, and as he was not there during Greg's freshman year, he decided to depart the institution for another opportunity. He had to change majors, from agriculture to business, and indicated he did lose credits when he transferred. He felt as though he had to start over academically when he arrived at his second institution. However, he said he studied hard and was able to graduate in four years.

Greg said his mindset during the redshirt year was to get better, bigger, and stronger from a basketball perspective. Additionally, he had the opportunity to get back on track academically. After graduating in four years, Greg took advantage of the graduate transfer policy and spent his fifth year at a Power Five institution where he was able to finish approximately half his master's degree. He is currently playing professional basketball overseas.

John. John decided to transfer after his sophomore year at his initial institution with a mid-major Division I program. He said his team had a great season that year and he, personally, did as well. However, he said he got advice from an upperclassman who was very successful at the mid-major level, but did not have the same opportunities to play at the professional level as other, less successful, players at Power Five programs were afforded due to the notoriety of their programs. John decided he wanted to go to a larger school to compete at a higher level in order to have more opportunity to play professionally. He said he had quite a few options after electing to transfer, but found his home across the country at a Power Five program.

He did not need to change majors and graduated in four years. During his redshirt year, he said he had a hard time as he was not able to play, but leaned on a teammate who too transferred at the same time. Instead of electing to play his fifth season of eligibility, he decided to enter the professional ranks. He is currently playing professional basketball in the G League in the United States and has aspirations of making an NBA roster in the near future.

Will. When Will was coming out of high school and going through the recruiting process, he knew he wanted to play at the highest level in college. He had the ability to start his freshman year at his initial institution, a mid-major Division I program with moderate success. His performance at this level gave him leverage to transfer to a more successful program, and he had the opportunity to play for a legendary coach in a programwith storied success. Through the transfer process, Will indicated he lost a few credits, but it did not derail him completely. He did have to change majors, and was encouraged to pursue a communications major at his receiving institution, as many men's basketball players had success in that major. He said the biggest pull to his receiving institution and what made him appreciate the redshirt year was that he was provided a 
skills coach who had NBA experience and allowed him to expand upon his basketball skills set.

After graduating in four years, Will said he had an honest conversation with his coach and they both decided what was best for his career and future as a professional basketball player was for him to elect a graduate transfer to another institution. He landed at a Power Five institution. Although he was immediately eligible to compete, he suffered a season-ending injury during his fifth season of eligibility. He petitioned to the NCAA to receive an extension of eligibility and was approved. He then played as a sixth-year senior at his final institution while he continued to pursue his graduate degree. He is currently playing professional basketball overseas.

Michael. Michael elected to transfer just one semester after he arrived at his initial institution. He indicated some of the staff that had recruited him as a prospective student-athlete promised him things he expected to hold true once he arrived to campus. However, upon his arrival, the head coach he was recruited by had departed with one of the assistant coaches on his staff taking the helm of the program. The new staff decided to do things differently than the old staff, and Michael said he felt as though he was misled. He said he came to the realization it was not the place for him to spend his college career and decided to part ways.

Michael knew that in order to be eligible to transfer, he had to at least pass his classes at his initial institution. He did so, and was able to transfer to another program. There, he said he had a tough time adjusting and had to learn to focus on the right things and not let distractions derail him. With the mid-year transfer, he was required to sit out the spring semester and fall semester of the following year, allowing him to play the following spring semester. However, after that semester, he had just two years of athletic eligibility remaining. He was able to graduate in five years from his receiving institution and is currently pursuing his graduate degree as a graduate assistant coach in Division I men's basketball .

Stephen. Stephen elected to transfer a bit later into his career than normal, as he spent three years at his initial institution before electing to leave. Stephen explained he always had dreams of playing in a particular Power Five conference, as it is rich in history and would allow him to play in historic arenas against historically successful teams with national prominence. His initial institution had a mid-major basketball program and by taking advantage of the transfer option, he was able to move up and play at the highest level.

From an academic perspective, Stephen entered into the transfer transition with a large amount of risk, as NCAA degree progress standards could have led Stephen to be ineligible if certain credits did not transfer to his receiving institution. In addition, Stephen was required to change his major from advertising to communication, as his receiving institution did not offer advertising as a major. Stephen took the full five years to graduate with his undergraduate degree and is currently playing professional basketball overseas.

Anthony. Anthony decided to transfer after two years at his initial institution because of a bad experience with the basketball program. He described how the 
environment within which he was playing completely changed from his freshman to sophomore year and he did not want to spend the rest of his career in such an environment. After two years of academic progress at his initial institution, Anthony had the intention of majoring in business marketing, but left before being required to declare the major. When he transferred to his receiving institution, the major was not available, and therefore, he elected to major in agricultural business. Additionally, the transfer to the receiving institution allowed Anthony to move much closer to his parents and support systems at home.

Anthony spent his redshirt season focused academically while also working on his progression from a basketball perspective. He graduated in four years and was able to complete approximately half his graduate degree during his fifth year of eligibility. He is currently playing professional basketball overseas.

Miles. Miles described his reason for transfer, after spending three years at his initial institution, to be closer to home and closer to family. He indicated his decision to transfer had nothing to do with basketball. He said his coach at his initial institution was very understanding of his situation and assisted him throughout the transfer process. As Miles had made significant progress towards degree completion at his initial institution, his transfer came with significant risk to his eligibility and meeting NCAA degree progress standards. He indicated the transfer caused him to lose approximately 60 percent of his credits. Additionally, he had to change majors from marketing to social work, as his previous degree progress did not transfer to the business program at his receiving institution. He took the full five years to finish his undergraduate degree.

Transferring schools allowed Miles to be closer to home. He indicated he loved the redshirt year because it allowed him to be a somewhat normal student for a few months and allowed him to focus primarily on academics. He is currently playing professional basketball overseas. 


\title{
CURRICULUM VITAE
}

\author{
Sarah B. Williams \\ SAC E 104T \\ University of Louisville \\ Louisville, Kentucky \\ (502) 852-8297 \\ sarah.williams.8@louisville.edu
}

\section{EDUCATION}

Ph.D. University of Louisville

Educational Leadership, Evaluation

and Organizational Development

Specialization: Sport Administration

M.S. James Madison University

2012

Sport and Recreation Leadership

B.B.A. James Madison University

2009

Business Administration,

Finance Concentration

\section{ACADEMIC POSITION}

Graduate Teaching Assistant, Sport Administration

August 2016 to Present

Courses taught include:

- SPAD 281: Principles of Sport Administration - Online

- SPAD 284: Issues and Ethics in Sport

- SPAD 382: Organizational Behavior in Sport - Online

- SPAD 390: Sport Governance

- SPAD 404: Financial Principles in Sport - Online

- SPAD 420/39: Sociology of Sport - Online

- SPAD 529: Women \& Sport - Online

- SPAD 561: Student Services in College Athletics - Online (Teaching Assistant)

- SPAD 571: Sport for Development \& Peace 
Additional Program Responsibilities:

- Co-coordinator for COSMA Accreditation candidacy application and self-study

- Oversee 10 to 15 interns per summer in SPAD 402/692, Internship in Sport Administration

- Liaison, Central High School Sport Marketing magnet and dual credit partnership

- Member, Health and Sport Sciences Student Engagement Committee

- Member, SPAD master's program admissions committee

Guest Lectures:

- SPAD 404: Financial Principles in Sport, University of Louisville, Fall 2016, Spring 2017, Fall 2018: The Cost of Cost of Attendance

- SPAD 489: Legal Aspects of Sport, University of Louisville, Fall 2016, Tort Principles in Sport and Premise/Spectator Issues

- SPAD 281: Principles of Sport Administration, University of Louisville, Spring 2017, Intercollegiate Athletics

- SPAD 382: Organizational Behavior of Sport, University of Louisville, Spring 2017, Sport Leadership

- HSS 293: Social and Psychological Dimensions of Physical Activity, University of Louisville, Fall 2017, Children and Sport Psychology

\section{CURRENT INDUSTRY POSITION}

Women's College Basketball Referee

August 2018 to Present

Conferences worked include:

- NCAA Division II Great Lakes Valley Conference

- NCAA Division III St. Louis Intercollegiate Athletic Conference

- NAIA Division II River States Conference

\section{RESEARCH}

\section{Refereed Publications:}

- Hums, M. A., Bower, G. G., \& Williams, S. B. (In press). Career paths of men working in leadership positions within intercollegiate athletic administration. Submitted to Journal of Intercollegiate Sport.

- Williams, S. B., \& Greenwell, T. C. (2019). The impact of scandal on NCAA division I women's basketball fan consumption and brand loyalty. Journal of Issues in Intercollegiate Athletics.

- Ransdell, L.B., Nguyen, N., Hums, M.A., Clark, M., \& Williams, S. B. (2018). Voices from the field: Perspectives of US kinesiology chairs on opportunities, challenges, and the role of mentoring in the chair position. Quest. (Impact Factor: 1.375) 


\section{Invited Publications and Reviews:}

- Williams, S. B. (2017). Book review. Invisible Seasons: Title IX and the Fight for Equity in College Sports. Journal of Issues in Intercollegiate Athletics, 10, xi-xiii.

\section{$\underline{\text { Research in Progress: }}$}

- Darvin, L., Hancock, M. G., \& Williams, S. B. (in review). Myth or reality? Athletic administrator's perceptions of the sport industry leadership labyrinth. Submitted to Sport Management Review.

- Weiner, J. F., Williams, S. B., \& Shreffler, M. B. (in review). Show me the money! A financial case study of multiple ticket revenue options. Case Studies in Sport Management.

- Williams, S. B. (data collected, completing manuscript). An examination of female athletes' experiences and perceptions of feminism before Title IX. Will be submitted to Sociology of Sport Journal.

- Williams, S. B., Weiner, J. F., Lee, S., \& Dallaire, N. (data collection in progress). eSport athletes and gendered communication on Twitch. Will be submitted to International Journal of Sport Communication.

\section{ACADEMIC PRESENTATIONS}

\section{Presentations in the United States:}

- Weiner, J.F. \& Williams, S.B. (2016, November). Show me the money! A financial case study of multiple ticket revenue options. Presented at the annual conference of the Sport Marketing Association, Indianapolis, Indiana.

- Hums, M. A., Bower, G. G., \& Williams, S. B. (2017, May). A comparison of the career experiences of men and women working in intercollegiate athletic administration. Presented at the annual conference of the North American Society for Sport Management, Denver, Colorado.

- Williams, S. B. (2018, March). The impact of scandal on Division I women's basketball fan consumption. Presented at the annual conference of the Graduate Student Regional Research Conference, Louisville, Kentucky.

\section{International Presentations:}

- Williams, S. B. (2017, November). How did participation in sport affect perceptions of feminism before the influence of Title IX? Presented at the annual conference of the North American Society for the Sociology of Sport, Windsor, Canada.

- Bower, G. G., Hums, M. A., \& Williams, S. B. (2018, June). A comparison of the mentoring characteristics and functions important to the advancement of men and women within intercollegiate athletic administration. Presented at the annual conference of the North American Society for Sport Management, Halifax, Nova Scotia. 
- Darvin, L., Williams, S. B., \& Hancock, M. G. (2018, June). Myth or reality? Athletic administrator's perceptions of the sport industry leadership labyrinth. Presented at the annual conference of the North American Society for Sport Management, Halifax, Nova Scotia.

\section{FUNDING}

- Williams, S. B. (2017). University of Louisville Graduate Student Council Travel Award. Funded by the University of Louisville Travel Funding Administration in the amount of $\$ 200$. Funded.

- Williams, S. B. (2018). The Division I Men's Basketball Transfer Redshirt Requirement: Hurting or Helping Black Student-Athletes? National Collegiate Athletic Association Graduate Student Research Grant in the amount of \$3,462. Not funded.

\section{SERVICE}

\section{Professional Service:}

- Student Director, Commission on Sport Management Accreditation (COSMA), 2018-Present

\section{College Service:}

- Student Academic Grievance Committee in the College of Education and Human Development Graduate Student Representative, 2016-Present

\section{Department Service:}

- NFL Draft Graduate Student Trip Leader to Dallas, Texas, 2018

- Sport Administration Master's Admissions Committee Member, 2017-Present

- Central High School and University of Louisville SPAD Program Partnership Liaison, 2016-Present

- Health and Sport Sciences Student Engagement Committee, 2017-Present

- Doctoral Student Virtual Open House Panelist, 2017

- Graduate Assistant Orientation Panelist, 2017

\section{Community Service:}

- Guest Lecturer, Central High School Senior Sport Marketing Class

- October 2016: Gender and Diversity in Sport

- October 2017: Transgender Athlete Policy

- Volunteer, Ironman Louisville 2016

- Volunteer Captain, Ironman Louisville 2017

- Presenter, Sacred Heart Model School Grade 4 Stewardship Workshop, Louisville, Kentucky, 2017

- Volunteer, USA Cycling National Championships, Louisville, Kentucky, 2017 
- Volunteer Basketball Official, Special Olympics Kentucky, 2018

\section{PROFESSIONAL DEVELOPMENT}

- Attended Workshop presented by the Delphi Center for Teaching and Learning

- Delphi U Principles of Online Course Design

- Building your Teaching Philosophy

\section{SPORT INDUSTRY PROFESSIONAL EXPERIENCE}

James Madison University, Harrisonburg, Virginia

May 2013 to April 2016

Division I Assistant Women's Basketball Coach

- NCAA Tournament berth, 2014, 2015, and 2016

- CAA Conference Champions, 2014, 2015, 2016

- Players selected in the WNBA Draft, 2015 and 2016

- Top 25 ranking in both USA Today and AP national polls, 2014 and 2015

- Instructed on-court individual skill development and training

- Scouted opposing teams, prepared instructive and effective schemes, instructed team tactical approaches

- Recruited prospective student-athletes possessing quality basketball and academic abilities, cultivated relationships with families and coaches nationally and internationally

- Marketing and Sports Information Coordinator

Longwood University, Farmville, Virginia

Division I Assistant Women's Basketball Coach

June 2012 to May 2013

- Big South Conference Tournament finalist

- Doubled previous season's win total (7 to 14)

- Instructed on-court individual skill development and training

- Scouted opposing teams, prepared instructive and effective schemes, and instructed team tactical approaches

- Recruited prospective student-athletes possessing quality basketball and academic abilities, cultivated relationships with families and coaches nationally and internationally

James Madison University, Harrisonburg, Virginia

Division I Women's Basketball Graduate Assistant

August 2011 to May 2012

- WNIT Finalist

- Assisted with practice and game preparation

- Organized, coordinated, and executed team operations including travel, meals, and scheduling 


\section{SPORT INDUSTRY ACTIVITY}

NFL Draft, Dallas, Texas

April 2018

Graduate Student Trip Leader

- Coordinated travel arrangements for 16 graduate students and 1 undergraduate student to volunteer at the NFL Draft

- Organized professional development opportunities throughout the trip including panel discussions with executives with the Dallas Mavericks and tours with the University of Memphis and Southern Methodist University athletic departments

- Volunteered for three days with fan experience coordination surrounding AT\&T Stadium

Kentuckiana Board of Officials, Louisville, Kentucky

High School Basketball Referee

November 2017 to Present

At-Large Member, Board of Directors

- basketball games in the $6^{\text {th }}$ and $7^{\text {th }}$ regions of the Kentucky High School Athletic Association

- Board responsibilities include: resources and staffing, grading criteria, delinquent member coordination, communication to prospective members, website management, retention, social activities, fundraising, and updating bylaws

\section{BUSINESS INDUSTRY EXPERIENCE}

Bank of New York Mellon, Wilmington, Delaware December 2010 to August 2011 Alternative Investments Fund Accountant

- Contributed to the production of client portfolio statements and Net Asset Value calculations for Hedge Fund clients serviced in the Bank of New York Mellon's Alternative Investment Services Division

- Contributed portfolios included multi-billion dollar funds for CITI, RBC, etc.

- Validated and verified securities pricing and expenses in AIS portfolios

- Managed processing of subscriptions, redemptions, and reconciliations of AIS portfolios

\section{HONORS AND AWARDS}

- Ursuline Academy Athletics Hall of Fame, 2019

- Faculty Guest Coach, University of Louisville Football, 2017

- Team captain, James Madison University Varsity Basketball (Division I), 20092010

- Dean Ehler's Leadership Award Nominee, Colonial Athletic Association, 2010

- Colonial Athletic Association First Team All-Academic, 2010 


\section{PROFESSIONAL AFFILIATIONS}

- Kentuckiana Basketball Officials Association ○ At-Large Board Member

- Kentucky High School Athletic Association

- North American Society for Sociology of Sport

- North American Society for Sport Management

- Sport Marketing Association

- Women's Basketball Coaches' Association
2017 to Present 2018 to Present 2017 to Present 2017 to Present 2016 to Present 2016 to Present 2011 to 2016 